\title{
Empirical Analyses on the Effects of Economic Incentives on Teacher Retention and Teacher Quality
}

\author{
A Dissertation presented to \\ the Faculty of the Graduate School \\ at the University of Missouri-Columbia
}

In Partial Fulfillment

of the Requirements for the Degree

Doctor of Philosophy

\section{by \\ XIQIAN WANG}

Dr. Shawn Ni, Dissertation Supervisor

May 2019 
The undersigned, appointed by the Dean of the Graduate School, have examined the dissertation entitled:

\section{EMPIRICAL ANALYSES ON THE EFFECTS OF ECONOMIC INCENTIVES ON TEACHER RETENTION AND TEACHER QUALITY}

presented by Xiqian Wang,

a candidate for the degree of Doctor of Philosophy and hereby certify that, in their opinion, it is worthy of acceptance.

\begin{tabular}{c}
\hline Dr. Shawn Ni \\
\hline Dr. Michael Podgursky \\
\hline
\end{tabular}

Dr. David Kaplan

Dr. Shaoming Zou 


\section{ACKNOWLEDGMENTS}

First of all, I would like to express my deepest thanks and respect to my advisor, Professor Shawn Ni. Professor Ni provides his greatest support for my research and academic career. He is a great advisor in my research life. Without his advice, encouragement, and support, I would not be able to achieve my PhD degree. I would also like to express my special thanks to Professor Michael Podgursky. Professor Podgursky is another important mentor for me. Without his support, I would not be able to complete this dissertation.

I would like to thank my other two committee members, Professor David Kaplan and Professor Shaoming Zou, for giving me very valuable suggestions on my dissertation. And I want to express gratitude for all support from the Economic and Policy Analysis Research Center (EPARC) and all scholars working at EPARC and Economics Department, Professor Cory Koedel, Professor Peter Mueser, Professor Mark Ehlert, Dr. Weiwei Wu, Dr. Wei Kong, Yang An, Yong Bian, Jing Song, Cheng Qian, and Fangda Wang. I really appreciate their suggestions and comments on my projects, and support throughout my $\mathrm{PhD}$ journey.

I would like to convey a special thanks to my parents, Xiaoming Wang and Hong Peng, and my husband Yijie Sun, for their understanding, caring and endless love. 


\section{TABLE OF CONTENTS}

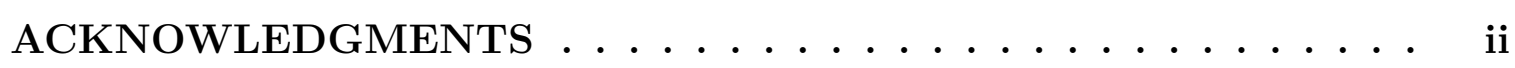

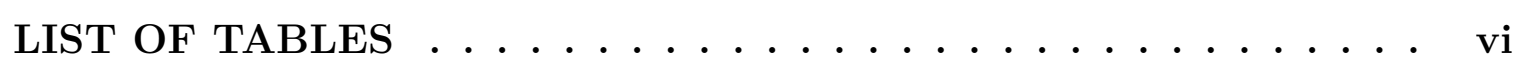

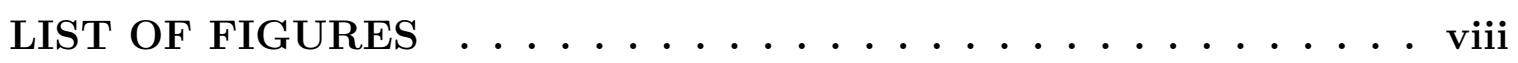

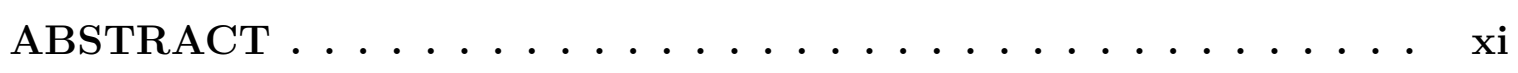

\section{CHAPTER}

1 Teacher Pension Enhancements and Staffing in an Urban School

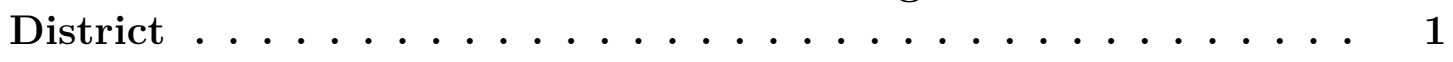

1.1 Introduction . . . . . . . . . . . . . . . . . . . . . . 1

$1.2 \quad$ Background and Descriptive Analysis . . . . . . . . . . . . . . . . 3

1.2.1 Public School Teachers in St. Louis . . . . . . . . . . . . . . . 3

1.2.2 Pension Wealth Accrual and Retirement Incentives . . . . . . 6

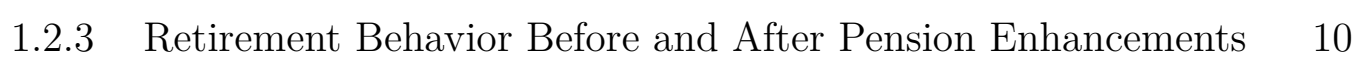

1.3 A Dynamic Structural Retirement Model . . . . . . . . . . . . . . . . 14

1.3 .1 Data . . . . . . . . . . . . . . . . . . 17

1.3.2 Expectations of Future Pension Rules . . . . . . . . . . . . . . 19

1.3.3 MLE Estimates . . . . . . . . . . . . . . . . 20

1.3.4 In-sample Goodness of Fit . . . . . . . . . . . . . . . . . . 22

1.3.5 Out-of-Sample Goodness of Fit . . . . . . . . . . . . . 22

1.3.6 Pension Incentives Underlying the DB Plan . . . . . . . . . . 26

1.4 Simulating the Effect of Pension Enhancements . . . . . . . . . . . . 27 


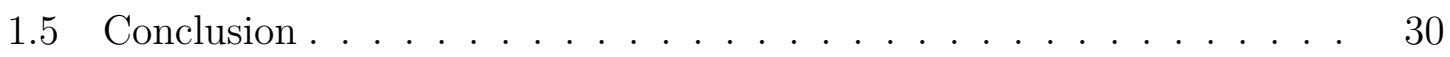

2 Teacher Pension Plan Incentives, Retirement Decisions, and Work-

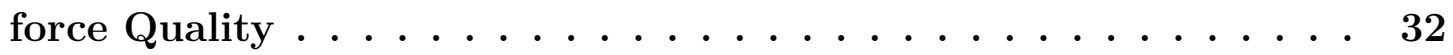

2.1 Introduction . . . . . . . . . . . . . . . . . . . . . . 32

2.2 Institutional Background $\ldots \ldots \ldots \ldots \ldots \ldots$

$2.2 .1 \quad$ Tennessee Consolidated Retirement System . . . . . . . . . 35

2.2 .2 Tennessee Teacher Evaluation System … . . . . . . . 38

2.3 Descriptive Statistics on Retirement. . . . . . . . . . . . . . . . 39

2.4 Teacher Quality and Retirement: Reduced-Form Estimates . . . . . . 44

2.5 Does Impending Retirement Induce Shirking? . . . . . . . . . . . 46

$2.6 \quad$ Estimating a Dynamic Structural Retirement Model . . . . . . . . . 47

$2.6 .1 \quad$ Methodological Issues in Estimation . . . . . . . . . . . 51

$2.6 .2 \quad$ MLE Estimates . . . . . . . . . . . . . . . . . . . 53

2.6 .3 Goodness of Fit . . . . . . . . . . . . . . . . 55

2.7 Policy Simulations $\ldots \ldots \ldots \ldots$

2.7 .1 Enhancing the Current Plan . . . . . . . . . . . . . 61

2.7 .2 Retention Bonuses . . . . . . . . . . . . . . . . 65

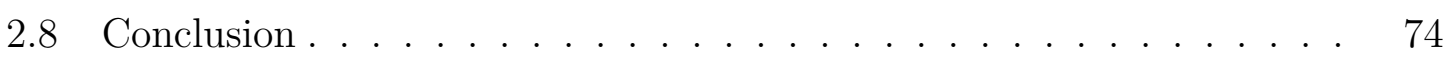

3 Teacher Attrition and Teacher Quality: Evidence from EarlyCareer Teachers ..................... 76

3.1 Introduction . . . . . . . . . . . . . . . . . 76

3.2 Data and Empirical Patterns of All Teachers in Tennessee . . . . . 80

3.2 .1 Ratings, Administrative and School Profile Data . . . . . . 80 
$3.2 .2 \quad$ Empirical Patterns $\ldots \ldots \ldots \ldots$

$3.3 \quad$ Model Teacher Attrition and Dynamics of

Teacher Quality for Novice Teachers . . . . . . . . . . . . . 84

3.3.1 Probit Model for Teacher Attrition and Teacher Quality ... 84

$3.3 .2 \quad$ Data for Estimation . . . . . . . . . . . . . . 86

3.3.3 $\quad$ Estimated Parameters and Goodness of Fit . . . . . . . . 87

3.3 .4 Discussions . . . . . . . . . . . . . . . . . . . . . 90 90

3.4 Conclusion $\ldots \ldots \ldots \ldots$

\section{APPENDIX}

A Calculation of Social Security Benefits . . . . . . . . . 94

A.1 Social Security at Full Retirement Age . . . . . . . . . . . . . . . 94

A.2 Social Security at Early Retirement Age . . . . . . . . . . . 95

A.3 Social Security at Delayed Retirement Age . . . . . . . . . . . . 96

B Calculation of Sample Likelihood Function and Correcting for Sample Selection Bias in a Dynamic Structural Retirement Model 97

B.1 Sample Likelihood Function . . . . . . . . . . . . . . . . 97

B.2 Correcting for Selection Bias in Baseline Sample . . . . . . . . . . . 99

C Calculation of Sample Likelihood in a Probit Model . . . . . . 101

C.1 Individual Likelihood . . . . . . . . . . . . . . . . . . . . . . . 101

C.2 Algorithm of Calculating Likelihood . . . . . . . . . . . . . 103

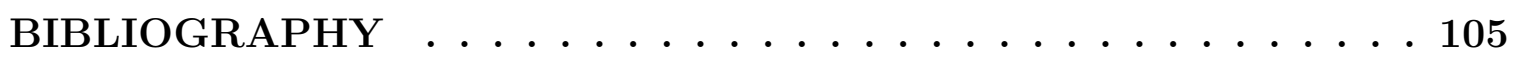

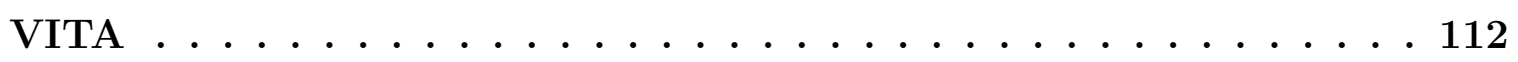




\section{LIST OF TABLES}

Table

1.1 Trends in Teachers Characteristics at St. Louis Public Schools from

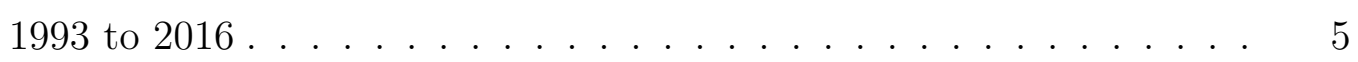

$1.2 \quad$ Summary of Pension Rules . . . . . . . . . . . . . . . 7

1.3 Sample Statistics: Before and After 1999 Enhancements . . . . . . 10

$1.4 \quad$ Regression Results of Linear Probability Models . . . . . . . . . . . . 14

$1.5 \quad$ Structural Model Parameters . . . . . . . . . . . . . . . . 17

1.6 Estimation Sample: Descriptive Statistics … . . . . . . . 18

1.7 Estimates of Six Behavioral Parameters . . . . . . . . . . . . . . 21

1.8 Out-of-Sample Simulation Sample: Descriptive Statistics . . . . . . . 24

1.9 Effects of Alternative Pension Rules on Teachers . . . . . . . . . . 30

$2.1 \quad$ Summary of Tennessee Teacher Pension Rules . . . . . . . . . . 36

2.2 Descriptive Statistics $\ldots \ldots \ldots \ldots$

2.3 Descriptive Statistics For Teachers in High and Low Poverty Schools 41

2.4 Retirement Behavior for High and Low Quality Teachers . . . . . . 42

2.5 Regression Results for Linear Probability Models . . . . . . . . . 45

$2.6 \quad$ Structural Model Parameters . . . . . . . . . . . . . . . 50 
2.7 Estimates of Structural Parameters . . . . . . . . . . . . . . . . 54

2.8 Disutility of Working versus Retirement for High and Low Quality Teachers . . . . . . . . . . . . . . . . . 5 56

2.9 Effects of Pension Enhancements . . . . . . . . . . . . . . . 62

2.10 Effects of One-Year Retention Bonuses for High Quality Teachers in High Poverty Schools . . . . . . . . . . . . . . . . . . . . 66

2.11 Effects of Retention Bonuses for High Quality Teachers at 31st Teaching Year . . . . . . . . . . . . . . . . . . . . . . 69

2.12 Effects of Retention Bonuses for High Quality Teachers at 31st Teaching Year in High Poverty Schools . . . . . . . . . . . . . . . 73

$3.1 \quad$ Summary Statistics for All Teachers . . . . . . . . . . . . . . . . 81

3.2 Descriptive Statistics $\ldots \ldots \ldots \ldots$

$3.3 \quad$ Estimated Parameters $\ldots \ldots \ldots$. . . . . . . . . . . . . . . . . 89

3.4 Observed and Predicted Teacher Quality Distribution at the End of Sample Period . . . . . . . . . . . . . . . . . . . . 9 90

A.1 Benefit Increase for Delayed Retirement $\ldots \ldots \ldots \ldots$ 


\section{LIST OF FIGURES}

Figure

Page

1.1 Trends in Teacher Numbers of St. Louis Charter Schools and Publid

Schools Teachers from 1993 and 2016 . . . . . . . . . . . . . . . . 4

1.2 Trends in Average Age and Average Experience of St. Louis Publid

Schools Teachers from 1993 to 2016 . . . . . . . . . . . . . . . . . . . 4

1.3 Pension Wealth Accrual for a Teacher Entering at Age 25 . . . . . . . 9

1.4 Annual Changes in Pension Wealth for a Teacher Entering at Age 25 9

1.5 Employment Survival Rate Before and After Pension Enhancements . 11

1.6 Age Distribution Before and After Pension Enhancements . . . . . . 12

1.7 Experience Distribution Before and After Pension Enhancements . . 12

1.8 Observed and Predicted Age and Experience Distribution (In Sample) 23

1.9 Observed and Predicted Survival Rate (In Sample) . . . . . . . . . . 23

1.10 Observed and Predicted Age and Experience Distribution (Out of Sample

1.11 Observed and Predicted Survival Rate (In Sample and Out of Sample) 25

1.12 Pension Incentives: $g_{t}\left(r_{t}^{\dagger}\right) / K_{t}\left(r_{t}^{\dagger}\right) \ldots \ldots \ldots 27$ 
1.1330 -Year Simulation Under Different Pension Rules for 02-Cohort Teach-

ers (Survival Rate) . . . . . . . . . . . . . . . . . . . 29

1.1430 -Year Simulation Under Different Pension Rules for 02-Cohort Teach-

ers (Age and Experience Distribution) . . . . . . . . . . . . . . . 29

2.1 Total Pension Wealth, Social Security Wealth and Retirement Wealth

Over a Teaching Career . . . . . . . . . . . . . . . . . 37

2.2 Annual Pension Wealth Accrual . . . . . . . . . . . . . . . . 37

2.3 Distribution of Teacher Quality (1-5) for Female and Male Teachers in the Base Year (2011-2012) . . . . . . . . . . . . . . . . . . . . . . 40

2.4 Distribution of Female Retired Teachers by Age, Experience, and Quality 43

2.5 Distribution of Male Retired Teachers by Age, Experience, and Quality 43

2.6 Year-to-Year Change in Quality Measure for Teachers Who Retired by

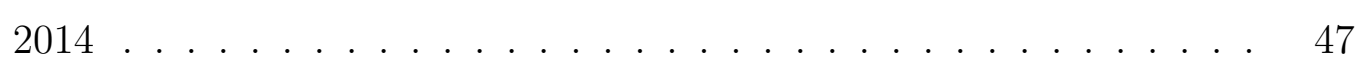

2.7 Observed and Predicted Age Distributions for Female Teachers by

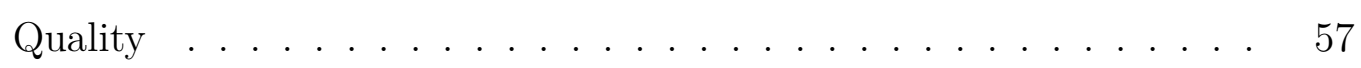

2.8 Observed and Predicted Age Distributions for Male Teachers by Quality 57

2.9 Observed and Predicted Exp. Distributions for Female Teachers by

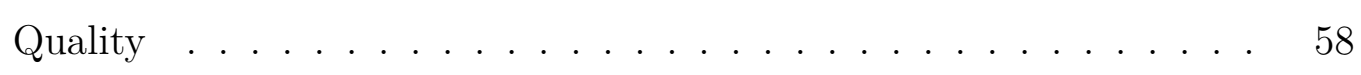

2.10 Observed and Predicted Exp. Distributions for Male Teachers by Quality 58

2.11 Observed and Predicted Survival Rates for Teachers by Quality . . . 59

2.12 Observed and Predicted Age Distributions, Experience Distributions, and Survival Rate for High Quality Teachers in High-Poverty Schools 60

2.13 Survival Rate Differences With Enhancements (Survival Rate under RF 2\%-Survival Rate under RF 1.5\%) . . . . . . . . . . . . . . . 64 
2.14 Share of High Quality Teachers Among Non-Retired Teachers . . . . 64

2.15 Experience Distribution of Retired High Quality Teachers with Retention Bonuses at 31st Teaching Year . . . . . . . . . . . . . . . 70

2.16 Share of High Quality Teachers Among Non-Retired Teachers with Retention Bonuses . . . . . . . . . . . . . . 70

2.17 Experience Distribution of Retired High Quality Teachers with Retention Bonuses at 31st Teaching Year in High Poverty Schools . . . . . 72

2.18 Share of High Quality Teachers Among Non-Retired Teachers with Retention Bonuses in High Poverty Schools . . . . . . . . . . . . . . . 72

3.1 Distribution of Experience at Given Teacher Rating . . . . . . . . . . 83

3.2 Distribution of Rating at Given Experience . . . . . . . . . . . . . . 83

$3.3 \quad$ Average Salaries in High-Poverty and Low-Poverty Schools . . . . . . 88

3.4 Observed and Predicted Survival Rate . . . . . . . . . . . . . . . 88 


\begin{abstract}
This study conducts empirical analysis on the effects of economic incentives on retaining teachers, both in the late-career and early-career, and improving teacher quality in public schools.

The first chapter analyzes whether a large pension enhancement helps to retain late-career teachers in an urban district, St. Louis City in Missouri. Many states enhanced pension benefits of public school teachers during the 1990s. St. Louis followed this trend with a major benefit enhancement in 1999. Descriptive analysis of administrative panel data and simple regression analysis suggest that senior teachers were highly responsive: teaching careers were shortened, and the likelihood of retirement increased. To gain further insight into the long run effect of the plan changes, and the differential effects of various components of the change, I estimate a dynamic structural model, which provides good in-sample and out-of-sample fit. Simulations of retirement behavior based on the estimated model under different pension rules imply a large long-run reduction in the labor supply of senior teachers. The expected years of additional teaching for the current cohort of senior teachers would be increased by nearly 27 percent if they were operating under the pre-enhancement pension rules.

The second chapter analyzes late-career teacher turnover induced by pension incentives. Using longitudinal data with performance measures for Tennessee public school teachers, we find higher quality teachers are less likely to retire conditional on age and experience. To quantify the effects of pension incentives, we estimate a structural model for retirement and find that high quality teachers have a lower disutility for teaching relative to retirement. We use the structural estimates to simulate
\end{abstract}


the effect of changes in retirement incentives. Enhancements to traditional plans accelerate teacher retirement, whereas targeted retention bonuses delay retirement and retain high quality teachers at a relatively modest cost.

The third chapter focuses on the joint dynamics of attrition behaviors and teaching effectiveness of early-career teachers. Using data from a comprehensive evaluation system in Tennessee, I analyze the factors of attrition, the dynamics of teacher quality, and the retention policies for retaining high-quality teachers. The data suggest teacher attrition is negatively correlated with teacher quality. A sequential probit model of binary attrition and binary rating produces good fits for both survival rate and quality distribution. The model shows the quality of novice teachers increases in experience, salary and education level. Increase in salaries of novice teacher could reduce attrition and improve quality.

Key Words: Teacher Retention, Workforce Quality, Teacher Pension Rules, Teacher Retirement and Attrition Behaviors 


\section{Chapter 1}

\section{Teacher Pension Enhancements and Staffing in an Urban School District}

\section{$1.1 \quad$ Introduction}

Most public school teachers in the United States are covered by traditional, or more precisely, final average salary defined-benefit (FAS-DB) pension plans that base a teacher's retirement annuity on the average of the highest (typically final) several years of earnings. These types of plans are common for state and local government

employees, but have largely disappeared in the private sector (Munnell, 2012)

The fiscal problems of state and local public sector pension plans has been widely noted (Rauh, 2017). A contributor to these fiscal problems was inadequately prefunded enhancements to plan generosity during the 1990s. In response to the stock market boom during that decade, many pension plans enhanced benefits, and educa- 
tor pensions were among the most actively enhanced (Koedel et al., 2014). However, there has been little analysis of the workforce staffing effects of these enhancements. Studies of senior teachers consistently show a high degree of responsiveness in retirement timing to pension system incentives (Furgeson et al., 2006; Costrell and McGee, 2010; Ni and Podgursky, 2016; Knapp et al., 2016). Some studies suggest that FASDB pension plans are ineffective for retaining teachers, especially for young teachers (Brown, 2013; Koedel et al., 2014). The shift away from DB plans in the private sector as well as increased funding problems with public pensions has increased the pressure to switch teachers cheaper plans (Friedberg and Turner, 2010; Munnell, 2012).

This study contributes to the retirement literature by examining the effect of a generous enhancement in 1999 in the St. Louis teacher pension plan on the labor supply of senior teachers. Koedel and Xiang (2017) examine the effect of this same pension enhancement on teacher retention in St. Louis public schools, using difference-in-difference models. The main focus of that study was the short-term effects of the pension enhancements on turnover across all experience cohorts. They find no effects for younger teachers, but retirement-eligible teachers were more likely to delay their retirements until the enhancement. This study extends this line of inquiry by examining in more detail the response of senior teachers to the pension enhancements in both the medium and long-run. Our descriptive analysis of retirement behavior before and after enhancements shows a clear pattern of earlier retirement and shorter teaching spells for senior teachers after the enhancements. To provide more insight into the long-run effects of the plan enhancements I estimate a dynamic structural retirement model. I find that the expected years of additional teaching for the current cohort of senior teachers would be increased by nearly 27 percent if they 
were operating under the pre-enhancement pension rules.

The remainder of this paper is organized as follows. Section 1.2 describes the background of St. Louis pension system and enhancements to the plan in 1999. This is followed by descriptive analysis of retirement patterns before and after the pension enhancements. Section 1.3 describes the dynamic structural retirement model used in this study and issues related to estimation. In Section 1.4 the model estimates are used to simulate the effects of pension enhancements. The Section 1.5 summarizes the findings and discusses some policy implications.

\subsection{Background and Descriptive Analysis}

In this section, I describe the background of St. Louis pension system and analyze administrative data on teacher retention and turnover before and after enhancements.

\subsubsection{Public School Teachers in St. Louis}

In the last twenty years, both the size and the age/experience of teachers in St. Louis public schools have been changing.

Figure 1.1 shows that the total number of teachers in St. Louis public schools gradually decreased after 2003. The figure also illustrates the emergence of charter schools in St. Louis. Missouri's charter schools which were initially only confined to two urban districts: Kansas City and St. Louis. In the past 10 years, the United States experienced a tremendous growth of charter schools. In St. Louis, charter schools began to develop in 2000 and consistently grew afterwards. In 2016, charter schools accounted for around 30 percent of total teachers in the city of St. Louis. All 
charter school teachers are required to participate in the St. Louis teacher plan.

Figure 1.1: Trends in Teacher Numbers of St. Louis Charter Schools and Public Schools Teachers from 1993 and 2016

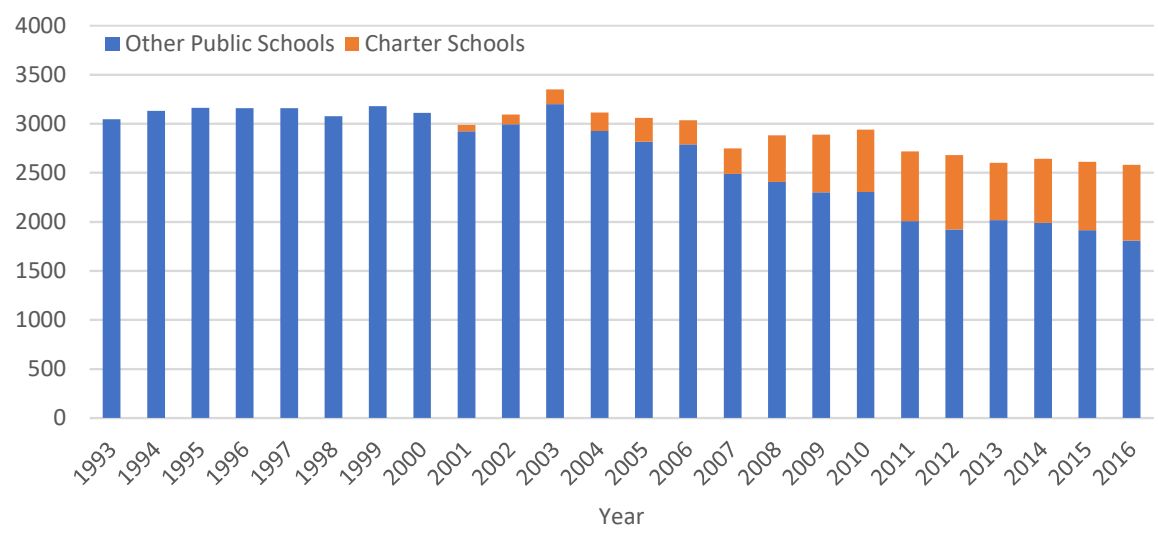

Note: This figure shows the total number of teachers in St. Louis public schools from 1993 to 2016. The figure also illustrates the emerging of charter schools in St. Louis.

Figure 1.2: Trends in Average Age and Average Experience of St. Louis Public Schools Teachers from 1993 to 2016

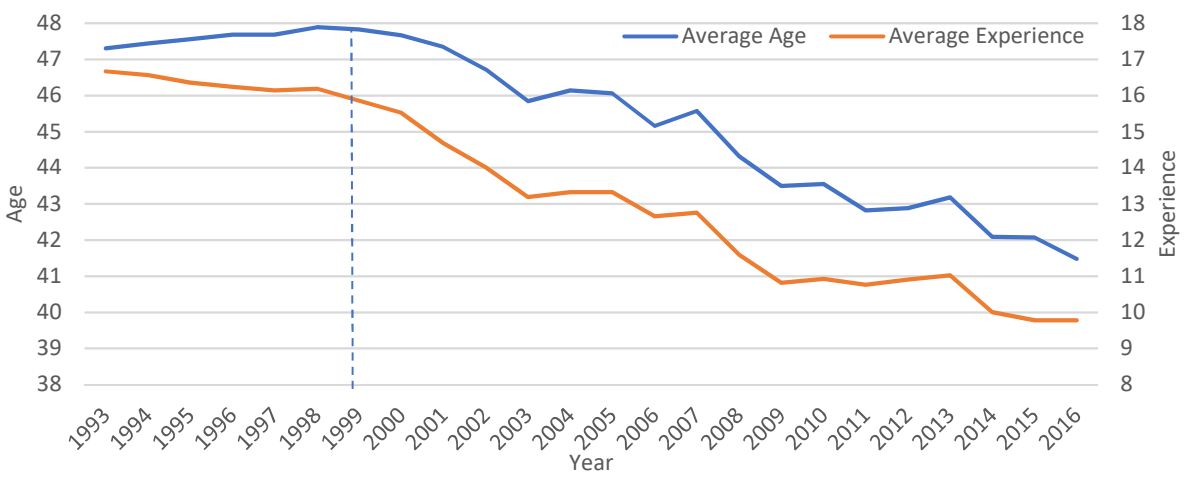

Note: This figure demonstrates the average age and experience of all public school teachers in St. Louis from 1992-93 school year to 2015-16 school year.

Figure 1.2 demonstrates the trends in average age and experience of public school teachers. Before 1999, the averages of both age and teaching experience were relatively steady. However, following the 1999 enhancements there was an approximately seven 
year drop in the average level of both age and teaching experience. More detailed information are shown in Table 1.1.

Table 1.1: Trends in Teachers Characteristics at St. Louis Public Schools from 1993 to 2016

\begin{tabular}{|c|c|c|c|c|}
\hline Year & Number of Teachers & Average Experience & Average Age & Average Salary $(\$)$ \\
\hline 1993 & 3045 & 16.67 & 47.31 & 31421 \\
\hline 1994 & 3130 & 16.57 & 47.44 & 32520 \\
\hline 1995 & 3162 & 16.36 & 47.56 & 33029 \\
\hline 1996 & 3158 & 16.24 & 47.68 & 33751 \\
\hline 1997 & 3157 & 16.14 & 47.68 & 33266 \\
\hline 1998 & 3077 & 16.19 & 47.89 & 33785 \\
\hline 1999 & 3178 & 15.85 & 47.83 & 34489 \\
\hline 2000 & 3110 & 15.52 & 47.67 & 35692 \\
\hline 2001 & 2987 & 14.68 & 47.34 & 37483 \\
\hline 2002 & 3092 & 14.01 & 46.72 & 39578 \\
\hline 2003 & 3348 & 13.19 & 45.84 & 40618 \\
\hline 2004 & 3114 & 13.33 & 46.14 & 40212 \\
\hline 2005 & 3059 & 13.33 & 46.06 & 40324 \\
\hline 2006 & 3033 & 12.66 & 45.16 & 42897 \\
\hline 2007 & 2746 & 12.76 & 45.57 & 44939 \\
\hline 2008 & 2881 & 11.59 & 44.32 & 45845 \\
\hline 2009 & 2888 & 10.82 & 43.50 & 44905 \\
\hline 2010 & 2938 & 10.93 & 43.55 & 47863 \\
\hline 2011 & 2713 & 10.76 & 42.82 & 46527 \\
\hline 2012 & 2676 & 10.91 & 42.88 & 46374 \\
\hline 2013 & 2595 & 11.03 & 43.18 & 47517 \\
\hline 2014 & 2637 & 10.01 & 42.09 & 46114 \\
\hline 2015 & 2605 & 9.78 & 42.07 & 45395 \\
\hline 2016 & 2579 & 9.78 & 41.48 & 45198 \\
\hline
\end{tabular}

Note: The table includes all teachers in St. Louis public schools from the 1992-93 school year to the 2015-16 school year. The table shows the number of teachers, average experience, average age and average salary each year.

These aggregate time series data suggest a break in trend associated with the 
enhancement. To better understand the potential effects of the plan I next examine the work versus retirement incentives arising from the rules in the plan, and how these changed.

\subsubsection{Pension Wealth Accrual and Retirement Incentives}

In this section, I describe teacher pension rules and examine pension wealth accrual before and after the 1999 pension enhancement. Teachers in Missouri are in three separate FAS-DB systems. Teachers in the St. Louis and Kansas City districts are covered by Social Security and are in two separate district plans. The rest of the public school teachers are in a state teacher plan, and are not covered by the Social Security system. There is no reciprocity for service years between Saint Louis and the other two plans. Our focus in this paper is St. Louis teachers, who are in the Saint Louis Public School Retirement System (STLPSRS).

St. Louis teachers become eligible for a regular pension when they are 65 with at least five years of service or when the sum of their years of service and age equals at least 85 (known as "Rule of 85 "). Benefits at retirement are determined by the formula:

$$
\text { Annual Benefit }=r f \times S \times F A S \text {, }
$$

where $r f$ stands for replacement factor. $S$ denotes years of teaching experience in the system. FAS is the average of the highest consecutive three years of salary, which are typically the three years prior to retirement. There is also a provision for early retirement at age 60 with a reduced annuity for teachers who do not qualify for

\footnotetext{
${ }^{1}$ All employees of St. Louis public schools, both charter and district, are required to participate in STLPSRS.
} 
regular retirement.

During the 1990's there were some small changes in the pension rules. However, there was only one major pension enhancement which occurred in 1999. Before 1999, the replacement factor was 1.25 percent. After 1999, the replacement factor increased to 2 percent. For example, before 1999, a retired teacher with 30 years teaching experience and a final average salary of $\$ 50,000$ received a $\$ 18,750$ annuity $(.0125 \times$ $30 \times \$ 50,000)$. After 1999 , this same teacher would receive an annual annuity of $\$ 30,000(.02 \times 30 \times \$ 50,0000)$. This benefit applied to all active teachers, including those nearing retirement.

Table 1.2: Summary of Pension Rules

\begin{tabular}{ccc}
\hline & Before 1999 & After 1999 \\
\hline Normal Pension & Age + Experience $\geq 85($ Rule of 85) & Age + Experience $\geq 85$ (Rule of 85) \\
& or Age $\geq 65$ with Experience $\geq 5$ & or Age $\geq 65$ with Experience $\geq 5$ \\
Early Pension & Age $\geq 60$ & Age $\geq 60$ \\
Replacement Factor & $1.25 \%$ & $2 \%$ \\
Maximum Benefit & No & $60 \%$ \\
\hline
\end{tabular}

However, the new benefit was capped at 60 percent of final average salary. Thus a teacher with 31 or more years teaching experience can still only receive 60 percent of her final average salary, in spite of the fact that she contributes five percent of salary to the plan. Table 1.2 reports the pension rules before and after the enhancement.

One way to assess the retirement incentives arising from these pension plan rules is to compute the pension wealth at different points in a teacher's work life. Previous literature, such as Costrell and Podgursky (2009), shows graphically that the lifelong pattern of pension wealth accumulation for defined benefit plans is nonlinear and has 
several spikes. These spikes encourage teachers to stay before gaining the peaks of wealth accumulation and retire after gaining the peaks, which are so-called "pull" and "push" incentives. The first spike usually occurs at the vesting date, when an employee first qualifies for pension benefits. The other spikes occur when the worker satisfies early, and then regular retirement standards. Pension wealth is calculated as the expected present value of pension benefits at retirement age $r$, which is formulated as follows:

$$
P W(r)=\sum_{s \geq r}(1+r)^{r-s} \pi(s \mid r) P(s \mid r)
$$

where $\pi(s \mid r)$ is the conditional probability of survival, and $P(s \mid r)$ is the pension benefit if the teacher retires at age $r$. Pension wealth captures the market value of obtaining this stream of annuity payments over time.

Following Costrell and Podgursky (2009), the pension wealth accumulation can be calculated as follows:

$$
p w(r)=\frac{P W(r)-(1+i n f) * P W(r-1)}{\operatorname{Salary}(r)},
$$

where $P W(r)$ is pension wealth if retiring at age $r$, inf is inflation rate, $\operatorname{Salary}(r)$ is salary at age $r$.

Figure 1.3 compares the pension wealth under the pension rules before and after pension enhancement for a representative teacher in St. Louis who enters the system at age 25. Figure 1.4 compares the pension wealth accumulation under the pension rules before and after pension enhancement.

Figures 1.3 and 1.4 are consistent with previous literature about the incentives underlying different pension rules. The higher spikes after the enhancement create a 
Figure 1.3: Pension Wealth Accrual for a Teacher Entering at Age 25

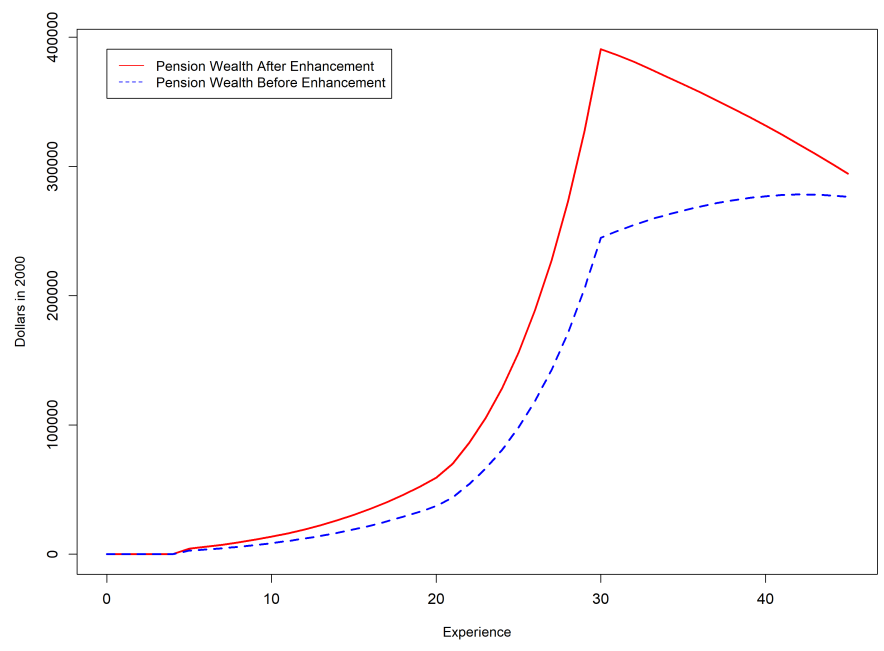

Note: The figure compares the pension wealth under the pension rules before and after pension enhancement for a representative teacher in St. Louis who enters the system at age 25. For prediction of salary I use a cubic function of experience.

Figure 1.4: Annual Changes in Pension Wealth for a Teacher Entering at Age 25

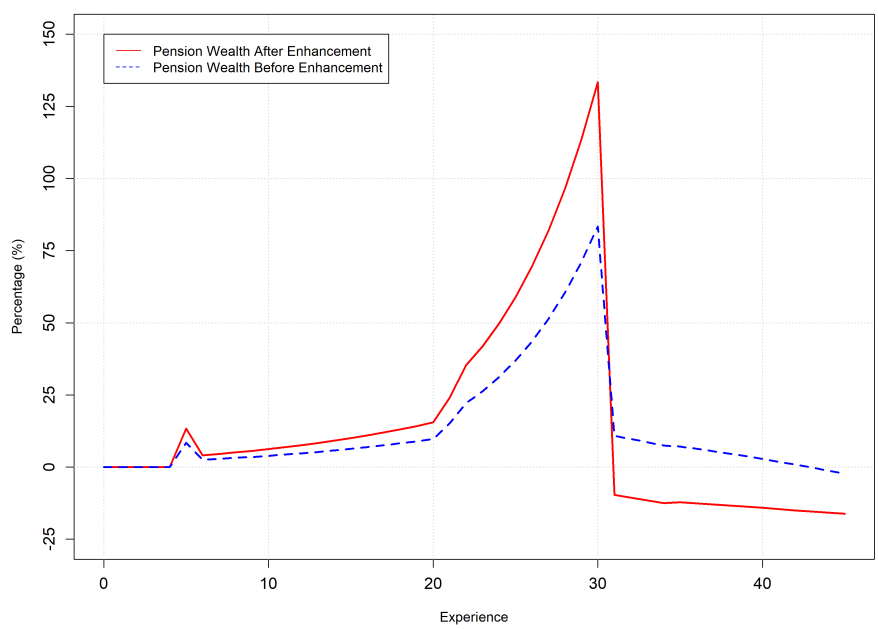

Note: The figure compares the pension wealth accumulation under the pension rules before and after pension enhancement.

stronger pull effect as well as a stronger push effect. 


\subsubsection{Retirement Behavior Before and After Pension Enhance- ments}

In this section I compare the empirical retirement behaviors before and after the 1999 pension enhancements. This study mainly focuses on the retirement timing of latecareer teachers. Thus, I examine two cohorts of teachers aged 50-62 at the base year and track them forward for the next five years. The pre-enhancement cohort begins at the 1992-93 school year. The post-enhancement cohort begins at the 2001-02 school year. Table 1.3 reports basic descriptive statistics for the two cohorts.

Table 1.3: Sample Statistics: Before and After 1999 Enhancements

\begin{tabular}{ccccccccc}
\hline & \# of Teachers & \multicolumn{2}{c}{ Age } & \multicolumn{2}{c}{ Experience } & \multicolumn{2}{c}{ Male Share } \\
& $93-97$ & $02-06$ & $93-97$ & $02-06$ & $93-97$ & $02-06$ & $93-97$ & $02-06$ \\
\hline All Teachers at 1993 (2002) & 880 & 1156 & 55.23 & 55.12 & 23.40 & 23.08 & 0.21 & 0.24 \\
Retired at 1993 (2002) & 53 & 75 & 58.30 & 57.08 & 26.55 & 25.49 & 0.30 & 0.27 \\
Retired at 1994 (2003) & 40 & 125 & 59.93 & 58.18 & 30.00 & 27.73 & 0.15 & 0.33 \\
Retired at 1995 (2004) & 50 & 119 & 59.44 & 58.87 & 28.76 & 29.11 & 0.36 & 0.20 \\
Retired at 1996 (2005) & 51 & 121 & 60.63 & 59.50 & 30.73 & 29.55 & 0.24 & 0.17 \\
Retired at 1997 (2006) & 63 & 116 & 60.62 & 59.23 & 29.76 & 28.86 & 0.27 & 0.30 \\
Not Retired & 623 & 600 & 58.22 & 57.79 & 25.91 & 24.18 & 0.18 & 0.23 \\
\hline
\end{tabular}

The difference in the number of teachers (880 vs. 1156) at the baseline year is because of the age distribution changes from 1993 to 2002. Although the total number of all St. Louis teacher at 1993 and 2002 is almost the same (see Table 1.1). The proportion of the teachers aged within 50-62 increases from 1993 to 2002 due to their "expected" pension enhancement. The first row of Table 1.3 shows that the two cohorts have similar average age and experience at the initial year of our sample period. The statistics in Table 1.3 suggest that teacher retirement behavior is quite 
different pre-enhancements and post-enhancements. There are much more retirees after enhancements. This is also reflected in the difference of survival rates. Figure 1.5 reports the employment survival rates over the five years. The post enhancement survival curve is well below the earlier cohorts. By year five, only one-third of the pre-enhancement cohort has retired, whereas in the post-enhancement cohort half of teachers have retired.

Figure 1.5: Employment Survival Rate Before and After Pension Enhancements

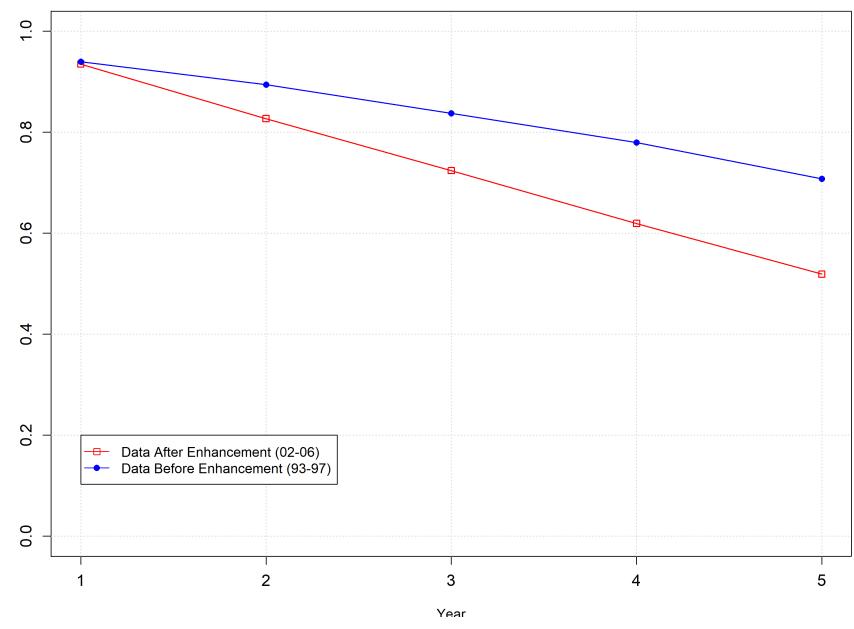

Note: The figure compares the employment survival rates for two cohorts of teachers aged 50-62 at the base year and then track them for the next five years (93-97 and 02-06).

Figures 1.6 and 1.7 report age and experience distributions for the two cohorts. Here it is important to note that we only observe completed age and experience spells for teachers who have retired and only one-third and one-second of the pre and post-enhancement cohorts, respectively, have retired. With this caveat in mind, we note that the median age of the retirees is roughly 2 years lower post-enhancements. Moreover, there are two spikes in the pre-enhancement age distribution, one is at age 57 and the other one is at age 62 . While there is only one steep spike at age 62 after enhancement. 
Figure 1.6: Age Distribution Before and After Pension Enhancements
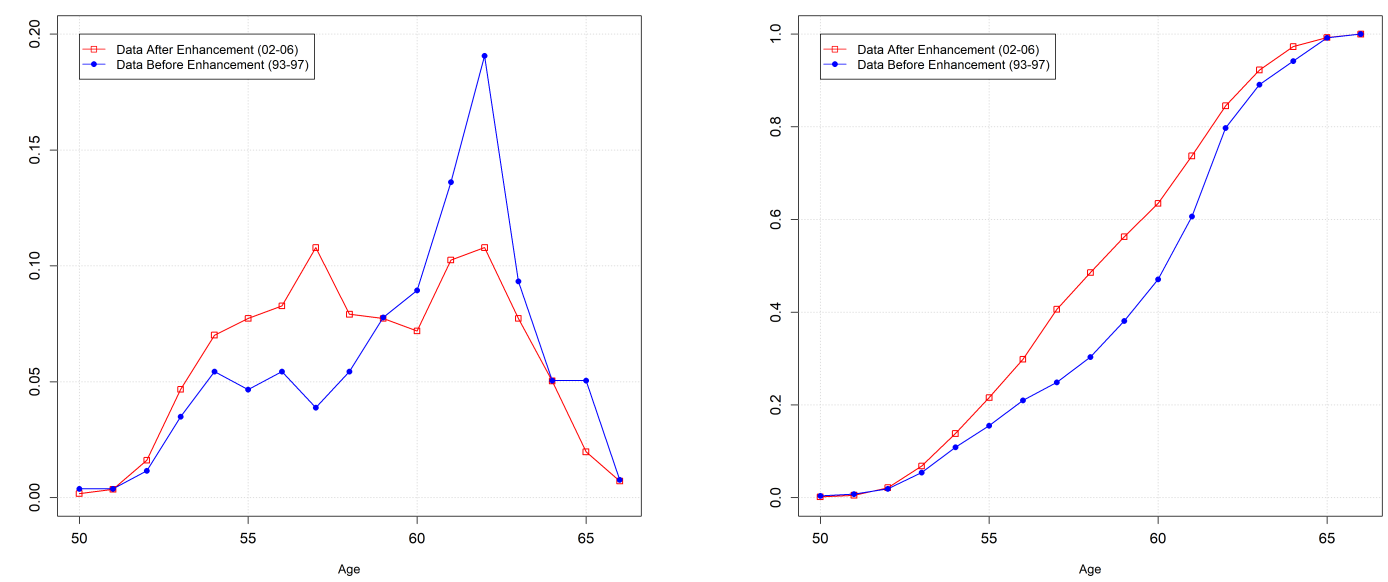

Note: The figure compares the age distributions for retired teachers during two periods before and after 99 enhancement. The teachers are aged 50-62 at the base year of two periods (93-97 and 02-06). The left graph compares the probability density, while the right graph compares the cumulative distribution.

Figure 1.7: Experience Distribution Before and After Pension Enhancements
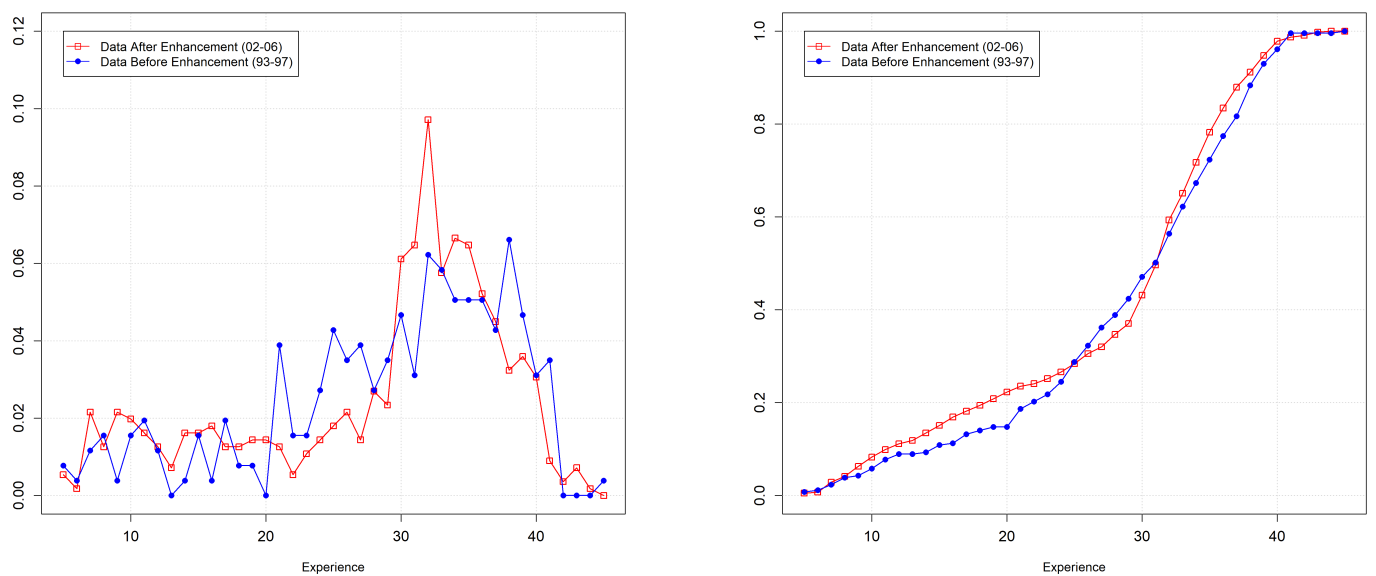

Note: The figure compares the experience distributions for retired teachers during two periods before and after 99 enhancement. The teachers are aged 50-62 at the base year of two periods (93-97 and 02-06). The left graph compares the probability density, while the right graph compares the cumulative distribution.

From the experience distribution, much more retirees after enhancement choose to retire with experience from 30 to 35 . The median experience of observed retirees 
is roughly the same. From the statistics and figures, teachers are more likely to retire and they retired at earlier age after pension enhancement.

I will round out our empirical discussion by presenting regression-adjusted retirement rates for the same pre and post-enhancement senior teacher cohorts. I estimate the following model:

$$
\text { Retire }_{i}=\alpha+\beta \text { Enhancements }_{i}+\theta X_{i}+\epsilon_{i},
$$

where Retire $_{i}$ is an indicator variable equal to 1 if the teacher $\mathrm{i}$ chooses to retire in the next five years; Enhancement ${ }_{i}$ is a dummy variable if the teacher $\mathrm{i}$ is in the post-enhancement cohort; $\epsilon_{i}$ is the error term; $X_{i}$ are control variables. Model 1, $X_{i}$ includes baseline age and experience, and Model 2, $X_{i}$ includes baseline age, experience and gender. Both models include and indicator variable for the postenhancement cohort. Table 1.4 reports the estimation results. The coefficient on the enhancement cohort dummy implies that the probability of retirement, averaged over all teachers, was .20 points higher.

The evidence in Tables 1.3 1.4 and Figures 1.5 1.7 suggests that the 1999 enhancements significantly shortened teaching careers and that the "push" effects were potent. However, the reduced-form estimates have limitations in analyzing the effects of pension enhancements. First, they cannot "unbundle" the effects of the different components of the enhancement (e.g., the 60 percent cap versus the increase in the formula factor). Second, and more importantly, they only indicate the short run effects of the changes. To get a better sense of the long term effects of the enhancements, I estimate a structural retirement model. 
Table 1.4: Regression Results of Linear Probability Models

\begin{tabular}{|c|c|c|}
\hline & \multicolumn{2}{|c|}{ Dependent Variable: Retirement } \\
\hline & Model 1 & Model 2 \\
\hline \multirow[t]{2}{*}{ With Enhancements } & $0.198^{* * *}$ & $0.195^{* * *}$ \\
\hline & $(0.019)$ & $(0.019)$ \\
\hline \multirow[t]{2}{*}{ Experience } & $0.011^{* * *}$ & $0.011^{* * *}$ \\
\hline & $(0.001)$ & $(0.001)$ \\
\hline \multirow[t]{2}{*}{ Age } & $0.048^{* * *}$ & $0.048^{* * *}$ \\
\hline & $(0.003)$ & $(0.003)$ \\
\hline \multirow[t]{2}{*}{ Male } & & $0.077^{* * *}$ \\
\hline & & $(0.023)$ \\
\hline \multirow[t]{2}{*}{ Constant } & $-2.640 * * *$ & $-2.668^{* * *}$ \\
\hline & $(0.146)$ & $(0.146)$ \\
\hline Observations & 2,036 & 2,036 \\
\hline $\mathrm{R}^{2}$ & 0.240 & 0.244 \\
\hline Adjusted $\mathrm{R}^{2}$ & 0.239 & 0.243 \\
\hline Residual Std. Error & $0.427(\mathrm{df}=2032)$ & $0.426(\mathrm{df}=2031)$ \\
\hline F Statistic & $213.534^{* * *}(\mathrm{df}=3 ; 2032)$ & $163.876^{* * *}(\mathrm{df}=4 ; 2031)$ \\
\hline \multicolumn{3}{|c|}{ Note: Model 1: Retire $_{i}=\beta_{0}+\beta_{1}$ Enhancement $_{i}+\beta_{2}$ Experience $_{i}+\beta_{3}$ Age $_{i}+\epsilon_{i}$} \\
\hline \multirow{2}{*}{\multicolumn{3}{|c|}{$\begin{array}{l}\text { Model 2: } \text { Retire }_{i}=\beta_{0}+\beta_{1} \text { Enhancement }_{i}+\beta_{2} \text { Experience }_{i}+\beta_{3} \text { Age }_{i}+\beta_{4} \text { Male }_{i}+\epsilon_{i} \\
\text { The standard errors are in parentheses. }\end{array}$}} \\
\hline & & \\
\hline \multicolumn{3}{|c|}{${ }^{*} \mathrm{p}<0.1 ; * * \mathrm{p}<0.05 ; * * * \mathrm{p}<0.01$} \\
\hline
\end{tabular}

\subsection{A Dynamic Structural Retirement Model}

Stock and Wise (1990) developed a structural model of retirement which was extended by $\mathrm{Ni}$ and Podgursky (2016) to an analysis of Missouri public school teachers. I apply this model, with several innovations, to an analysis of St. Louis teachers.

Consider a teacher who has not retired at the beginning of year $t$. The present 
value of expected lifetime utility for the teacher if she retires in year $\mathrm{r}(r \geq t)$ is:

$E_{t} V_{t}(r)=\max _{c_{1}, c_{2}} E_{t}\left\{\sum_{s=t}^{r-1} \beta^{s-t} \pi(s \mid t) U_{w}\left(Y_{s}, B_{s}\left(c_{1}\right)\right)+\sum_{s=r}^{T} \beta^{s-t} \pi(s \mid t) U_{r}\left(P_{s}\left(c_{2}\right), B_{s}\left(c_{1}\right)\right)\right\}$

where

$$
\begin{gathered}
U_{w}\left(Y_{s}, B_{s}\left(c_{1}\right)\right)=\left(k_{s}\left((1-c) Y_{s}+I_{s}^{1} B_{s}\left(c_{1}\right)\right)\right)^{\gamma}+\omega_{s} \\
U_{r}\left(P_{s}\left(c_{2}\right), B_{s}\left(c_{1}\right)\right)=\left(I_{s}^{2} P_{s}\left(c_{2}\right)+I_{s}^{1} B_{s}\left(c_{1}\right)\right)^{\gamma}+\xi_{s} .
\end{gathered}
$$

$$
\begin{aligned}
& I_{s}^{1}= \begin{cases}1 & \text { if } s \geq c_{1} \\
0 & \text { otherwise }\end{cases} \\
& I_{s}^{2}= \begin{cases}1 & \text { if } s \geq c_{2} \\
0 & \text { otherwise }\end{cases}
\end{aligned}
$$

The value function depends on future annual earnings $Y_{s}$ before retirement, pension benefits $P_{s}\left(c_{2}\right)$ if the teacher starts collecting a pension benefit at year $c_{2}$, and Social Security benefits $B_{s}\left(c_{1}\right)$ if she starts collecting Social Security at year $c_{1}$. The collection years are optimally chosen to maximize the expected utility given the retirement year $\mathrm{r}$. The parameter $\mathrm{c}$ is the contribution rate for teachers before retirement; and $k_{s}$ represents teachers' preference of teaching versus retiring, which depends on age. $\pi(s \mid t)$ is the conditional survival rate, which is calculated using mortality rates. I assume that $k_{s}=k\left(\frac{60}{\text { age }}\right)^{k_{1}}$. 
The expected gain from postponing retirement to year $\mathrm{r}$ is:

$$
G_{t}(r)=E_{t} V_{t}(r)-E_{t} V_{t}(t)
$$

Each year, a non-retired teacher has two choices: continue teaching or retire. The expected gain from postponing retirement can be seen as the "option value" of continuing working, which is the key feature of this model. Retirement occurs if the value of continuing teaching is less than the value of retiring. In other words, the option value of continued teaching is negative.

The teacher's future salary, pension benefits, and Social Security benefits are assumed to be predictable. In the empirical analysis I replace the expected salary and benefits with forecasts based on historical data.

The expected gain from retiring in year $\mathrm{r}$ (later than $\mathrm{t}$ ) becomes

$$
G_{t}(r)=E_{t} V_{t}(r)-E_{t} V_{t}(t)=g_{t}(r)+K_{t}(r) \nu_{t}
$$

where the first term $g_{t}(r)=\sum_{s=t}^{r-1} \beta^{s-t} \pi(s \mid t)\left(\left(k_{s}\left((1-c) Y_{s}+I_{s}^{1} B_{s}\left(c_{1}\right)\right)\right)^{\gamma}\right)+$

$$
\sum_{s=r}^{T} \beta^{s-t} \pi(s \mid t)\left(\left(I_{s}^{2} P_{s}\left(c_{2}\right)+I_{s}^{1} B_{s}\left(c_{1}\right)\right)^{\gamma}-\left[\sum_{s=t}^{T} \beta^{s-t} \pi(s \mid t)\left(I_{s}^{2} P_{s}\left(c_{2}\right)+I_{s}^{1} B_{s}\left(c_{1}\right)\right)^{\gamma}\right] .\right.
$$

And the second term, $K_{t}(r)=\sum_{s=t}^{r-1}(\beta \rho)^{s-t} \pi(s \mid t)$, depends on parameters I need to estimate. The preference error $\nu_{t}=\omega_{t}-\xi_{t}$. I assume $\nu_{t}$ follows an $\operatorname{AR}(1)$ process: $\nu_{t}=\rho \nu_{t-1}+\epsilon_{t}$. Moreover, I assume $\epsilon_{t}$ is iid $N\left(0, \sigma^{2}\right)$.

Suppose $r^{\dagger}$ solves $\max _{r \in\{t+1, t+2, \ldots \ldots . . T\}} E_{t} V_{t}(r)$. Thus, the teacher will continue working at $\mathrm{t}$ if $G_{t}\left(r^{\dagger}\right)=E_{t} V_{t}\left(r^{\dagger}\right)-E_{t} V_{t}(t)>0$. The probability of retirement at time $\mathrm{t}$ is $\operatorname{Pr}[R=t]=\operatorname{Pr}\left[G_{t}(r) \leq 0, \forall r \geq t+1\right]=\operatorname{Pr}\left[G_{t}\left(r^{\dagger}\right) \leq 0\right]$, which can be 
represented as

$$
\operatorname{Pr}\left[g_{t}\left(r_{t}^{\dagger}\right) / K_{t}\left(r_{t}^{\dagger}\right) \leqslant-\nu_{t}\right]
$$

In this model, there are six unknown parameters to be estimated, which are listed in Table 2.6. Details concerning the construction and estimation of the sample likelihood function are given in the Appendix B.

Table 1.5: Structural Model Parameters

\begin{tabular}{cc}
\hline Parameters & Economic Interpretation \\
\hline$\beta \in(0,1)$ & discount factor \\
$k \in(0,1) \& k_{1}>0$ & $k_{s}=k\left(\frac{60}{a g e}\right)^{k_{1}}:$ preference of teaching versus retiring \\
$\gamma \in(0,1]$ & curvature in the utility function $(\gamma<1$ indicates concavity $)$ \\
$\sigma>0$ & magnitude of unobserved preference shocks \\
$\rho \in(-1,1)$ & persistence in unobserved preference shocks \\
\hline
\end{tabular}

\subsubsection{Data}

Using the above dynamic structural retirement model, I began by estimating the related unknown parameters for St. Louis Teachers. The data I use for estimation of the structural model consists of a cohort of St. Louis teachers aged 50-62 at the beginning of the 1992-93 school year. I tracked this cohort of teachers forward to the 2013-14 school year. Descriptive statistics on this sample are shown in Table 1.6. In the base year (1992-93 school year), there are 880 teachers and seventy-nine percent of teachers in the sample are female. At the end of 2013-14 school year, all teachers in the cohort are retired. During this period, teachers at the first 6 years are covered under pre-enhancement pension rules and then post-enhancement rules afterwards. 
Table 1.6: Estimation Sample: Descriptive Statistics

\begin{tabular}{|c|c|c|c|c|}
\hline & Number of Teachers & Age & Experience & Male Share \\
\hline All Teachers at 1993 & 880 & 55.23 & 23.40 & 0.21 \\
\hline Retired at 1993 & 53 & 58.30 & 26.55 & 0.30 \\
\hline Retired at 1994 & 40 & 59.93 & 30.00 & 0.15 \\
\hline Retired at 1995 & 50 & 59.44 & 28.76 & 0.36 \\
\hline Retired at 1996 & 51 & 60.63 & 30.73 & 0.24 \\
\hline Retired at 1997 & 63 & 60.62 & 29.76 & 0.27 \\
\hline Retired at 1998 & 41 & 61.80 & 28.61 & 0.17 \\
\hline Retired at 1999 & 96 & 61.39 & 28.29 & 0.26 \\
\hline Retired at 2000 & 104 & 62.07 & 29.24 & 0.21 \\
\hline Retired at 2001 & 57 & 63.60 & 30.98 & 0.04 \\
\hline Retired at 2002 & 47 & 62.64 & 33.00 & 0.21 \\
\hline Retired at 2003 & 78 & 63.73 & 33.85 & 0.18 \\
\hline Retired at 2004 & 58 & 64.02 & 31.57 & 0.26 \\
\hline Retired at 2005 & 54 & 64.35 & 33.28 & 0.20 \\
\hline Retired at 2006 & 23 & 66.22 & 33.00 & 0.04 \\
\hline Retired at 2007 & 32 & 66.13 & 29.84 & 0.13 \\
\hline Retired at 2008 & 12 & 68.17 & 36.00 & 0.08 \\
\hline Retired at 2009 & 5 & 68.60 & 35.00 & 0.20 \\
\hline Retired at 2010 & 8 & 69.25 & 35.75 & 0.13 \\
\hline Retired at 2011 & 3 & 69.33 & 28.33 & 0.33 \\
\hline Retired at 2012 & 2 & 70.50 & 31.50 & 0.00 \\
\hline Retired at 2013 & 2 & 72.50 & 40.50 & 0.00 \\
\hline Retired at 2014 & 1 & 71.00 & 46.00 & 0.00 \\
\hline
\end{tabular}

Table 1.6 shows some evidence that the teachers respond to the enhancement at 1999. At 1998, those teachers who would retire expect an enhancement next year. They are more likely to stay one more year and get a huge increase in benefits after retirement. Thus, in 1998, the number of retirees is only 41, which is abnormally 
low. While at the first two years of the enhancement (1999 and 2000), the number of retirees increases to roughly 100. After that, the number of retirees still remains at a high level.

\subsubsection{Expectations of Future Pension Rules}

The dynamic retirement model discussed above assumes that employed teachers can accurately predict their future pension benefits. However, future pension benefits depend on the pension rules in place at the time of retirement. As noted, these rules changed dramatically in 1999. This leads us to consider two models of teachers' expectations, "Perfect Foresight" and "Myopic".

Perfect foresight expectations assume that teachers know exactly the pension policies in the future. The expected pension benefits are calculated based on the pension rules in place at that future retirement year. I label this the "Perfect Foresight" assumption. An alternative polar case is that teachers make decisions on the basis of current pension rules pension rules which they assume will pertain at their future retirement year, which I label "Myopic". I will take both of these models to the data and examine which expectation model fits the data better.

The future cannot be fully predicted. But the information about pension enhancements in St. Louis as well as the policy changes in other states will update teachers' expectations. Many states enhanced teacher pension in 1990s, including PSRS, which is a nearby separate pension system in the same state as the City of St. Louis. Thus, many teachers also expect the pension enhancements in St. Louis during the 1990s. Especially during the 1997-1998 school year, one year before the enhancement, when the enhancement was approved, teachers know when and how the 
enhancements enact. Thus, perfect foresight assumption that teachers knows exactly the future pension policy is plausible during the periods close to 1999. However, during the years far before 1999, the perfect foresight assumption is not that reasonable. Moreover, some teachers could be reckless about future pension rules as well as their future pension benefits. Thus, from this perspectives, the other extreme assumption that teachers calculate the expected pension benefit based only on the current rules could be more reliable.

In reality, neither "Perfect Foresight" nor "Myopic" can fully represent the expectations of all teachers. However, when modelling the retirement behaviors in St. Louis public schools in this section, teachers are assumed to make decisions under above-mentioned two extreme cases to simplify our model setting.

\subsubsection{MLE Estimates}

MLE estimates of the six parameters in our structural model based on above two expectation assumptions are reported in Table 1.7. All estimates are statistically significant. These estimates are quite similar to those in Ni and Podgursky (2016), in spite of the fact that these are teachers covered by a different pension plan. Two sets of parameters are also quite similar, although they are under two extreme assumptions of expectation.

The parameter $\beta$ implies an annual discount rate of $\frac{1}{\beta}-1$. The parameter $\gamma$ is less than 1 , which means the utility function is concave. The concavity of the utility function implies that teachers are risk-averse and prefer to avoid a sharp drop in income. Parameters $\sigma$ and $\rho$ pertain to unobserved preference errors, which capture the magnitude and persistence of unobserved heterogeneity, respectively. The estimates 
Table 1.7: Estimates of Six Behavioral Parameters

\begin{tabular}{ccc}
\hline & Perfect Foresight Assumption & Myopic Assumption \\
\hline$\beta$ & 0.936 & 0.938 \\
$\gamma$ & $(0.012)$ & $(0.015)$ \\
& 0.661 & 0.676 \\
$\sigma$ & $(0.031)$ & $(0.034)$ \\
& 3279.538 & 3530.965 \\
$\rho$ & $(1387.522)$ & $(1847.465)$ \\
& 0.478 & 0.526 \\
$k$ & $(0.034)$ & $(0.061)$ \\
& 0.893 & 0.897 \\
$k_{1}$ & $(0.040)$ & $(0.054)$ \\
& 1.291 & 1.394 \\
& $(0.387)$ & $(0.462)$ \\
Log-Likelihood & & 880 \\
\hline Number of Teachers & -2366.902 & -2358.587 \\
\hline
\end{tabular}

Note: The standard errors are in parentheses.

of $\sigma$ indicate that unobserved heterogeneity is quite large relative to the flow of utility generated by salary, and the estimates of $\rho$ indicates that unobserved preference errors are positively correlated over time and persistent.

The parameters $k$ and $k_{1}$ together capture preferences teaching versus retiring. The preference not only measures the burden of working for a teacher but also represents the level of non-teaching opportunities (Ni and Podgursky, 2016). The pref-

\footnotetext{
${ }^{2}$ I also allow an increase in the variance of preference shocks when teachers are aged between 62 and their Social Security Full retirement age. on the assumption that retirement uncertainty increases due to the unobserved spousal decisions. I have no information on spouses in our data. In fact, this parameter was statistically significant, and indicated an approximately 40 percent increase in the variance between these ages.
} 
erence of teaching evaluates the utility equivalent benefits after retirement to one dollar of earnings while working. The number declines with age, which indicates a decreasing preference for work versus leisure as age increases.

\subsubsection{In-sample Goodness of Fit}

Figures 1.8 to 1.9 provide information regarding the overall goodness of fit of the model. Figure 1.8 compares the observed and predicted age and experience distribution of retired teachers. The in-sample predictions are good for age and experience distributions of retired teachers under both assumptions of teacher expectation.

Figure 1.9 shows that the observed and predicted survival rates are quite close. Under the myopic assumption, teachers did not expect a future enhancement in 1999. As a consequences, the model overpredicts the retirement rate before 1999, especially during the two years before the enhancement. Thus, the survival rates are lower than what we observe as well as what the model predicts under the assumption of perfect foresight.

\subsubsection{Out-of-Sample Goodness of Fit}

The out-of-sample simulation provides a robust check for the validity of our model. The data I use for out-of-sample simulation includes all teachers aged 50-62 at the 2001-02 school year, which I used above. I tracked this cohort of teachers forward to the 2005-06 school year. Descriptive statistics on this sample are shown in Table 1.8. In the base year of the 2001-02 school year, there are 1156 teachers. At the end of the 2005-06 school year, 600 teachers are not retired. During this period, the only 
Figure 1.8: Observed and Predicted Age and Experience Distribution (In Sample)
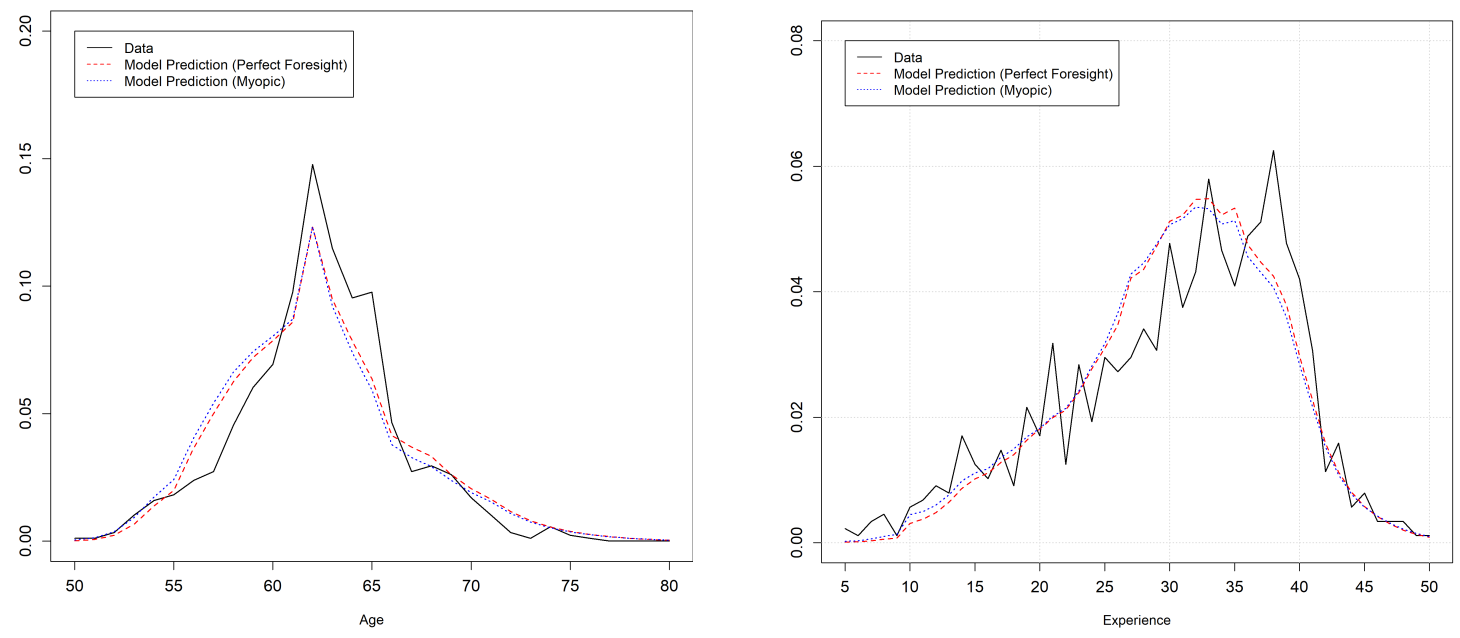

Note: The figure compares the observed and predicted age and experience distribution of retired teachers. The solid line is the observed distribution while the dashed line and dotted line are the predicted distributions under the assumption of perfect foresight expectation and myopic expectation respectively.

\section{Figure 1.9: Observed and Predicted Survival Rate (In Sample)}

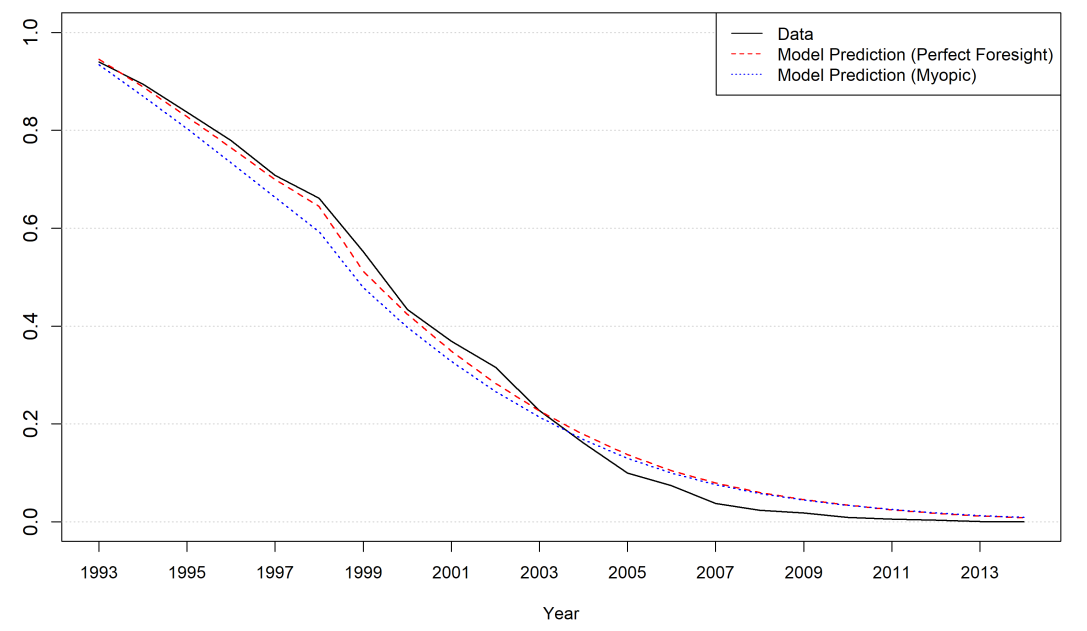

Note: The figure compares the observed and predicted survival rate for 93 cohort teachers from 1993 to 2014. The solid line is the observed distribution while the dashed line and dotted line are the predicted distributions under the assumption of perfect foresight expectation and myopic expectation respectively. 
pension rules applied to teachers are post-enhancement pension rules.

Table 1.8: Out-of-Sample Simulation Sample: Descriptive Statistics

\begin{tabular}{ccccc}
\hline & \# of Teachers & Experience & Age & Male Share \\
\hline All Teachers at 2002 & 1156 & 23.08 & 55.12 & 0.24 \\
Retired at 2002 & 75 & 25.49 & 57.08 & 0.27 \\
Retired at 2003 & 125 & 27.73 & 58.18 & 0.33 \\
Retired at 2004 & 119 & 29.11 & 58.87 & 0.20 \\
Retired at 2005 & 121 & 29.55 & 59.50 & 0.17 \\
Retired at 2006 & 116 & 28.86 & 59.23 & 0.30 \\
Not Retired & 600 & 24.18 & 57.79 & 0.23 \\
\hline
\end{tabular}

Using the estimated parameters in Table 3.3, I simulate the teachers retirement behaviors within the next five years. Figures 1.10 provides the out-of-sample goodness of fit of the model. Figure 1.10 compares the observed and predicted age and experience distribution of retired teachers. The model successfully matches the two peaks of the age distribution and the peak around 32 of experience distribution. The model fits the out-of-sample data reasonably well in both age and experience distributions of retired teachers. However, the model predicts the first peak at age 55, earlier than that in data at age 57. The explanation of the postponing retirement behaviors could be their expectations of more pension enhancements for the first few years after 1999, especially for the teachers close to pension retirements.

Figure 1.11 compares the survival rate for 93 cohort teachers and 02 cohort teachers for the next five years, which is also shown in Figure 1.5. Moreover, Figure 1.11 adds the prediction of our structural model. The survival rate predictions for both two cohorts works plausibly. Based on the in-sample and out-of-sample test, the model predicts teachers' retirement behaviors quite well. 
Figure 1.10: Observed and Predicted Age and Experience Distribution (Out of Sample)
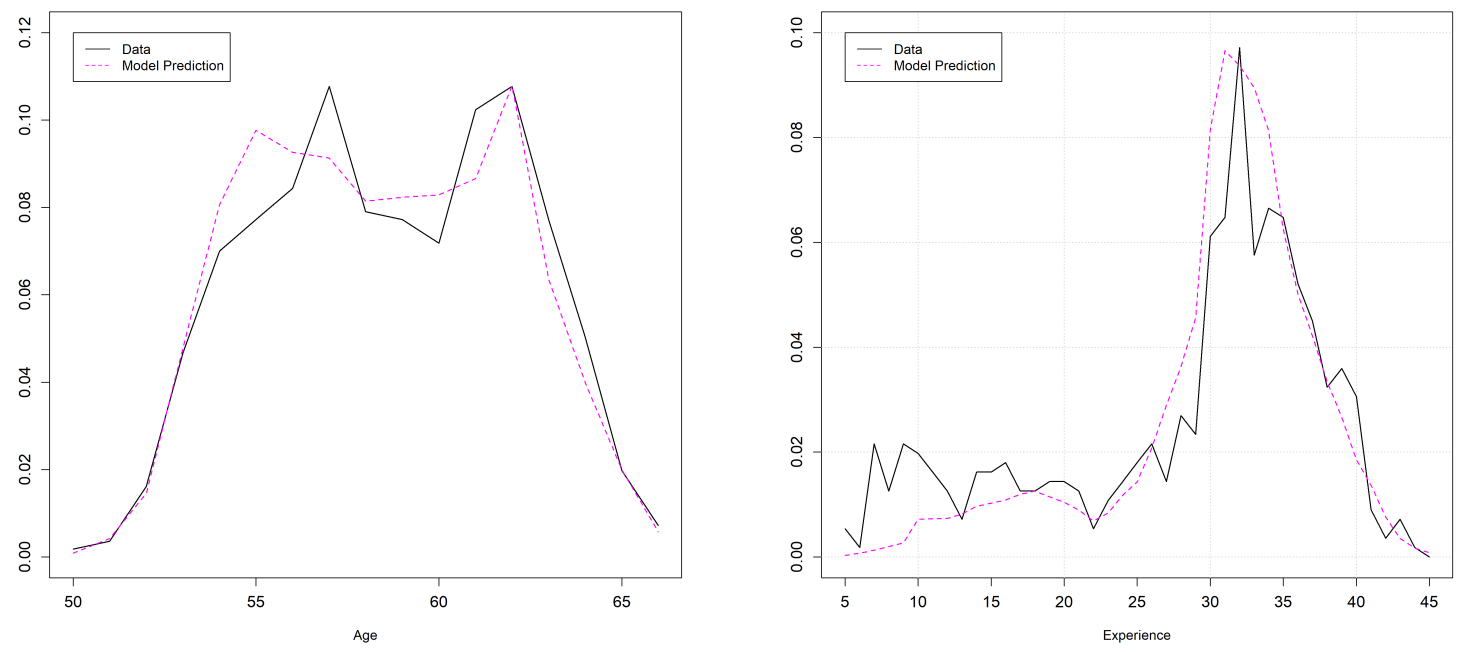

Note: The figure compares the observed and predicted age and experience distribution of retired teachers. The solid line is the observed distribution while the dashed line are the predicted distributions.

Figure 1.11: Observed and Predicted Survival Rate (In Sample and Out of Sample)

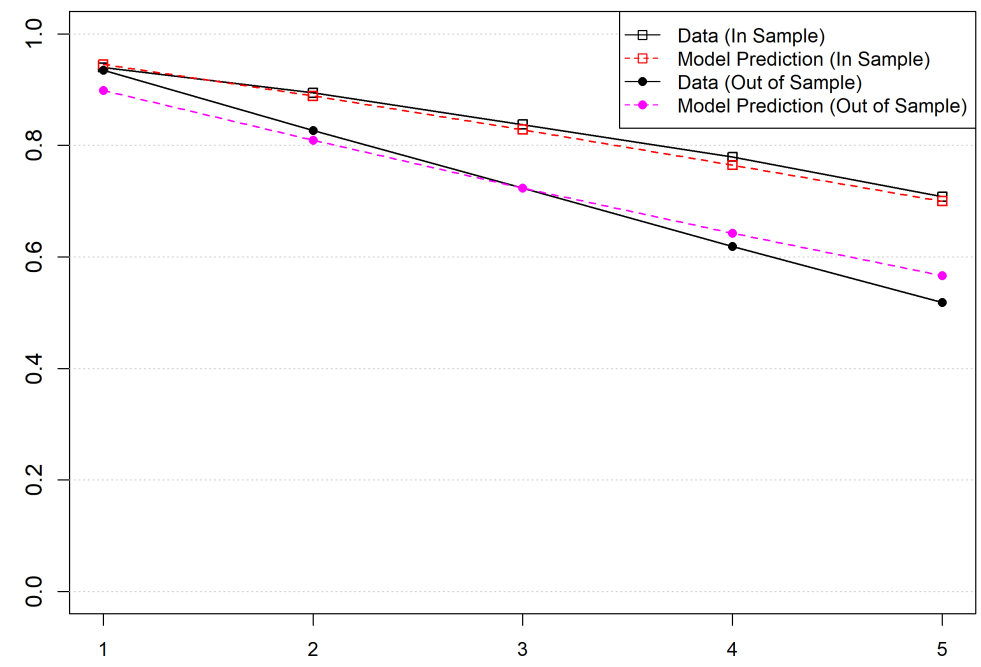




\subsubsection{Pension Incentives Underlying the DB Plan}

Steep rises in annual pension wealth accrual usually occurs when teachers satisfy early or full pension requirements. Costrell and Podgursky (2009) shows that those peaks will create incentives for teachers to stay before gaining the peak value, while the decline in pension wealth past the peak tends to push teachers in to retirement, which are so-called "pull" and "push" effect respectively. To further understand the pension incentives underlying the defined benefit plan, I will discuss the "pull" and "push" effect from the perspective of our dynamic retirement model in this section.

As I mentioned above, the probability of retirement for an employee at time $\mathrm{t}$ can be represented as formula (B.3): $\operatorname{Pr}\left[g_{t}\left(r_{t}^{\dagger}\right) / K_{t}\left(r_{t}^{\dagger}\right) \leqslant-\nu_{t}\right]$. The retirement occurs if the maximized $g_{t}\left(r_{t}\right) / K_{t}\left(r_{t}\right)$ is less than $-\nu_{t}$. Thus the lower the $g_{t}\left(r_{t}^{\dagger}\right) / K_{t}\left(r_{t}^{\dagger}\right)$ is, the more likely the teachers will retire and the higher the "push" effect is. Figure 1.12 shows $g_{t}\left(r_{t}^{\dagger}\right) / K_{t}\left(r_{t}^{\dagger}\right)$ with different age and experience combination under preand post-enhancement pension rules borrowing the estimates from Ni and Podgursky (2016). The bottom graph shows the difference of $g_{t}\left(r_{t}^{\dagger}\right) / K_{t}\left(r_{t}^{\dagger}\right)$ under post- and pre-enhancement pension rules.

There are several implications from Figure 1.12. First, $g_{t}\left(r_{t}^{\dagger}\right) / K_{t}\left(r_{t}^{\dagger}\right)$ under postenhancement pensions are significantly lower. This suggests a more powerful "push" effect under post-enhancement pension plan. Second, from the bottom figure, the difference of $g_{t}\left(r_{t}^{\dagger}\right) / K_{t}\left(r_{t}^{\dagger}\right)$ reflects the difference of retirement incentives under pensions after and before enhancements. The difference at experience 30 is lowest at every age. This reflects the effects of the cap of annual benefits, $60 \%$ of final average salary. When teachers reach the experience of 30 years, they have achieved the highest amount of their benefits. This further "push" them to retire because staying 
Figure 1.12: Pension Incentives: $g_{t}\left(r_{t}^{\dagger}\right) / K_{t}\left(r_{t}^{\dagger}\right)$

After Enhancement

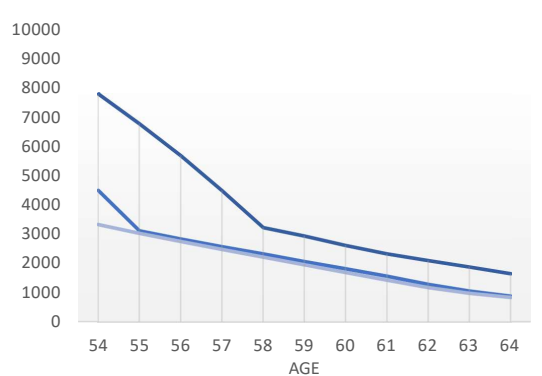

Before Enhancement

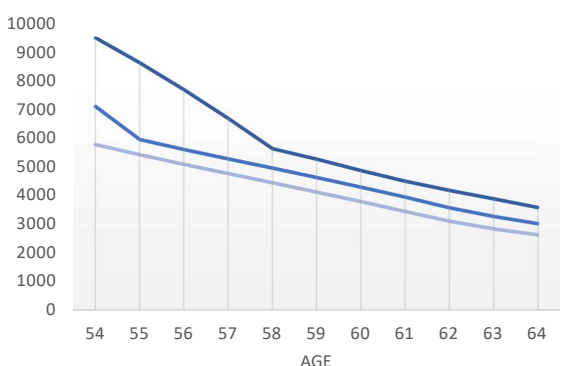

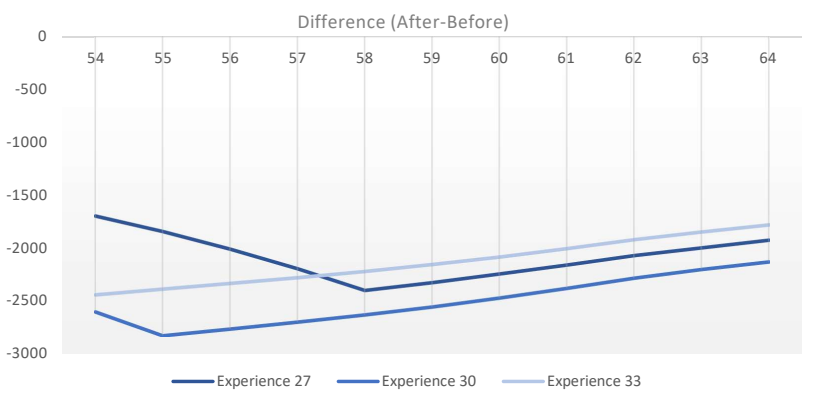

Note: The retirement occurs if $g_{t}\left(r_{t}^{\dagger}\right) / K_{t}\left(r_{t}^{\dagger}\right)$ is less than $-\nu_{t}$ (preference shock). Thus the lower the $g_{t}\left(r_{t}^{\dagger}\right) / K_{t}\left(r_{t}^{\dagger}\right)$ is , the more likely the teachers will retire. The top graphs show the $g_{t}\left(r_{t}^{\dagger}\right) / K_{t}\left(r_{t}^{\dagger}\right)$ with different age and experience combination under pre- and post-enhancement pension rules borrowing the estimates from Table 3.3. The bottom graph shows the difference of $g_{t}\left(r_{t}^{\dagger}\right) / K_{t}\left(r_{t}^{\dagger}\right)$ under post- and pre-enhancement pension rules.

longer will not induce higher benefits after retirement. Third, the difference is less negative at relatively young age and at relative old age. At experiences and ages around pension requirements there are stronger "push" effects after enhancements.

\subsection{Simulating the Effect of Pension Enhancements}

Many states are facing challenges financing existing teacher retirement plans. In addition, the "push" incentives built into DB plans tend to push them into retirement at relatively early ages. On average, public school teachers retire relatively earlier than white collar workers in other industries. To solve such problems, some states 
start adopting hybrid plans, which combine both DB and DC plans, and other retention pension policies recently. However, those new policies only apply to new-entry teachers. It will talk a few years to evaluate their effects on retirement behaviors. The dynamic retirement model is useful for simulating counterfactural pension rules in the long run. In this section, In this section, I choose the after-enhancement cohort of teachers in St. Louis public schools (teachers aged 50-62 at the 2001-2002 school year) to analyze the effects of the recent pensions and three counterfactual pensions for the next 30 years.

The simulated survival rates for the next 30 years are illustrated in Figure 1.13 and the simulated age and experience distributions under four pension rules are showed in Figure 1.14. The after-enhancement pension rules with highest replacement factor $(2 \%)$ and lowest cap of pension benefits (60\% of Final Average Salaries) yield the highest retirement rate and thus lowest survival rate every year. With the elimination of benefit cap or a decrease in replacement factor, the probability of retiring declines. The teachers under the before-enhancement pension rules, lowest replacement factor(1.25\%) without benefit cap, tend to stay longer.

Table 1.9 reports the effects of the different pensions on the timing of retiring statistically. I regard the after-enhancement pensions as our baseline rule. The elimination of pension cap of $60 \%$ or a decline of $0.25 \%$ in replacement factor lead to a higher level of average retired age and experience. The cheaper (before-enhancement) pensions induced less "push" effects than other three generous rules, and thus yield the highest future teaching years for this group of teachers.

Moreover, this table decomposes the effects of pension enhancement into the effects of increasing replacement factor and adding benefit cap. In average, teachers 
Figure 1.13: 30 -Year Simulation Under Different Pension Rules for 02-Cohort Teachers (Survival Rate)

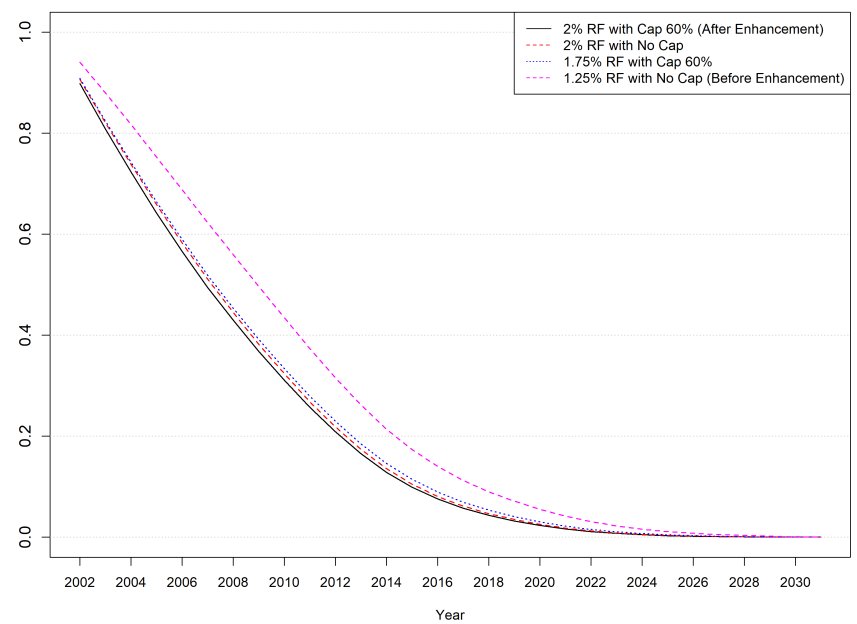

Note: The figure shows the simulated age and experience distributions of retired teachers under four pension rules for the next 30 years. The teachers are aged 50-62 at the 2001-2002 school year(base year).

Figure 1.14: 30 -Year Simulation Under Different Pension Rules for 02-Cohort Teachers (Age and Experience Distribution)
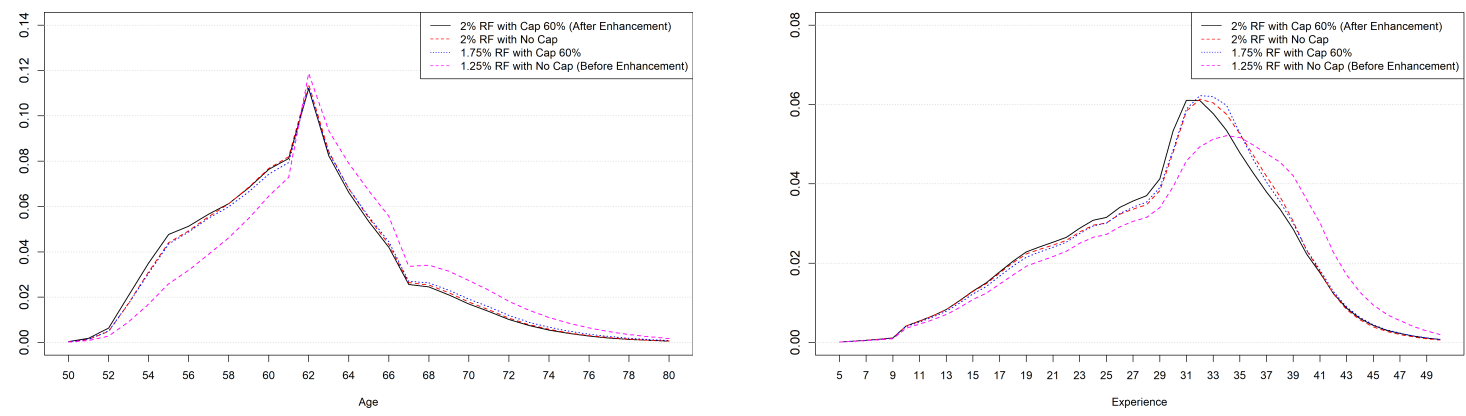

Note: The figure shows the simulated survival rates of retired teachers under four pension rules for the next 30 years. The teachers are aged 50-62 at the 2001-2002 school year(base year).

under pre-enhancement rules works 1.7 years longer compared with post-enhancement teachers. By eliminating the cap of pension benefits, the average retired age increase 0.2 years (61.7-61.5). By further decreasing replacement factor from $2 \%$ to $1.25 \%$, the average retired age increase additional 1.5 years (63.2-61.7). Thus, increasing the 
Table 1.9: Effects of Alternative Pension Rules on Teachers

\begin{tabular}{ccccc}
\hline & $\begin{array}{c}2 \% \text { RF \& } \\
\text { Cap 60\% (Baseline) }\end{array}$ & $\begin{array}{c}2 \% \text { RF \& Cap } \\
\text { No }\end{array}$ & $\begin{array}{c}1.75 \% \text { RF \& } \\
\text { Cap 60\% }\end{array}$ & $\begin{array}{c}1.25 \% \text { RF \& } \\
\text { No Cap }\end{array}$ \\
\hline Average Retired Age & 61.5 & 61.7 & 61.9 & 63.2 \\
Average Retired Experience & - & $(+0.2)$ & $(+0.4)$ & $(+1.7)$ \\
Additional Years of Teaching & 29.5 & 29.7 & 29.8 & 31.2 \\
& - & $(+0.2)$ & $(+0.3)$ & $(+1.7)$ \\
& 7387.9 & 7611.2 & 7792.9 & 9406.8 \\
& - & $(+223.3)$ & $(+405.0)$ & $(+2018.9)$ \\
\hline
\end{tabular}

Note: The first four rows show the changes in averages of retired age and experience of 02 cohort teachers under four different pensions for the next 30 years. The difference of average retired age and experience compared with baseline rule is shown in parentheses. The fifth row shows their future teaching years. The last row in the parentheses is the difference between the future teaching years under corresponding pension rules and that under baseline rules.

replacement factor and imposing the cap of annual benefits both push the cohort of teachers retire earlier.

\subsection{Conclusion}

Many states enhanced benefits in teacher retirement plans during the 1990s. This paper examined the effect of a major enhancement in 1999 for public school teachers in St. Louis, which is in a small but separate pension system. Pension rule changes in 1999 resulted in very large increases in pension wealth for active teachers, as well has a powerful increase in "push" incentives for teachers as long as they satisfy pension requirements. The larger "push" incentives at relative young age compared with workers in other industry tend to push teachers retire early after the enhancements. Descriptive statistics on retirement patterns before and after the enhancements suggest earlier retirement resulted as well. 
However, to better understand the long run effects of these changes, I estimated a structural retirement model using panel data for the St. Louis teachers. Both insample and out-of-sample simulations show that the model fits the data well. Teachers respond to the incentives embedded in different pension plans. Simulations based on the structural estimates under different pension rules suggest shorter completed teaching spells and earlier retirement age as a result of the enhancements. More specifically, imposing a cap on pension benefits and increasing the replacement factor both imply earlier retirement and shorter teaching additional years. These shorter teaching spells imply a steady state with more teaching vacancies and a larger share of novice teachers in classrooms.

Pension enhancements are counter-productive in retaining late-career teachers. On one hand, it is costly to enhance pension rules and directly lead to larger amount of underfunded pension funds. Due to rising plan costs and a growth in unfunded liabilities, retirement benefits for new St. Louis teachers (hired in 2018 or later) were cut and contribution rates for new teachers increased sharply from 5 to 9 percent of salary. On the other, the analysis above suggests that pension enhancements are not efficient since enhancements "push" senior teachers to retire early. However, previous studies suggest that pension enhancements do not attract more young teachers because of young teachers highly discount their future pensions (Koedel et al., 2014). Thus, in the environment of teacher shortages, the decision of pension enhancements that reduce teacher labors should be carefully considered. 


\section{Chapter 2}

\section{Teacher Pension Plan Incentives, Retirement Decisions, and Workforce Quality}

\subsection{Introduction}

Teacher pensions have attracted considerable media and policy attention. Pension costs have been rising, often sharply, as states seek to pay down unfunded liabilities of these plans. Nationally, employer costs for public teacher pensions have increased from 11.9 percent of salaries in 2004, to 22.6 percent. On a per student basis over the same period these pension costs have increased from $\$ 530$, or 4.8 percent of per pupil operating expenditures, to $\$ 1312$ (10.7 percent of operating expenditures) currently. These increasing costs have led school districts to make cuts in other areas of school

\footnotetext{
${ }^{1}$ Per student costs are inflation-adjusted. See http://www.uaedreform.org/downloads/2017/12/employee-contribution-rates-6-8-18.pdf and http://www.uaedreform.org/downloads/2017/12/employer-contributions-per-pupil-6-8-18.pdf.
} 
budgets (Burnette and Will, 2018; Krausen and Willis, 2018).

A number of papers have examined the structure and effects of the strong retention and retirement incentives built into these teacher plans. From early to mid-career, a typical defined benefit (DB) plan contains strong "pull" incentives which impose sharp penalties on mobility and tend to lock teachers into the current plans. Later in a career, after around 30 years on the job, strong "push" incentives encourage retirement at relatively early ages (Costrell and Podgursky, 2009). A number of studies have shown that teachers respond to the incentives built into these teacher retirement benefit plans in timing of retirement (Friedberg and Turner, 2010; Costrell and McGee, 2010; Brown, 2013; Fitzpatrick and Lovenheim, 2014; Knapp et al., 2016; Ni and Podgursky, 2016).

While the effect of teacher pensions on overall school staffing and teacher turnover has been studied, much less attention has focused on their effect on the quality of the teaching workforce. This is an important issue since recent research highlights the role that teacher quality plays not only in raising short-term student achievement, but also consequential long-term outcomes such as high school graduation, college attendance, and labor market earnings (Chetty et al., 2014). Several studies have examined the effect of general teacher attrition on the quality of the teaching workforce (e.g., Kreig (2006); Feng and Sass (2017); Goldhaber et al. (2010)), but the focus is on early career turnover. Indirect evidence is found in Fitzpatrick and Lovenheim (2014), who report that the district take-up rate of a one-time pension enhancement in Illinois, which encouraged retirement, was associated with student achievement increases at the district level, suggesting that the "pull" effect tends to retain weaker teachers. On the other hand, Koedel et al. (2013) explicitly compare the value-added of teachers 
who retire at different points in the late-career cycle and find historical changes in pension rules have no significant effect effects on the quality of the overall teaching workforce. Many states face the challenges of staffing public schools, especially high poverty schools, with high quality teachers. One reason for the difficulty in staffing is that teachers retire earlier than other comparable professionals (Harris and Adams, 2007). However, there is little research on how retirement decisions differ for teachers of different quality or performance level.

This paper contributes to the literature on retirement and teacher labor markets by examining the effect of teacher pension plan incentives on late-career teacher workforce quality using a statewide administrative educator database in Tennessee that includes performance measures. I use both reduced-form and structural estimates to analyze data on retirement and teacher quality. These data show that higher quality teachers are less likely to retire conditional on age and experience. To quantify the effects of pension plan incentives on retirement behavior and assess policy alternatives, I estimate a structural retirement model that allows for different work-retirement preferences for high and low quality teachers. I find that high quality teachers have a lower disutility for teaching as compared to retirement, which makes them less costly to retain than low quality teachers of the same age and experience. I use the estimated structural parameters that are independent of pension rules to simulate the effects of three policies aimed at retaining late-career teachers.

First, I examine how enhancements to the traditional DB plans of all teachers affect the timing of retirement of teachers of different qualities. I find the pension enhancement shortens the career and reduces the average quality of senior teachers. Specifically, I find enhancements to traditional plans increase the "push" effect and 
lead to relatively more early retirement of high versus low quality teachers, resulting in a reduction in average quality among senior teachers. I then consider two retention bonuses targeted to high quality teachers: a one-time retention bonus to all high quality teachers in high poverty schools, and a retention bonus to high quality teachers who satisfy a longevity condition. Both types of retention bonuses extend the career of high quality teachers, hence improve the average quality of the late-career teaching force. However, one-time bonuses have a small impact on teacher retirement, and thus generate each additional teaching year at high costs. By contrast, retention bonuses with a longevity target can delay retirement of high quality teachers and improve average workforce quality at relatively modest costs.

In the following sections, I describe the background of Tennessee pension rules, the teacher evaluation system, and the longitudinal data for Tennessee teachers. I then examine the empirical relationship between performance scores and teacher retirement and estimate a structural retirement model that incorporates teacher quality directly into preferences. I then use the structural estimates to simulate the effect of changes in pension plan incentives.

\subsection{Institutional Background}

\subsubsection{Tennessee Consolidated Retirement System}

Teachers in Tennessee are in a consolidated public employee retirement plan - specifically, a final average salary defined benefit (FAS-DB) pension plan - which is typical for U.S. public school teachers. Tennessee teachers are also covered by Social Se- 
curity (teachers in some states are not). Tennessee teachers become eligible for a regular pension at age 60 with at least five years of service or when their years of service equals at least 30. Benefits at retirement are determined by the formula Annual Benefit $=r f \times S \times F A S$, where $r f$ stands for replacement factor. $S$ denotes years of teaching experience in the system. $F A S$ is the average of the highest consecutive five years of salary, which are typically the five years prior to retirement. Table 2.1 summarizes some key features of the Tennessee pension rules.

\begin{tabular}{|c|c|}
\hline Normal Pension & $\begin{array}{c}\text { Age } \geq 60 \text { with Experience } \geq 5 \\
\text { or Experience } \geq 30\end{array}$ \\
\hline Early Pension (Age 55) & Age $\geq 55$ with Experience $\geq 5$ \\
\hline Early Pension (Experience 25) & Experience $\geq 25$ with $A g e \geq 47$ \\
\hline Replacement Factor & $1.50 \%$ \\
\hline
\end{tabular}

Note: There is a $5 \%$ benefit increase in the annual pension benefit for every Tennessee teacher after retirement.

One way to assess the retirement incentives arising from these pension plan rules is to compute the pension wealth at different points in a representative teacher's work life. Pension wealth is calculated as the expected present value of pension benefits at retirement year $r$, which is given by $P W(r)=\sum_{s \geq r}(1+b)^{r-s} \pi(s \mid r) P(s \mid r)$, where $\pi(s \mid r)$ is the conditional probability of survival of mortality, and $P(s \mid r)$ is the pension benefit at year $s \geq r$ if the teacher retires at year $r$, and $b>0$ is the annual discount rate. Pension wealth accrual can be calculated as $p w(r)=\frac{P W(r)-(1+\inf ) * P W(r-1)}{\operatorname{Salary}(r)}$, where $P W(r)$ is pension wealth if the teacher retires at year $r$, inf is inflation rate, $\operatorname{Salary}(r)$ is salary at year $r$. 
Figure 2.1: Total Pension Wealth, Social Security Wealth and Retirement Wealth Over a Teaching Career

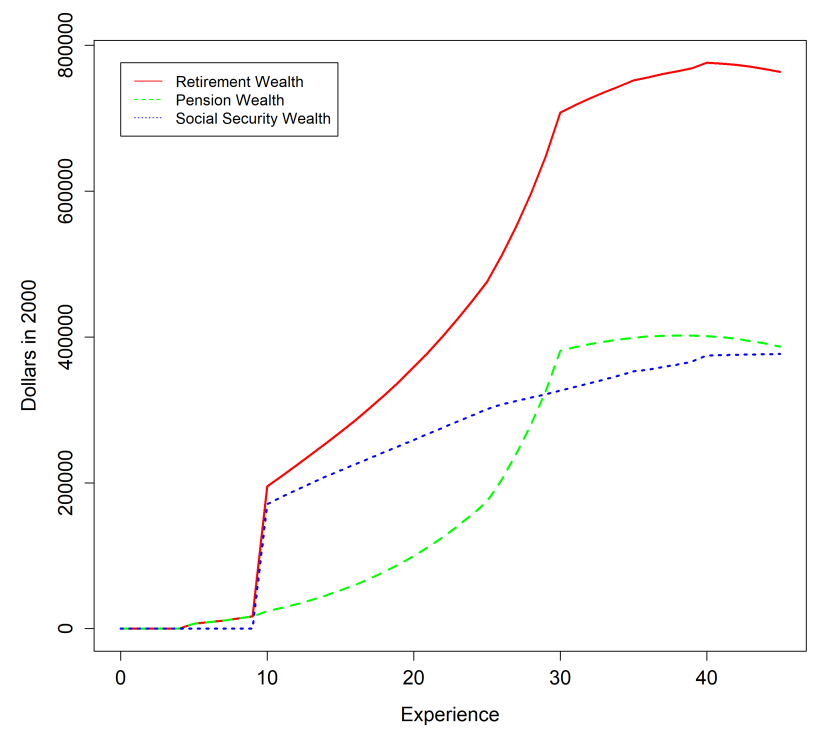

Note: This figure illustrates the life pattern of pension wealth, social security wealth and retirement wealth for a representative teacher who enters the system at age 25 .

Figure 2.2: Annual Pension Wealth Accrual

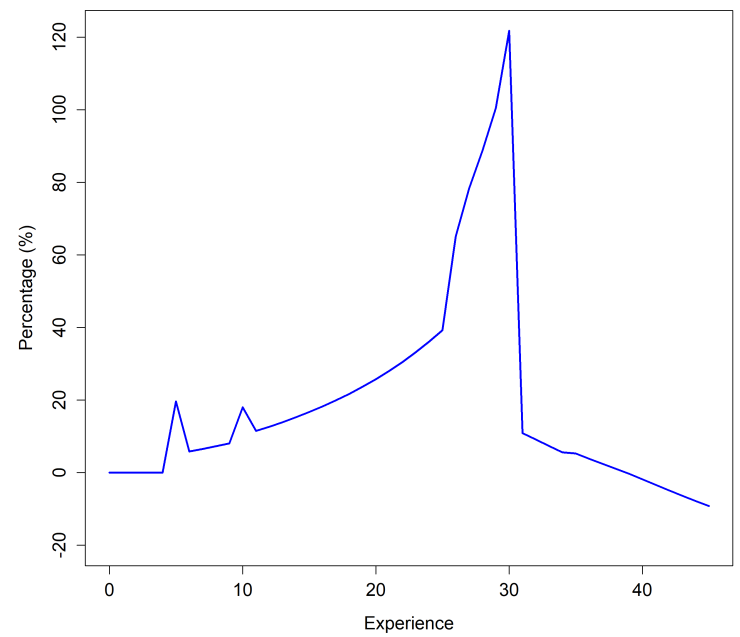

Note: This figure illustrates the life cycle pattern of pension wealth accumulation for a representative teacher who begins teaching at age 25 . 
Figure 2.1 shows life-cycle pension wealth, Social Security wealth, and total retirement wealth for a representative teacher in Tennessee who enters the system at age 25. Figure 2.2 reports annual pension wealth accrual. Figures 2.1 and 2.2 are consistent with previous literature about the incentives underlying FAS-DB plans, which show that the life-cycle pattern of pension wealth accrual is nonlinear and has several spikes (Costrell and Podgursky, 2009). These spikes encourage teachers to retire at local peaks of wealth accumulation.

\subsubsection{Tennessee Teacher Evaluation System}

As a winner in the US Department of Education "Race to the Top" grants competition, Tennessee received funding to implement a new statewide teacher evaluation system which began operation in the 2011-2012 school year. Half of a teacher's evaluation score is based on a qualitative measure (classroom observations) and the remaining half is based on student outcome measures, including student growth represented by a value-added score (35 percent) and student achievement (15 percent). The classroom observations represent process-oriented measures while the student growth and achievement scores are output-based measures Steinberg and Sartain, 2015). Thus the teachers are rated by multi-dimensional measures. Every teacher in the new evaluation system is evaluated regardless of teaching experience or tenure status. There are five effectiveness levels for evaluation scores, from Level 1 (Significantly Below Expectations), to Level 5 (Significantly Above Expectations). 


\subsection{Descriptive Statistics on Retirement}

In this section, I compare the empirical retirement behavior of female and male teachers. The data include all teachers aged 50-65 in the 2011-2012 school year with at least 5 years of service experience. This cohort is tracked forward to the 2014-2015 school year. Table 2.2 reports descriptive statistics for female and male teachers. Note that the average evaluation levels (based on the five point scale) are the levels reported in the base year (2011-2012 school year). The number of female senior teachers is about four times that of males and the average evaluation score of females is higher than for males.

Table 2.2: Descriptive Statistics

\begin{tabular}{lcccccccc}
\hline & \multicolumn{2}{c}{ \# of Teachers } & \multicolumn{2}{c}{ Age } & \multicolumn{2}{c}{ Experience } & \multicolumn{2}{c}{ Evaluation Level } \\
& Female & Male & Female & Male & Female & Male & Female & Male \\
\hline Teachers in 2011-12 & 13989 & 3139 & 56.67 & 56.79 & 24.25 & 22.82 & 4.11 & 3.75 \\
Retire 2012 & 1345 & 291 & 59.31 & 59.64 & 28.41 & 26.85 & 4.01 & 3.54 \\
Retire 2013 & 1941 & 399 & 59.89 & 59.86 & 28.47 & 25.72 & 3.98 & 3.42 \\
Retire 2014 & 1700 & 365 & 60.15 & 60.47 & 28.83 & 27.22 & 4.12 & 3.79 \\
Not Retired 2014-15 & 9003 & 2084 & 57.52 & 57.70 & 24.45 & 23.48 & 4.15 & 3.83 \\
\hline
\end{tabular}

Note: Tennessee teachers aged 50-65 and with at least 5 years of experience in the 2011-2012 school year. The evaluation levels in all rows are those reported at the base year (2011-2012 school year). The age and experience columns report the averages for teachers who retired in that year.

Figure 2.3 plots the distribution of teacher evaluation scores (1-5) for female and male teachers in our sample at the base year (2011-2012 school year). Note that there is a considerable spread in the scores - not all teachers receive the highest score. In addition, male teachers are underrepresented in the top performance category, and over-represented in the bottom two. To make our structural estimation more 
tractable, I group levels 1-3 and label them low quality teachers, and define levels 4-5 as high quality teachers.

Figure 2.3: Distribution of Teacher Quality (1-5) for Female and Male Teachers in the Base Year (2011-2012)

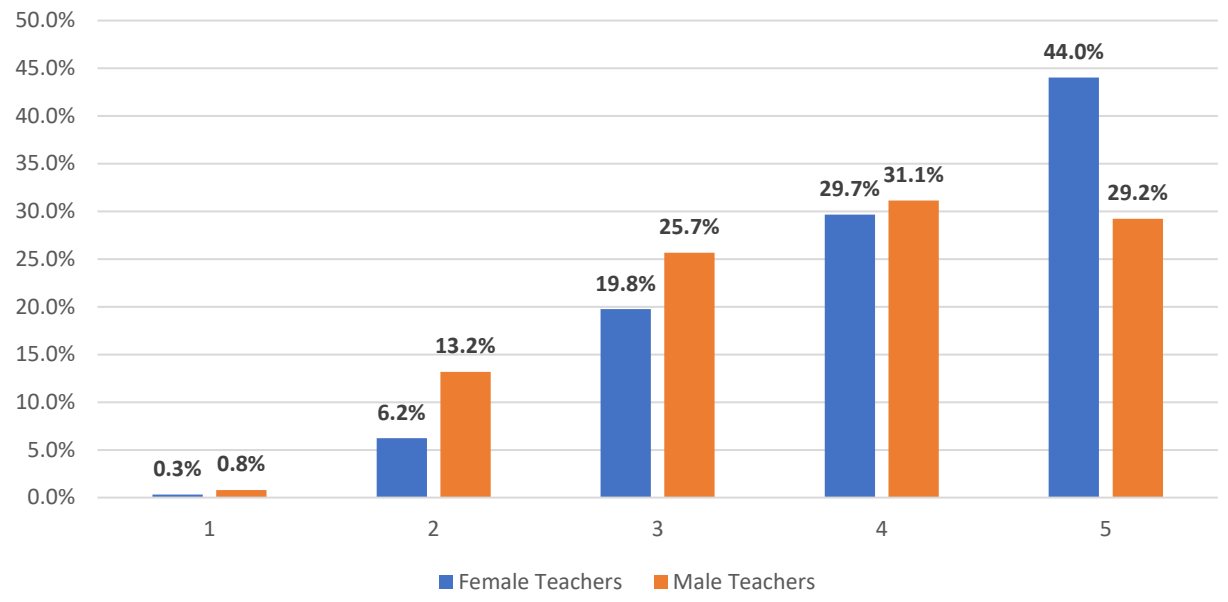

Table 2.3 reports the descriptive statistics for Tennessee teachers in high- and low-poverty schools aged 50-65 and with at least 5 years of experience in the 20112012 school year. Low-poverty schools are defined as public schools with less than the median level of students eligible for free or reduced-price lunch and high-poverty schools above the median. 2 The teacher quality in all rows are based on evaluation scores in the base year (2011-2012 school year). The age and experience columns report the averages for retired teachers in that year or for not retired teachers at the end of the sample period.

Table 2.4 reports retirement rates for male and female, high and low quality teachers over the three year sample period. For both males and females the retirement

\footnotetext{
${ }^{2}$ There are 189 female teachers and 80 male teachers in public schools where percentage of students who are eligible for free or reduced-price lunch is unknown in our dataset. These teachers are excluded in Table 2.3.
} 
Table 2.3: Descriptive Statistics For Teachers in High and Low Poverty Schools

\begin{tabular}{|c|c|c|c|c|c|c|c|c|}
\hline \multirow[t]{2}{*}{ Female Teachers } & \multicolumn{2}{|c|}{ Number of Teachers } & \multicolumn{2}{|c|}{ Age } & \multicolumn{2}{|c|}{ Experience } & \multicolumn{2}{|c|}{ High Quality Share } \\
\hline & High & Low & High & Low & High & Low & High & Low \\
\hline Teachers at $2011-12$ & 6024 & 7776 & 56.72 & 56.62 & 24.37 & 24.18 & 0.68 & 0.78 \\
\hline Retire 2012 & 624 & 708 & 59.17 & 59.43 & 28.57 & 28.29 & 0.66 & 0.79 \\
\hline Retire 2013 & 998 & 901 & 59.95 & 59.85 & 28.03 & 28.99 & 0.63 & 0.77 \\
\hline Retire 2014 & 674 & 1012 & 59.69 & 60.44 & 28.84 & 28.80 & 0.69 & 0.77 \\
\hline Non-Retired by $2014-15$ & 3728 & 5155 & 57.54 & 57.48 & 24.51 & 24.44 & 0.69 & 0.79 \\
\hline \multirow[t]{2}{*}{ Male Teachers } & \multicolumn{2}{|c|}{ Number of Teachers } & \multicolumn{2}{|c|}{ Age } & \multicolumn{2}{|c|}{ Experience } & \multicolumn{2}{|c|}{ High Quality Share } \\
\hline & High & Low & High & Low & High & Low & High & Low \\
\hline Teachers at 2011-12 & 1015 & 2044 & 56.50 & 56.89 & 21.71 & 23.51 & 0.50 & 0.66 \\
\hline Retire 2012 & 94 & 187 & 58.98 & 59.96 & 26.98 & 27.13 & 0.45 & 0.63 \\
\hline Retire 2013 & 174 & 206 & 59.34 & 60.38 & 23.91 & 27.86 & 0.34 & 0.59 \\
\hline Retire 2014 & 107 & 249 & 59.50 & 60.83 & 25.71 & 27.67 & 0.49 & 0.71 \\
\hline Non-Retired by $2014-15$ & 640 & 1402 & 57.47 & 57.77 & 22.27 & 24.14 & 0.55 & 0.66 \\
\hline
\end{tabular}

Note: Tennessee teachers in high poverty and low poverty schools aged 50-65 and with at least 5 years of experience in the 2011-2012 school year. Low-poverty schools are defined as public schools with less than or the median share of free or reduced-price lunch eligible students while high-poverty schools are those with rates above the median. The teacher quality in all rows are based on evaluation scores in the base year (2011-2012 school year). The age and experience columns report the averages for retired teachers in that year or for not retired teachers at the end of the sample period.

rate for low quality teachers is higher than for high quality teachers, with a larger gap for males. It is worth noting that this finding is consistent with recent studies of teacher quality and early career turnover - less effective teachers are more likely to exit the profession (Kreig, 2006; Feng and Sass, 2017; Goldhaber et al., 2010). This pattern seems to hold at the end as well as the beginning of teaching careers. 3

\footnotetext{
${ }^{3}$ Note also that low and high quality male and female teachers in our retirement window sample have nearly identical age but low quality teachers have less experience. This is consistent with a higher exit rate for low quality teachers. It also highlights the importance of correcting for censoring
} 
Table 2.4: Retirement Behavior for High and Low Quality Teachers

\begin{tabular}{lcccc}
\hline & \multicolumn{2}{c}{ Female } & \multicolumn{2}{c}{ Male } \\
& Low Quality & High Quality & Low Quality & High Quality \\
\hline Number of Teachers in 2011-12 & 3682 & 10307 & 1245 & 1894 \\
Average Age 2011-12 & 56.67 & 56.67 & 56.85 & 56.74 \\
Average Experience 2011-12 & 23.64 & 24.47 & 22.40 & 23.10 \\
Number of Retired Teachers & 1387 & 3599 & 467 & 588 \\
Retirement Rate & 0.377 & 0.349 & 0.375 & 0.310 \\
Average Age at Retirement & 59.69 & 59.87 & 59.83 & 60.15 \\
Average Experience at Retirement & 27.83 & 28.86 & 25.48 & 27.41 \\
\hline
\end{tabular}

Note: Retirement rate is defined as Row 4 divided by Row 1 .

Figures 2.4 and 2.5 plot the age and experience distributions for the 36 percent of teachers who retired during the three year sample period. Among teachers who retired, low quality teachers tended to retire with less experience and at a younger age, with the pattern more pronounced for male teachers. However, it should be kept in mind that 64 percent of our observations are right-censored (i.e., still teaching at the end of the panel), so we do not observe a value of retirement age and completed experience for these teachers.

in our baseline sample when estimating a dynamic retirement model, a topic I will take up below. 
Figure 2.4: Distribution of Female Retired Teachers by Age, Experience, and Quality
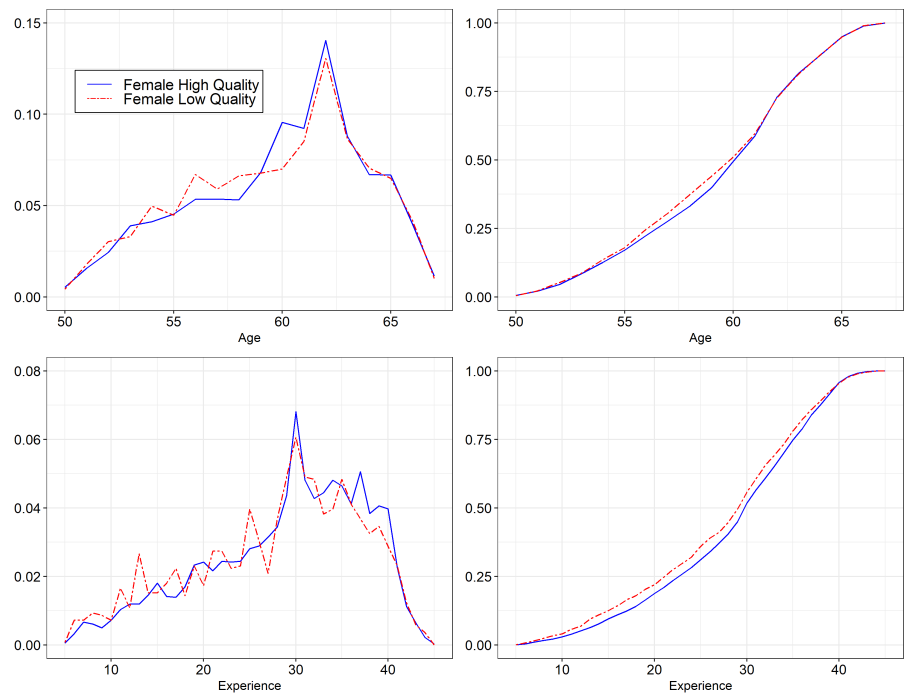

Note: The graphs plot the age and experience distributions of female retired teachers. The two graphs on the left are probability density functions while the two graphs on the right are cumulative density functions.

Figure 2.5: Distribution of Male Retired Teachers by Age, Experience, and Quality
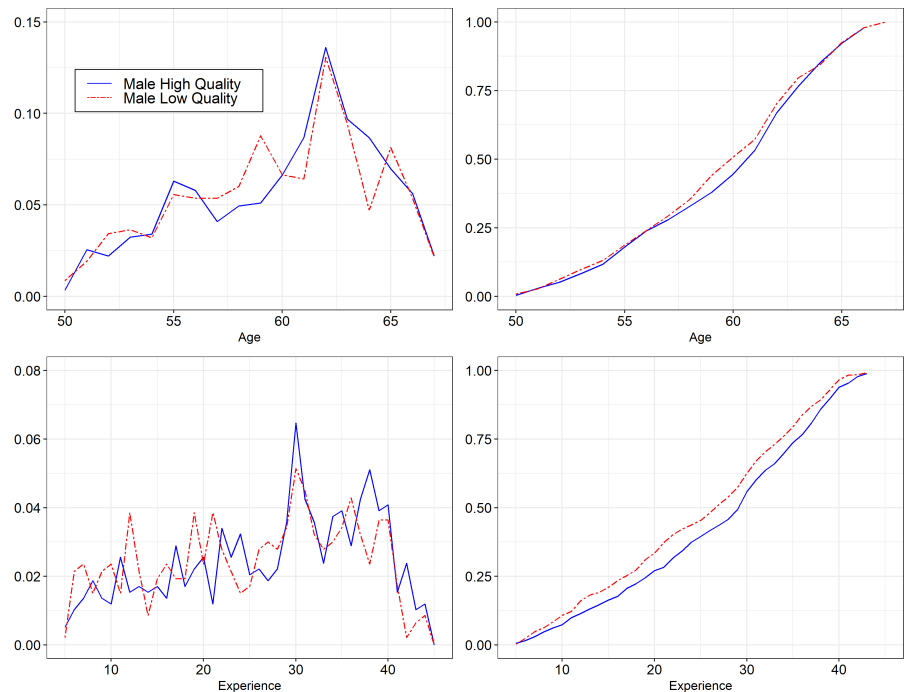

Note: The graphs plot the age and experience distributions of male retired teachers. The two graphs on the left are probability density functions while the two graphs on the right are cumulative density functions. 


\subsection{Teacher Quality and Retirement: Reduced-Form Estimates}

To quantify the relationship between teacher quality and retirement behavior, I begin by estimating a linear probability regression. The data I use are teachers aged 50-65 in the baseline 2011-2012 school year, the same cohort of teachers as above. The model is as follows:

$$
\text { Retire }_{i}=\alpha+\beta \text { Quality }_{i}+\theta X_{i}+\epsilon_{i},
$$

where Retire $_{i}$ is an indicator variable equal to 1 if the teacher $i$ chooses to retire in the next three years. Quality is teacher i's binary quality measure in the baseline 2011-2012 school year; $\epsilon_{i}$ is the error term; $X_{i}$ is a vector of control variables. In regressions (1) and (2), $X_{i}$ includes baseline age and experience. In regressions (3) and (4), $X_{i}$ includes an additional dummy variable indicating whether teacher $i$ is in a high poverty school.

Table 2.5 reports estimated coefficients for linear probability models for female and male teachers respectively. All regressions include district fixed effects. The coefficients on the binary teacher quality measure for all regressions are negative and statistically significant indicating that higher quality teachers are less likely to retire than low quality teachers who have the same age and experience. Table 2.4 shows that the difference between retirement rates in the sample period for high quality and low quality teachers is -0.028 and -0.056 for females and males, respectively. These numbers are similar to the estimates of the high quality dummy in Table 2.5. 
Table 2.5: Regression Results for Linear Probability Models

\begin{tabular}{ccccc}
\hline & & Dependent Variable: & Retire & \\
& $(1)$ & $(2)$ & $(3)$ & $(4)$ \\
& Female Teachers & Male Teachers & Female Teachers & Male Teachers \\
\hline High Quality & $-0.028^{* * *}$ & $-0.059^{* * *}$ & $-0.028^{* * *}$ & $-0.056^{* * *}$ \\
& $(0.009)$ & $(0.018)$ & $(0.009)$ & $(0.018)$ \\
Experience & $0.008^{* * *}$ & $0.005^{* * *}$ & $0.008^{* * *}$ & $0.005^{* * *}$ \\
& $(0.0004)$ & $(0.001)$ & $(0.0004)$ & $(0.001)$ \\
Age & $0.035^{* * *}$ & $0.036^{* * *}$ & $0.036^{* * *}$ & $0.037^{* * *}$ \\
& $(0.001)$ & $(0.002)$ & $(0.001)$ & $(0.002)$ \\
High Poverty & & & $0.036^{* * *}$ & -0.002 \\
& & & $(0.009)$ & $(0.023)$ \\
Constant & $-1.825^{* * *}$ & $-1.986^{* * *}$ & $-1.847^{* * *}$ & $-2.017^{* * *}$ \\
& $(0.069)$ & $(0.148)$ & $(0.07)$ & $(0.151)$ \\
Observations & 13,989 & & & 3,059 \\
Adjusted $R^{2}$ & 0.176 & 3,139 & 13,800 & 0.167 \\
\hline
\end{tabular}

Note: ${ }^{*} \mathrm{p}<0.1 ;{ }^{* *} \mathrm{p}<0.05 ;{ }^{* * *} \mathrm{p}<0.01$. All regressions includes district fixed effect. Dummy variable High Quality $=1$ if the teacher is one of high quality and Dummy variable High Poverty $=1$ if the teacher is in a high poverty school.

There are 189 female teachers and 80 male teachers in public schools where the percentage of students who are eligible for free or reduced-price lunch is unknown in our dataset. Thus, the numbers of observations in regressions (3) and (4) are 189 and 80 fewer than those in regressions (1) and (2). 


\subsection{Does Impending Retirement Induce Shirking?}

Before undertaking further analysis of teacher retirement by quality, it is worth considering whether the association between baseline teacher quality and retirement may be spurious in that teachers who plan to retire may shirk or exert less effort (and hence get lower evaluation scores) immediately prior to retirement. Unfortunately, our panel only extends for three years, reflecting the introduction of the statewide performance measures in the 2011-2012 school year. In Figure 2.6 I report statistics on the year-to-year changes in the binary quality measure for teachers who retired by 2014. The first thing to note is that for the vast majority of teachers, the binary performance measure does not change from one year to the next. Because the high quality teachers greatly outnumber low quality teachers, there are far more high quality teachers reclassified as low quality teachers than the other way around. Roughly 17-19 percent fell from high to low, and about 9-12 percent rose from low to high. For our purposes, however, it is important to note that there is very little difference in these percentages for teachers who retired in the next year and those who did not. In fact, for both males and female teachers, the probability of decline is slightly lower in the year prior to retirement, as compared to two years prior, which is inconsistent with the shirking hypothesis. In addition, I compare the evaluations of "stayers" at 2015 to their evaluation at 2012, and find the frequency of decreases in quality is about twice of the frequency of increases in quality, and very similar to the patterns of changes in quality among those who retired during the sample period.

In sum, the pattern of changes in quality does not support the hypothesis of widespread shirking prior to retirement. Rather, these data suggest that our high/low 
quality classification is relatively stable and independent of retirement. 1

Figure 2.6: Year-to-Year Change in Quality Measure for Teachers Who Retired by 2014

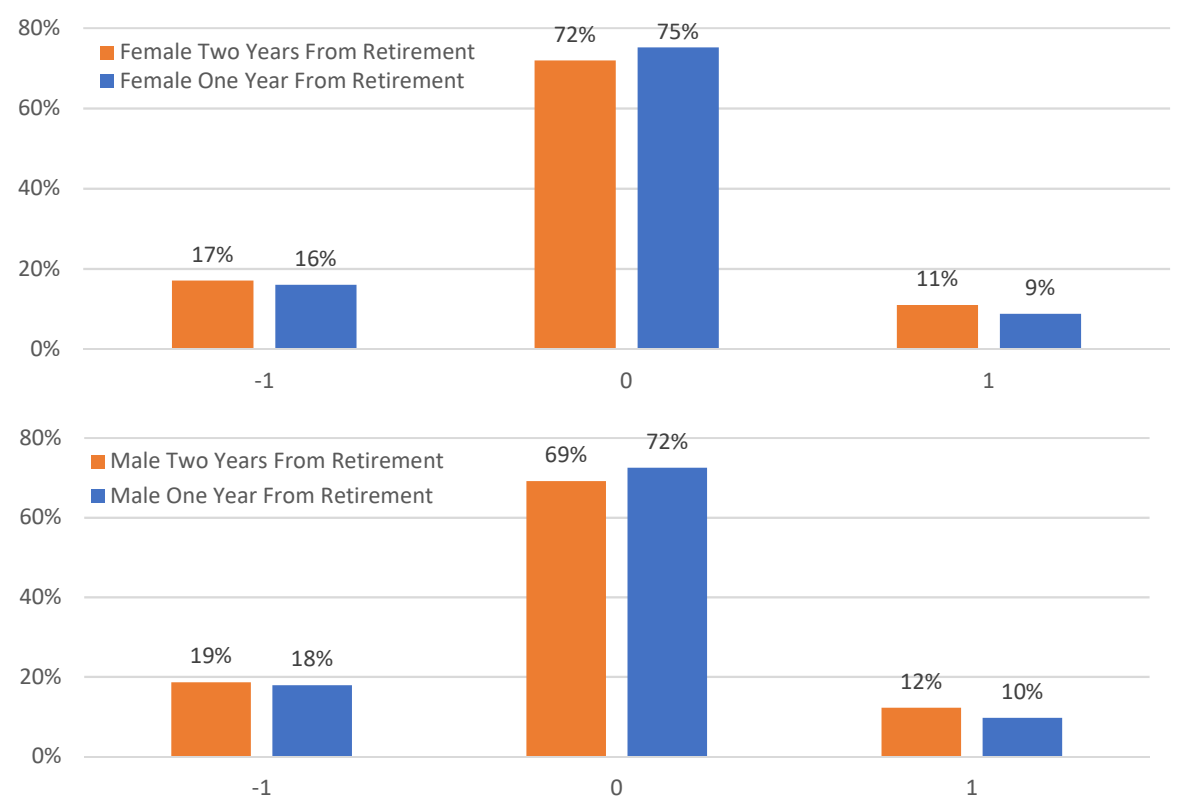

Note: The histograms show the change in quality measure for the same teacher in the two years prior to retirement. If the teacher retired in year $t$, the left bar indicates the change in score from t-2 to t-1, while the right bar reports the change from t-3 to t-2. The vast majority of teachers have no change in classification. -1 illustrates a fall in classification and +1 indicates a rise.

\subsection{Estimating a Dynamic Structural Retirement Model}

Stock and Wise (1990) developed a structural model of retirement which was extended by $\mathrm{Ni}$ and Podgursky (2016) to an analysis of public school teachers. This study further modifies and extends the Stock-Wise model to include Social Security along

\footnotetext{
${ }^{4}$ A recent study of the Tennessee teacher evaluation system by Koedel et al. (2017) finds that when otherwise similar teachers are given a lower evaluation (i.e., at a regression discontinuity) job satisfaction drops. Their measure of job satisfaction includes questions about plans to quit teaching and satisfaction with her career choice. Hence, a poor evaluation score induces job exit.
} 
with the teacher pension and incorporates teacher quality parametrically into the model, so as to permit high and low quality teachers to have different work-retirement preferences.

Consider a teacher who has not retired at the beginning of year t. The present value of expected lifetime utility for the teacher if she retires in year $\mathrm{r}$ is:

$E_{t} V_{t}(r)=\max _{c_{1}, c_{2}} E_{t}\left\{\sum_{s=t}^{r-1} \beta^{s-t} \pi(s \mid t) U_{w}\left(Y_{s}, B_{s}\left(c_{1}\right)\right)+\sum_{s=r}^{T} \beta^{s-t} \pi(s \mid t) U_{r}\left(P_{s}\left(c_{2}\right), B_{s}\left(c_{1}\right)\right)\right\}$

where

$$
\begin{aligned}
& U_{w}\left(Y_{s}, B_{s}\left(c_{1}\right)\right)=\left(k_{s}\left((1-c) Y_{s}+I_{s}^{1} B_{s}\left(c_{1}\right)\right)\right)^{\gamma}+\omega_{s}, \\
& U_{r}\left(P_{s}\left(c_{2}\right), B_{s}\left(c_{1}\right)\right)=\left(I_{s}^{2} P_{s}\left(c_{2}\right)+I_{s}^{1} B_{s}\left(c_{1}\right)\right)^{\gamma}+\xi_{s} . \\
& I_{s}^{1}=\left\{\begin{array}{cc}
1 & \text { if } s \geq c_{1} \\
0 & \text { otherwise }
\end{array}\right. \\
& I_{s}^{2}=\left\{\begin{array}{cc}
1 & \text { if } s \geq c_{2} \\
0 & \text { otherwise }
\end{array}\right.
\end{aligned}
$$

The value function depends on future annual earnings $Y_{s}$ before retirement, pension benefits $P_{s}\left(c_{2}\right)$ if the teacher starts collecting a pension benefit at year $c_{2}$, Social Security benefits $B_{s}\left(c_{1}\right)$ if she starts collecting Social Security at year $c_{1}$. The collection years are optimally chosen to maximize the expected utility given the retirement year $\mathrm{r}$. The parameter $\mathrm{c}$ is the contribution rate for teachers before retirement; and $k_{s}$ represents the disutility of working, which depends on age; a smaller $k_{s}$ means 
lower utility in teaching. I assume that $k_{s}=k\left(\frac{60}{a g e}\right)^{k_{1}}$ for high quality teachers, and $k_{s}=k_{2} * k\left(\frac{60}{a g e}\right)^{k_{1}}$ for low quality teachers, where $k_{2}$ differentiates utility for the two groups. If $k_{2}$ is close to 1 , it means the low quality teachers value teaching similarly to high quality teachers. However, if $k_{2}$ is much less than 1, the same salary produces much less utility for low quality teachers.

In every year, a nonretired teacher has two choices: continue teaching or retire. The expected gain from postponing retirement can be seen as the "option value" of continuing working, which is the key feature of this model. Retirement occurs if the value of continuing teaching is less than the value of retiring, i.e., the option value of continued teaching is negative.

The teacher's future salary, pension benefits, and Social Security benefits are assumed to be predictable. In the empirical analysis I replace the expected salary and benefits with forecasts based on historical data. For prediction of the logarithm of salary I fit a cubic function of experience. With predictable salaries and pension benefits, there are still two types of uncertainty. One is uncertainty of survival. The conditional survival rate $\pi(s \mid t)$ is based on U.S. mortality data. Another is uncertainty in preference shocks. The preference error $\nu_{t}=\omega_{t}-\xi_{t}$. I assume $\nu_{t}$ follows an $\operatorname{AR}(1)$ process: $\nu_{t}=\rho \nu_{t-1}+\epsilon_{t}$, where $\epsilon_{t}$ is assumed to be iid $N\left(0, \sigma^{2}\right)$. Parameters $\sigma$ and $\rho$ pertain to unobserved preference errors. They capture the magnitude and persistence of unobserved heterogeneity, respectively. The seven unknown parameters to be estimated are listed in Table 2.6.

The expected gain from retiring in year $\mathrm{r}$ (later than $\mathrm{t}$ ) conditional on information 
Table 2.6: Structural Model Parameters

Parameters

\begin{tabular}{cc}
\hline$\beta \in(0,1)$ & discount factor \\
$k \in(0,1) \& k_{1}>0$ & $k_{s}^{\text {high }}=k\left(\frac{60}{\text { age }}\right)^{k_{1}}:$ disutility of working for high quality teachers \\
$k_{2}>0$ & $k_{s}^{l o w}=k_{2} * k\left(\frac{60}{\text { age }}\right)^{k_{1}}:$ disutility of working for low quality teachers \\
$\gamma \in(0,1]$ & curvature in the utility function $(\gamma<1$ indicates concavity) \\
$\sigma>0$ & standard deviation of preference shocks \\
$\rho \in(-1,1)$ & persistence in preference shocks
\end{tabular}

available in year $\mathrm{t}$ is:

$$
G_{t}(r)=E_{t} V_{t}(r)-E_{t} V_{t}(t)=g_{t}(r)+K_{t}(r) \nu_{t}
$$

where the first term $g_{t}(r)=\sum_{s=t}^{r-1} \beta^{s-t} \pi(s \mid t)\left(k_{s}\left((1-c) Y_{s}+I_{s}^{1} B_{s}\left(c_{1}\right)\right)\right)^{\gamma}+$

$$
\sum_{s=r}^{T} \beta^{s-t} \pi(s \mid t)\left(I_{s}^{2} P_{s}\left(c_{2}\right)+I_{s}^{1} B_{s}\left(c_{1}\right)\right)^{\gamma}-\left[\sum_{s=t}^{T} \beta^{s-t} \pi(s \mid t)\left(I_{s}^{2} P_{s}\left(c_{2}\right)+I_{s}^{1} B_{s}\left(c_{1}\right)\right)^{\gamma}\right],
$$

the second term, $K_{t}(r)=\sum_{s=t}^{r-1}(\beta \rho)^{s-t} \pi(s \mid t)$, depends on parameters I need to estimate.

Suppose $r^{\dagger}$ solves $\max _{r \in\{t+1, t+2, \ldots \ldots . . T\}} E_{t} V_{t}(r)$. Thus, the teacher will continue working at $\mathrm{t}$ if $G_{t}\left(r^{\dagger}\right)=E_{t} V_{t}\left(r^{\dagger}\right)-E_{t} V_{t}(t)>0$. The probability of retirement for an employee at time $\mathrm{t}$ is $\operatorname{Pr}\left[G_{t}(r) \leq 0, \forall r \geq t+1\right]=\operatorname{Pr}\left[G_{t}\left(r^{\dagger}\right) \leq 0\right]$, which can be represented as:

$$
\operatorname{Pr}\left[g_{t}\left(r_{t}^{\dagger}\right) / K_{t}\left(r_{t}^{\dagger}\right) \leqslant-\nu_{t}\right]
$$

If $k_{2}<1$, the above condition implies that a low quality teacher is more likely to retire in current year than a high quality teacher with the same age and experience 
and the same distribution of preference errors. This is because with $k_{2}<1, g_{t}\left(r^{\dagger}\right)$ for the low quality teacher is smaller than that for the high quality teacher for any $\mathrm{r}$, while the denominator $K_{t}\left(r^{\dagger}\right)$ only depends on the preference parameters other than $k_{2}$.

\subsubsection{Methodological Issues in Estimation}

Since the timing of retirement is the key variable of interest, I would like to focus on a teacher population who are eligible to retire at some point during the sample period. I track Tennessee teachers from the 2011-2012 school year for three years until the 2014-2015 school year. Given the short panel, I chose a sample of teachers aged 50-65 and with at least 5 years of experience in the base year (2011-2012 school year). Almost all of these teachers are eligible for early or regular retirement. However, teachers who would have been in the sample but chose to retire before the baseline year are excluded, while those who chose to continue teaching remain in the sample. Thus, for the same age and experience, the "stayers" have preference errors that favor teaching over retirement. This produces sample selection bias and results in

overprediction of retirement for relatively young teachers (Ni and Podgursky, 2016).

This selection bias also depends on teacher quality. Given age and experience, low quality teachers are more likely to retire, therefore low quality "stayers" in the initial sample year must have preference shocks that more strongly favoring staying. Hence, the selection bias is larger for low quality teachers. The average experience in the initial sample differs by teacher quality. Table 2.4 shows that in the initial sample high and low quality teachers have roughly the same average age but low quality teachers have 0.8 (female) and 0.7 (male) fewer years of experience. 
If teacher quality did not affect retirement probability, the probability of retirement during the sample period would be higher for a sample with more years of experience, hence the low quality teachers should be less likely to retire during the sample period. I observe the opposite. In Table 2.4 retirement rates for low quality teachers are 0.028 and 0.065 higher for females and males respectively, than their high quality counterparts. The regression in Table 2.5 shows that the probability of retirement during the sample period for low quality teachers is higher after controlling for the initial age and experience.

The experience gap between low and high quality teachers in the initial sample is expected from the sample selection prior to 2011, because low quality teachers are less likely to survive until 2011 than their high quality counterparts with the same age and experience. To estimate the parameters I need to take into account the difference in survival bias by quality conditional on the teachers having survived until 2011.

Details concerning the construction and estimation of the sample likelihood function are given in the Appendix B. The appendix also includes the correction of sample selection bias in the sample.

In this chapter, I use the following features common in pension rules and retirement data to further reduce computation cost of the sample likelihood. In a DB system, a teacher's retirement incentive depends on age and experience. In the structural model, the deterministic factors in retirement decision are age, experience, gender, and teacher quality. Senior teachers teach continuously until retirement, hence tracking the retirement counts of a group of teachers given the age and experience in the initial sample period is equivalent to tracking the retirement data of all teachers in that group. Since there are a limited number of age/experience combinations in 
the initial sample (e.g., age 50-65, experience 5-45), the group-based counts exhibit a limited number of patterns, which does not depend on the number of teachers in the sample. When the number of teachers is large enough (our data include all teachers in Tennessee) tracking the counts by group makes evaluation of the likelihood for the sample much less costly. The conditional probabilities that track each age-experience cell over the sample period are used to construct the likelihood of the sample. I estimate the model parameters by maximizing the sample likelihood.

\subsubsection{MLE Estimates}

MLE estimates of the seven parameters in the structural model are reported in Table 2.7. All estimates are statistically significant. These estimates are quite similar to those in Ni and Podgursky (2016), in spite of the fact that these teachers are different states, covered by different state pension rules, and have quite different patterns of retirement. This suggests Tennessee and Missouri teachers have similar preferences and the differences in retirement behavior between the two states are largely due to the differences in pension rules.

The parameter $\beta$ implies an annual discount rate of $\frac{1}{\beta}-1$. The estimated parameter $\gamma$ for both female and male teachers is less than 1 , which means the utility function is concave. The concavity of the utility function implies that teachers are risk-averse and prefer income-smoothing. The estimates of $\sigma$ indicate that unobserved heterogeneity is quite large relative to the flow of utility generated by salary, 0 and

\footnotetext{
${ }^{5}$ Using grouped data also makes it possible to estimate this type of model in other states where researchers do not have access to individual-level data. Data aggregated to age-experience groups are more readily available to researchers. For further discussion of grouped data estimation methods see Kong et al. (2018).

${ }^{6}$ I allow an increase in the variance of preference shocks when teachers are between 62 and the
} 
Table 2.7: Estimates of Structural Parameters

\begin{tabular}{ccc}
\hline & Female & Male \\
\hline$\beta$ & 0.959 & 0.955 \\
& $(0.007)$ & $(0.020)$ \\
& 0.673 & 0.707 \\
$k_{1}$ & $(0.004)$ & $(0.011)$ \\
& 1.021 & 0.835 \\
$k_{2}$ & $(0.006)$ & $(0.019)$ \\
& 0.876 & 0.829 \\
$\gamma$ & $(0.007)$ & $(0.021)$ \\
& 0.731 & 0.784 \\
$\sigma$ & $(0.007)$ & $(0.018)$ \\
& 5708.019 & 7774.064 \\
$\rho$ & $(58.183)$ & $(154.624)$ \\
& 0.619 & 0.693 \\
Log-Likelihood & -13798.534 & -3050.272 \\
Number of Teachers & 13,989 & 3,139 \\
\hline
\end{tabular}

Note: The standard errors in parentheses.

the estimates of $\rho$ indicate that unobserved preference errors are positively correlated over time and persistent.

Of particular interest for this study are the parameters $k$ and $k_{1}$, which together measure the utility of working for high quality teachers, while for low quality teachers, the utility of working is $k_{2} * k\left(\frac{60}{a g e}\right)^{k_{1}}$. Estimates in Table 2.7 show that $k_{2}$ is significantly less than unity, meaning that low quality teachers have lower utility from teaching relative to retirement. Table 2.8, which is based on the estimates of $k, k_{1}$

age for their Social Security full retirement, under the assumption that teachers' willingness to stay is more uncertain in this age range because of the unobserved family influence and peer effects, for instance. 
and $k_{2}$, illustrates the size of this difference. In this table I report the utility equivalent pension benefit to one dollar of teaching earnings. Note first that the utility equivalent pension declines with age for all groups, indicating a growing preference for leisure (retirement) with age. For example, at age 50 a female high quality teacher would require at least $\$ 0.811$ of pension income to replace one dollar of teaching salary. By age 65 this drops to $\$ 0.620$.

More important, for our purposes, is the difference in utility of teaching between high and low quality teachers. For example, a 60 year old female high quality teacher is indifferent between earning a salary of $\$ 50,000$ and a pension benefit of $\$ 33,650$ $(\$ 50,000 * 0.673=\$ 33,650)$. A similar calculation for a low quality teacher is $\$ 29,500$. In other words, focusing only on the current period and without considering the preference errors, a $\$ 30,000$ pension would induce a low quality teacher to retire but not a high quality teacher. The gap in preference between high and low quality male teachers is even larger. This implies that it is relatively cheaper to keep a high quality teacher on the job. In fact, high quality teachers exhibit greater job satisfaction (Koedel et al., 2017), which presumably means it is cheaper to keep them on the job. Indeed, our finding is consistent with a large occupational psychology literature which

finds a positive relationship between job satisfaction and job performance (Judge et al., 2001).

\subsubsection{Goodness of Fit}

Figures 2.7 2.11 provide information regarding the overall goodness of fit of the model. Figures 2.7 and 2.8 compare the observed and predicted age distributions of retired and non-retired female and male teachers by quality. Figures 2.9 and 2.10 compare 
Table 2.8: Disutility of Working versus Retirement for High and Low Quality Teachers

\begin{tabular}{ccccc} 
Age & Female High & Female Low & Male High & Male Low \\
\hline 50 & 0.811 & 0.710 & 0.823 & 0.682 \\
51 & 0.794 & 0.696 & 0.810 & 0.671 \\
52 & 0.779 & 0.682 & 0.797 & 0.660 \\
53 & 0.764 & 0.669 & 0.784 & 0.650 \\
54 & 0.749 & 0.657 & 0.772 & 0.640 \\
55 & 0.736 & 0.644 & 0.760 & 0.630 \\
56 & 0.722 & 0.633 & 0.749 & 0.621 \\
57 & 0.709 & 0.621 & 0.738 & 0.612 \\
58 & 0.697 & 0.610 & 0.727 & 0.603 \\
59 & 0.685 & 0.600 & 0.717 & 0.594 \\
60 & 0.673 & 0.590 & 0.707 & 0.586 \\
61 & 0.662 & 0.580 & 0.697 & 0.578 \\
62 & 0.651 & 0.570 & 0.688 & 0.570 \\
63 & 0.640 & 0.561 & 0.679 & 0.563 \\
64 & 0.630 & 0.552 & 0.670 & 0.555 \\
65 & 0.620 & 0.543 & 0.661 & 0.548 \\
66 & 0.611 & 0.535 & 0.653 & 0.541 \\
67 & 0.601 & 0.527 & 0.645 & 0.535 \\
68 & 0.592 & 0.519 & 0.637 & 0.528 \\
69 & 0.584 & 0.511 & 0.629 & 0.522 \\
70 & 0.575 & 0.504 & 0.622 & 0.515 \\
\hline
\end{tabular}

Note: The table shows the retirement benefit utility equivalent of one dollar of earnings for teachers aged 50 to 70 based on the estimates of $k, k_{1}$ and $k_{2}$ in Table 3.3. For example, at age 60, one dollar of teaching earnings is worth $\$ 0.673$ in retirement benefits for a high quality female teacher.

the observed and predicted experience distributions of retired and non-retired female and male teachers by quality. Visual inspection suggests that in-sample prediction is good for the disaggregated age and experience distributions. Figure 2.11 also shows that the predicted employment survival rate for each subgroup closely tracks the observed rate. 
Figure 2.7: Observed and Predicted Age Distributions for Female Teachers by Quality
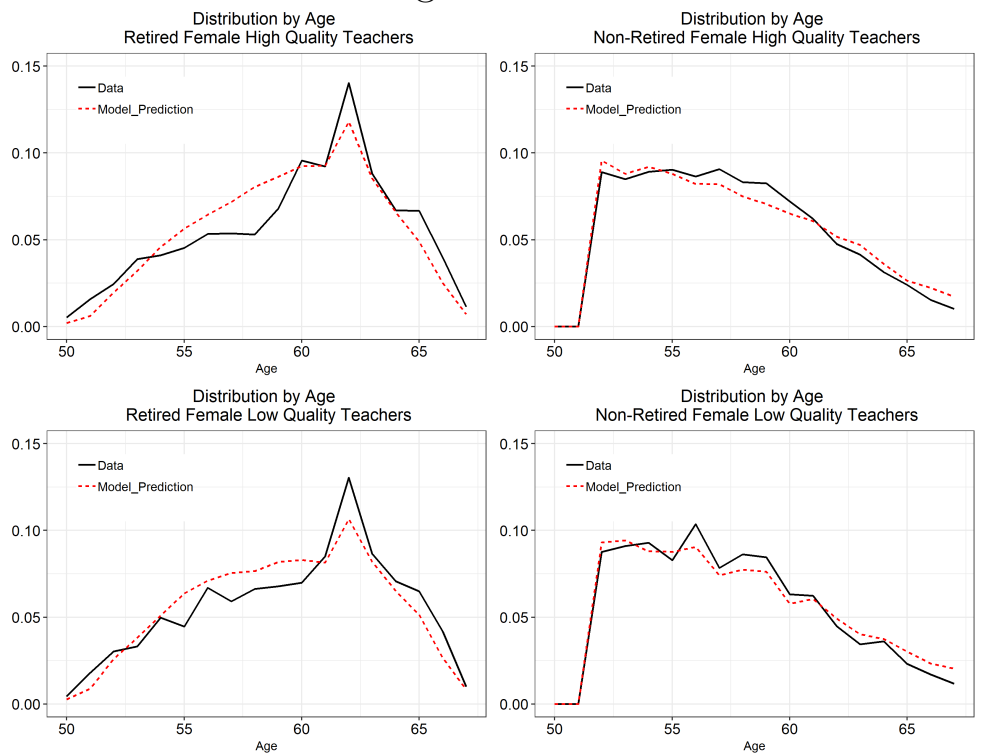

Note: The figure compares observed and predicted age distribution of female teachers with high and low performance. The model prediction is the in-sample prediction based on the estimates in Table 2.7. The left panels are distributions of retired teachers while the right panels are distributions of non-retired teachers.

Figure 2.8: Observed and Predicted Age Distributions for Male Teachers by Quality
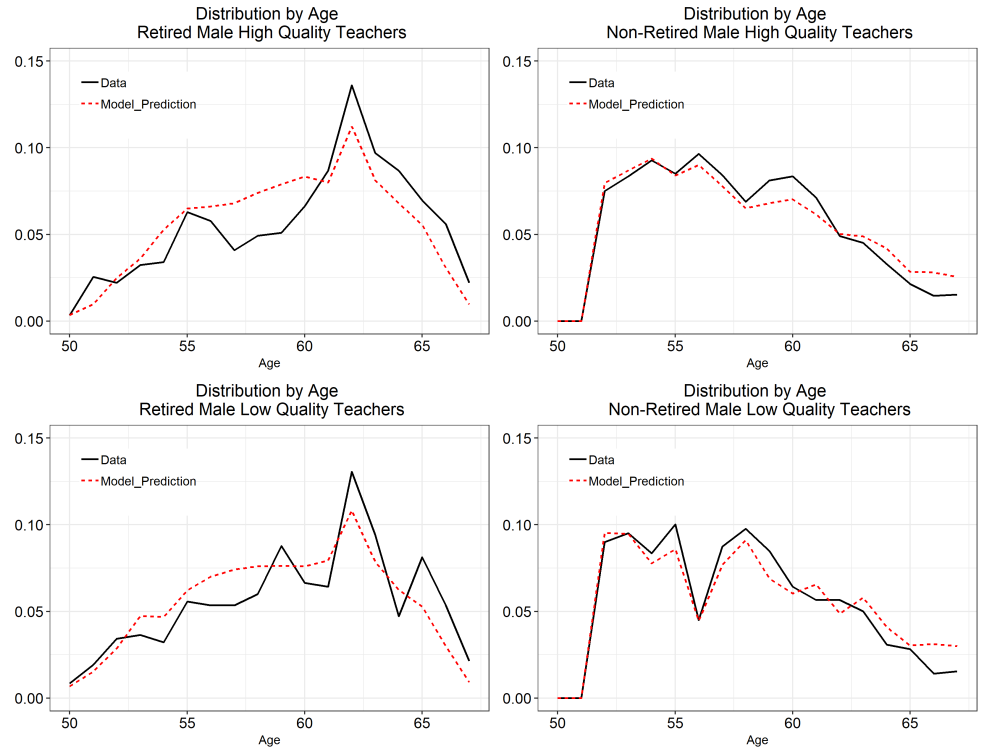

Note: The figure compares observed and predicted age distribution of male teachers with high and low performance. The model prediction is the in-sample prediction based on the estimates in Table 2.7. The left panels are distributions of retired teachers while the right panels are distributions of non-retired teachers. 
Figure 2.9: Observed and Predicted Exp. Distributions for Female Teachers by Quality
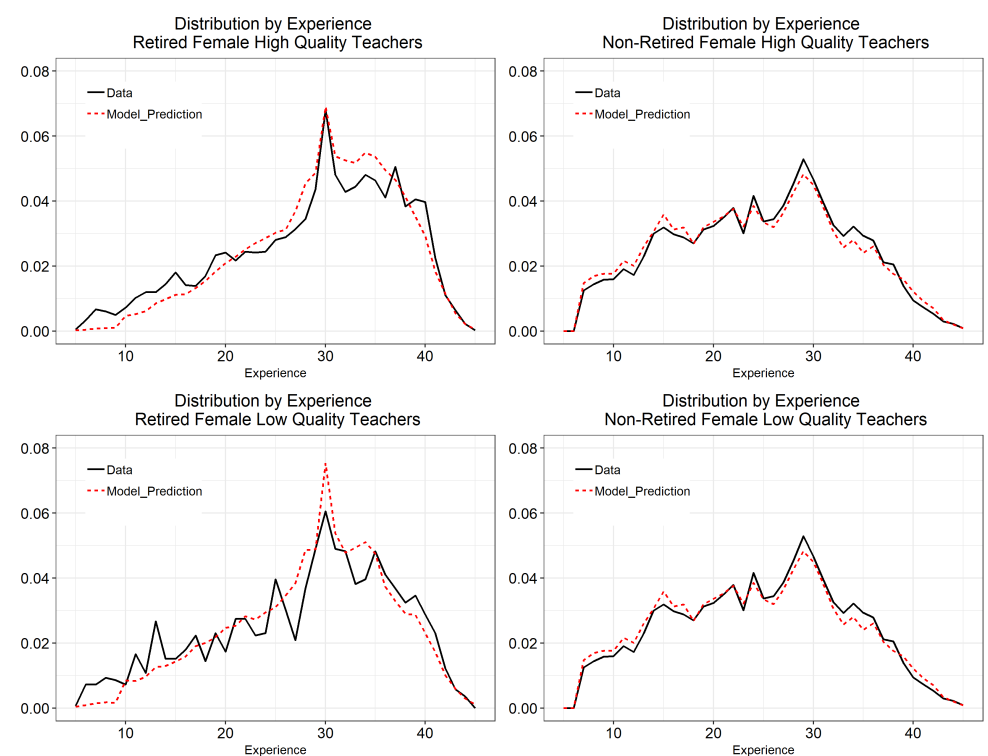

Note: The figure compares observed and predicted experience distribution of female teachers with high and low performance. The model prediction is the in-sample prediction based on the estimates in Table 2.7. The left panels are distributions of retired teachers while the right panels are distributions of non-retired teachers.

Figure 2.10: Observed and Predicted Exp. Distributions for Male Teachers by Quality
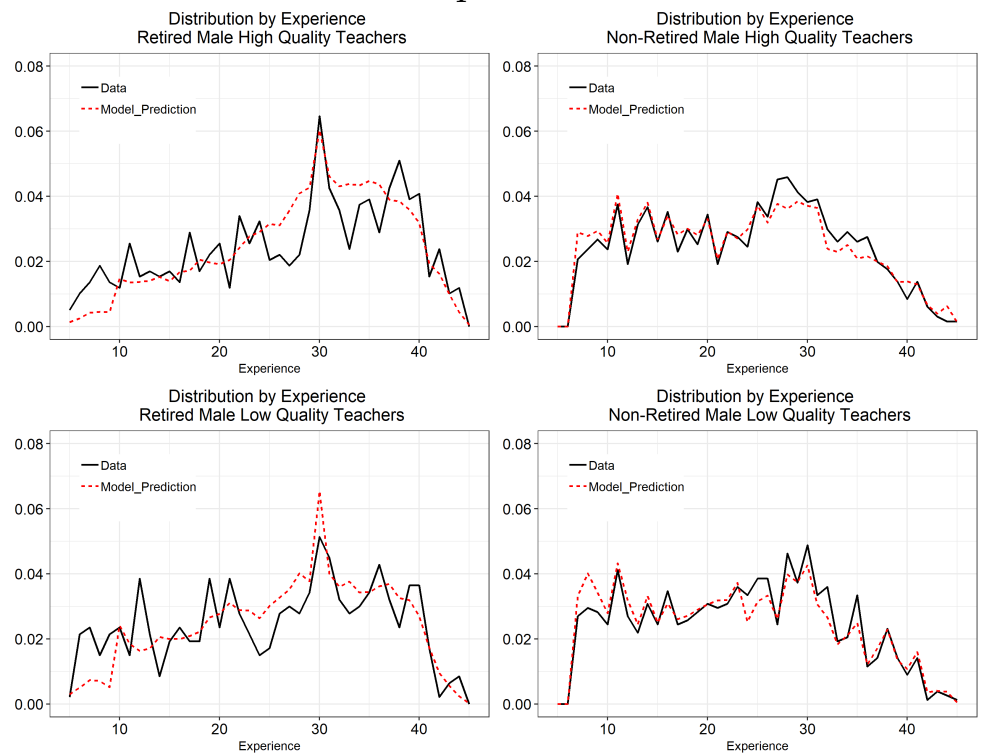

Note: The figure compares observed and predicted experience distribution of male teachers with high and low performance. The model prediction is the in-sample prediction based on the estimates in Table 2.7. The left panels are distributions of retired teachers while the right panels are distributions of non-retired teachers. 
Figure 2.11: Observed and Predicted Survival Rates for Teachers by Quality
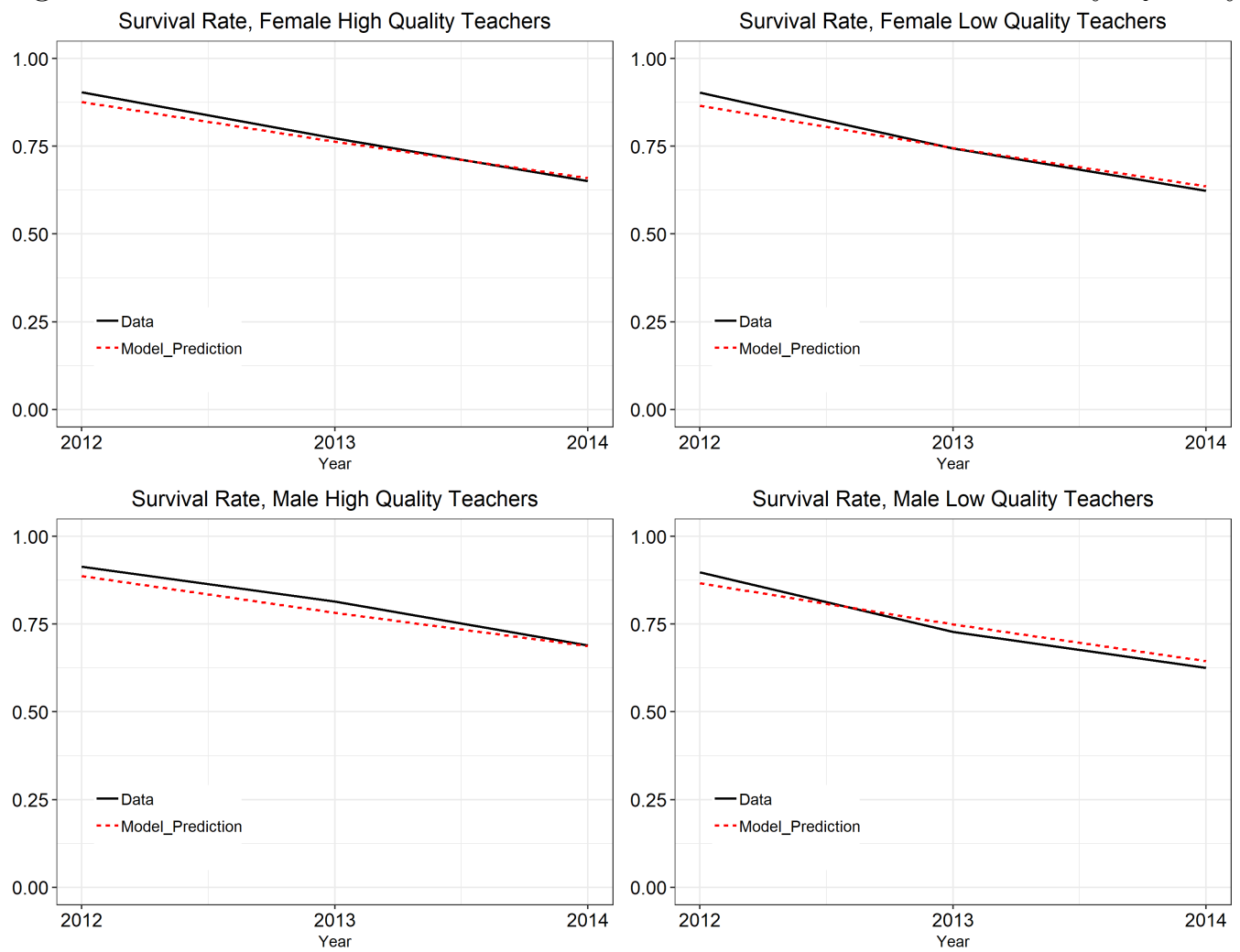

Note: The figure compares observed and predicted employment survival rates for female and male teachers by high and lowperformance. The model prediction is the in-sample prediction based on the estimates in Table 2.7. The left panels are high performance female and male teachers while the right panels are low performance female and male teachers. 
Figure 2.12: Observed and Predicted Age Distributions, Experience Distributions, and Survival Rate for High Quality Teachers in High-Poverty Schools
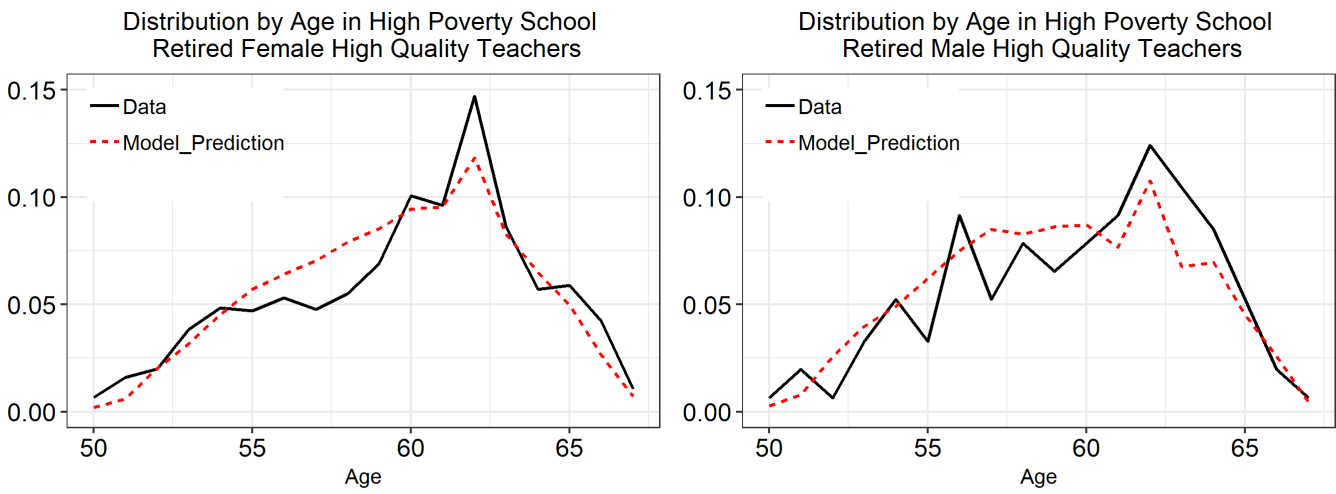

Distribution by Experience in High Poverty Schools

Distribution by Experience in High Poverty Schools Retired Male High Quality Teachers
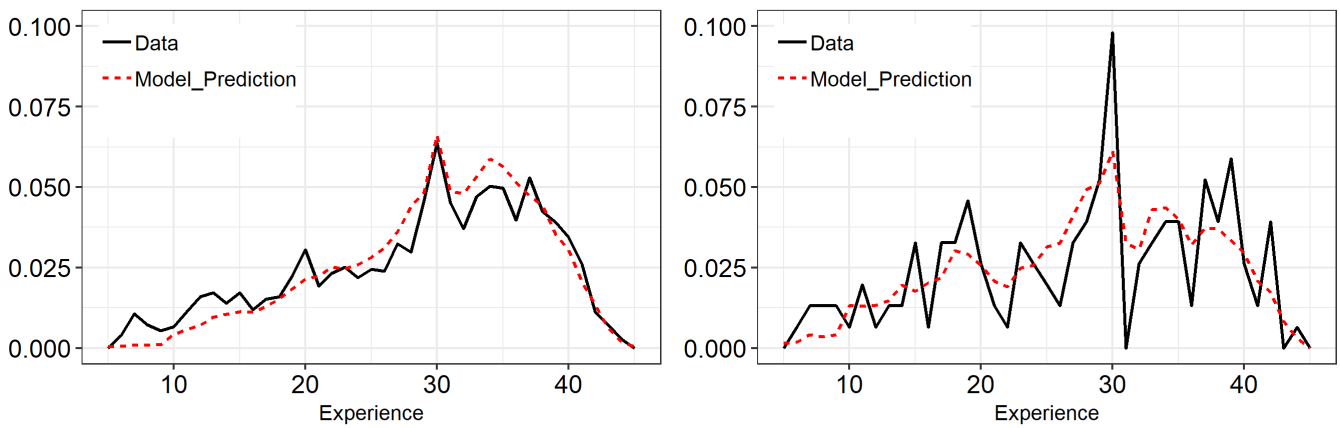

Survival Rate in High Poverty Schools Female High Quality Teachers
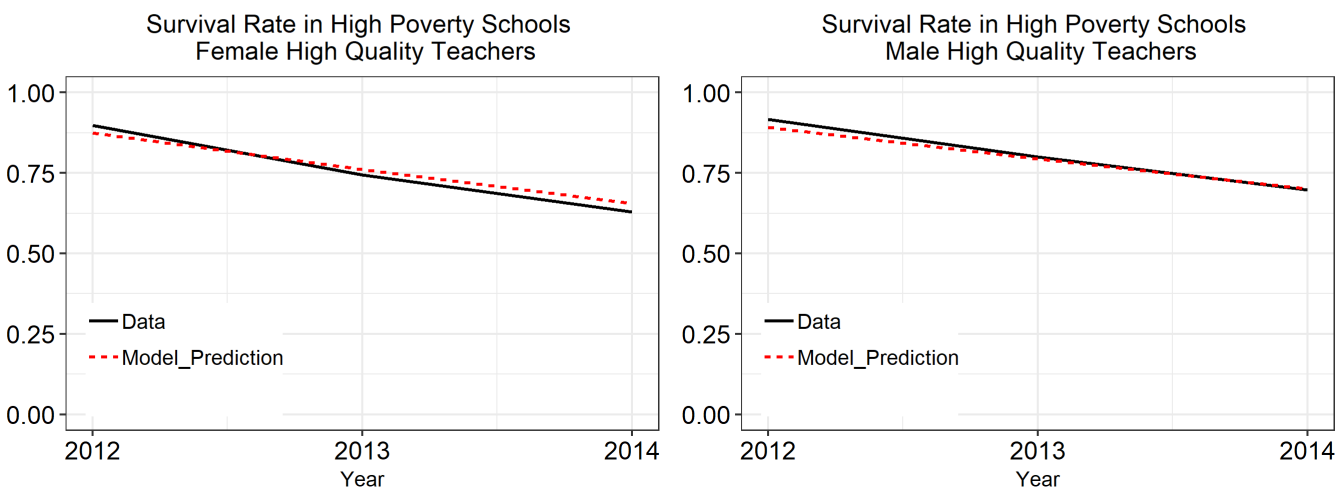

Note: The figure compares observed and predicted age distributions, experience distributions, and survival rates of female and male high quality teachers in high-poverty schools. The model prediction is the in-sample prediction based on the estimates in Table 2.7. 
Retaining high-quality teachers in high need schools is a challenge. In the next section I explore the efficacy and costs of retention bonuses which might target high poverty schools. Thus it is of interest to examine the goodness-of-fit of our model as well for high quality teachers in high need schools. Figure 2.12 compares the observed and predicted age and experience distributions of retired teachers in highpoverty schools for female and male subgroups with high performance. The bottom two graphs compare the observed and predicted survival rate in high-poverty schools for female and male subgroups with high performance. In all of these cases, the structural model forecasts fits the data relatively well.

\subsection{Policy Simulations}

The key advantage in estimating a structural model is that it allows us to simulate retirement behavior under different pension rules and work-retirement incentives, so I can address the school staffing and workforce quality effects.

\subsubsection{Enhancing the Current Plan}

Our first simulation simply enhances the existing DB plan by increasing the replacement factor, an enhancement common during the 1990's (Koedel et al., 2014). The question of interest is the effect of such an un-targeted enhancement on workforce quality. I simulate retirements of our cohort of senior teachers forward for the next 30 years under two cases: a baseline with the current replacement factor of $1.5 \%$ and a counter-factual pension plan, otherwise identical, with a $2 \%$ replacement factor. Table 2.9 provides details about the effects of enhancements on teacher behavior and 
costs. After increasing the replacement factor from 1.5\% to $2 \%$, total teaching years for the cohort decreases by $7.6 \%$ for female high quality teachers and $6.9 \%$ for female low quality teachers, and $6.9 \%$ and $5.8 \%$, respectively, for male high and low quality teachers.

Table 2.9: Effects of Pension Enhancements

\begin{tabular}{|c|c|c|c|c|c|c|}
\hline & \multicolumn{2}{|c|}{ Female High Quality } & \multicolumn{2}{|c|}{ Female Low Quality } & \multicolumn{2}{|c|}{ Female Teachers } \\
\hline & Baseline & Enhancement & Baseline & Enhancement & Baseline & Enhancement \\
\hline & $R F 1.5 \%$ & $R F 2 \%$ & $R F 1.5 \%$ & $R F 2 \%$ & $R F 1.5 \%$ & $R F 2 \%$ \\
\hline Remaining Teaching Years & 43268 & 40183 & 14709 & 13752 & 57977 & 53934 \\
\hline Change (Bonus - Baseline) & - & -3085 & - & -957 & - & -4042 \\
\hline Average Retired Age & 60.87 & 60.57 & 60.67 & 60.41 & 60.82 & 60.53 \\
\hline \multirow[t]{4}{*}{ Average Retired Experience } & 28.68 & 28.38 & 27.63 & 27.37 & 28.40 & 28.12 \\
\hline & \multicolumn{2}{|c|}{ Male High Quality } & \multicolumn{2}{|c|}{ Male Low Quality } & \multicolumn{2}{|c|}{ Male Teachers } \\
\hline & Baseline & Enhancement & Baseline & Enhancement & Baseline & Enhancement \\
\hline & $R F 1.5 \%$ & $R F 2 \%$ & $R F 1.5 \%$ & $R F 2 \%$ & $R F 1.5 \%$ & $R F 2 \%$ \\
\hline Remaining Teaching Years & 8887 & 8314 & 5359 & 5065 & 14246 & 13379 \\
\hline Change (Bonus - Baseline) & - & -573 & - & -294 & - & -867 \\
\hline Average Retired Age & 61.44 & 61.14 & 61.17 & 60.93 & 61.33 & 61.06 \\
\hline Average Retired Experience & 27.82 & 27.52 & 26.71 & 26.47 & 27.38 & 27.10 \\
\hline
\end{tabular}

Note: Simulation tracks all teachers in Tennessee for 30 years under two cases: a baseline with the current replacement factor $1.5 \%$ and a counter-factual pension plan with a $2 \%$ replacement factor.

To see why raising the pension benefit factor can lead to earlier retirement, note that the increase in the replacement factor creates two effects. It raises pension wealth and generates a stronger "pull" towards retiring in the peak-value year, but it also increases the "push" on teachers passing the pension peak. The net effect on retirement 
depends on the relative strength of these opposing effects. Our simulation shows that the "push" effect dominates the "pull" effect. The result is earlier retirement and higher pension liabilities for the plan.

I then examine whether the increase in the replacement factor changes the mix in teacher quality in Tennessee public schools by comparing the change in the employment survival rate (i.e., survival rate under replacement factor $2 \%$ - survival rate under replacement factor 1.5\%) for high quality teachers and low quality teachers. The comparison is illustrated in Figure 2.13. Although our simulation of pension rules is for 30 years, after 15 years most of the teachers retire under either policy, so to illustrate the difference in outcomes between these policies I only plot the first 15 years. With the increase in the replacement factor, the employment survival rates of high and low quality teachers both fall (i.e., retirement rates increase) but the fall is greater for high quality teachers. Over time, as the survival rate converges to zero under all policies, the difference in the survival rates under different policies converges to zero as well.

Figure 2.14 compares the evolution of the share of high quality teachers among non-retired teachers for the next fifteen years. With a higher replacement factor, the high quality share is always below that under the baseline. Because high quality teachers tend to retire later and more of them pass the pension peak, the increase in the replacement factor has a larger net push effect on high quality teachers as compared to low quality teachers. Hence the earlier retirements also lead to a decrease in the average quality of the remaining senior teachers.

\footnotetext{
${ }^{7}$ The following algebra explains the shape of the share of high quality teachers for the remaining teachers in each year. Denote the year- $t$ number of high and low quality teachers remain in year $t$ as $H_{t}$ and $L_{t}$. The year- $t$ retirement of high and low quality teachers are $H_{t}-H_{t+1}$ and $L_{t}-L_{t+1}$. The high quality teacher share for the remaining teachers increases, i.e., $\frac{H_{t+1}}{H_{t+1}+L_{t+1}}>\frac{H_{t}}{H_{t}+L_{t}}$, if and only
} 
Figure 2.13: Survival Rate Differences With Enhancements (Survival Rate under RF $2 \%$ - Survival Rate under RF 1.5\%)
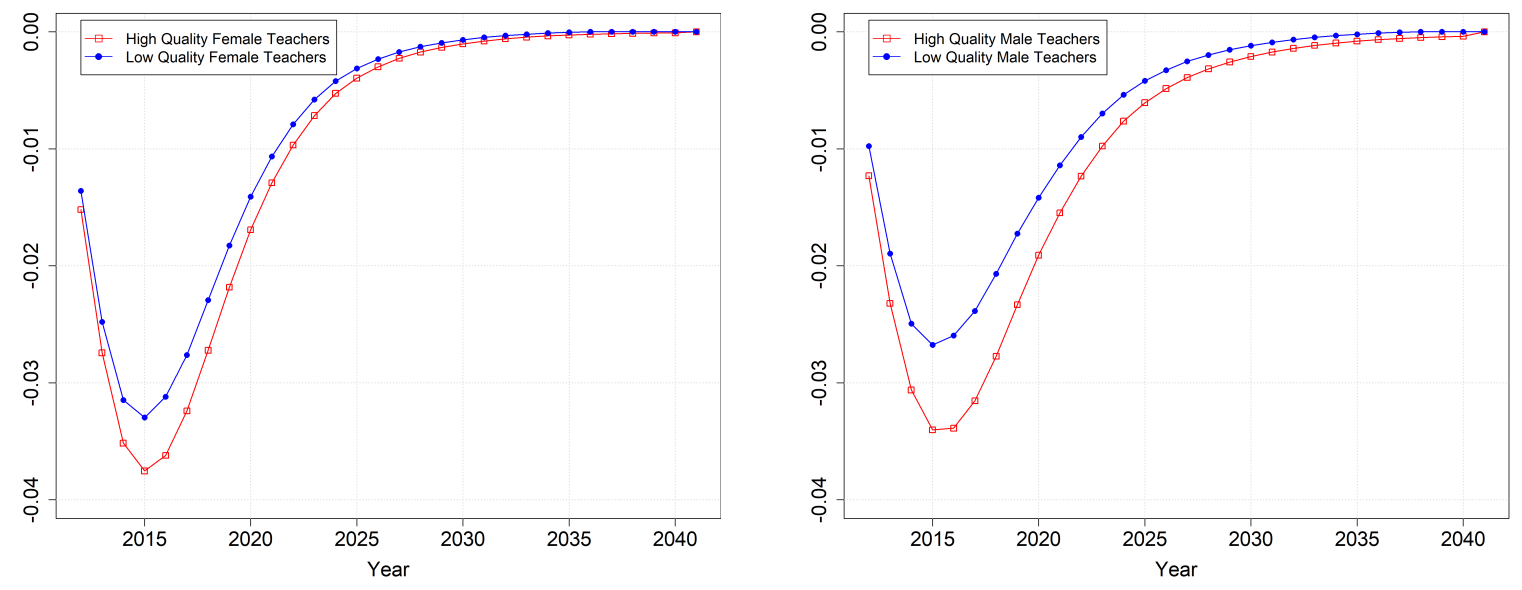

Figure 2.14: Share of High Quality Teachers Among Non-Retired Teachers
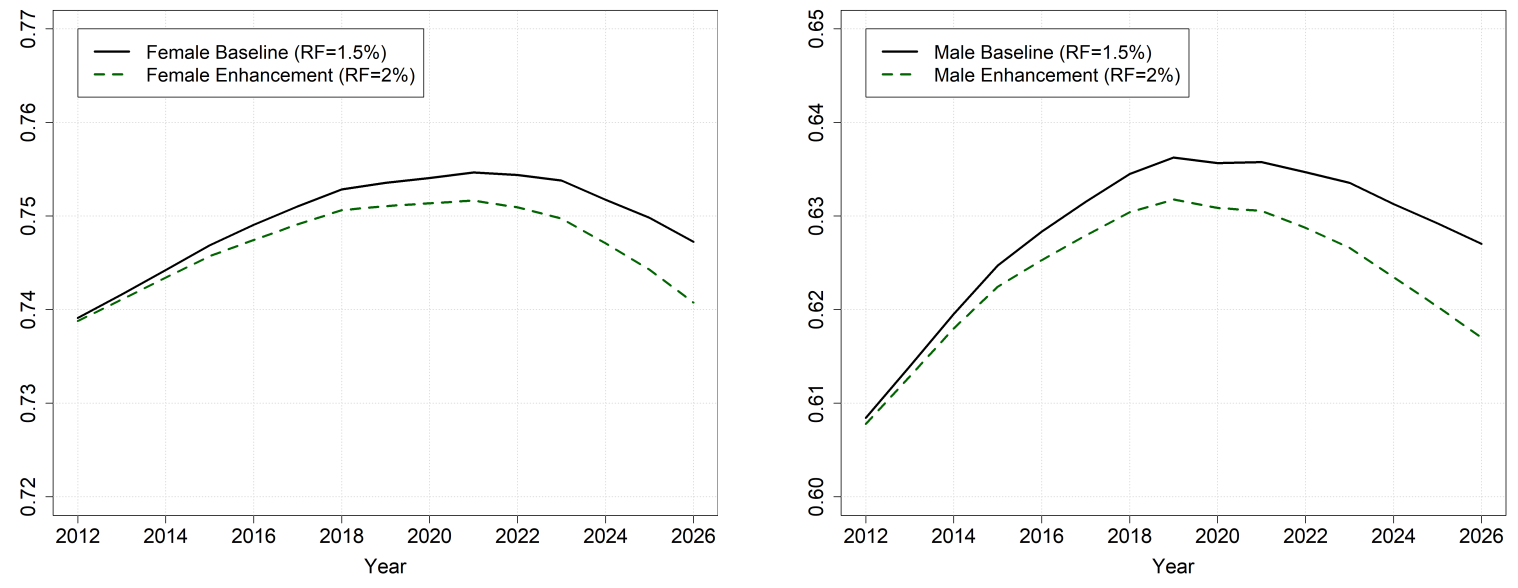

Note: The figure shows the share of high quality teachers in non-retired teachers for the next 15 years under two pension rules: with replacement factor $1.5 \%$ and with replacement factor $2 \%$.

if the retirement hazard rate for the high quality teachers in year $t$ is smaller than that of the low quality teachers, i.e., $\frac{H_{t}-H_{t+1}}{H_{t}}<\frac{L_{t}-L_{t+1}}{L_{t}}$. Because all teachers retire eventually, after a certain year the retirement hazard for high quality teachers should be larger than that for low quality teachers and the share of high-quality teachers declines after that. 


\subsubsection{Retention Bonuses}

Our simulation shows that enhancing the replacement factor for all teachers regardless of quality shortens teacher careers and lowers the average quality of remaining latecareer teachers. In the following I use the structural model to examine the cost effectiveness of three retention bonus policies targeted to high quality teachers.

\section{One-Time Retention Bonuses Paid in One Year}

The Tennessee Department of Education implemented a program to pay a $\$ 5,000$ bonus to all level 5 teachers to stay in selected low performing schools. The program

ran for a single year (2013-2014 school year). Springer et al. (2016) find no significant effect on overall teacher retention. The policy in the simulations below are broadly similar, except that that focus on retirement rather than all turnover. The programs in our simulations are targeted at high quality teachers in high poverty schools. The program offers an unexpected bonus in a single year (for high quality teachers who complete the 2012-2013 school year in a high poverty school). In theory a teacher who delays retirement because of the bonus may choose to stay for more than one year (depending on the subsequent draws of the preference shocks), hence it may take multiple years for the impact of the bonus to materialize. I simulate retirement for our cohort of senior teachers forward for the next 30 years under three scenarios: a baseline with no retention bonus and the two bonus payments, $\$ 5,000$ and $\$ 10,000$. Table 2.10 reports the additional teaching years and the costs of the retention program. The bonus produces a small gain in the teaching years, at a very high cost per additional year: $\$ 420,000-\$ 450,000$.

The one-time bonus to all high quality teachers is inefficient because it does not 
Table 2.10: Effects of One-Year Retention Bonuses for High Quality Teachers in High Poverty Schools

\begin{tabular}{lccc}
\hline \hline \multirow{2}{*}{ Female High Quality Teachers } & & \multicolumn{2}{c}{ Retention Bonus at 2012-13 } \\
& Baseline & Bonus 5K & Bonus 10K \\
\hline Total Additional Years of Working & 16976 & 17016 & 17055 \\
Additional Teaching Years (Bonus minus Baseline) & - & 40 & 79 \\
Teachers Retired at 2012 & 507 & 492 & 478 \\
Teachers Non-Retired at 2013 & 3562 & 3577 & 3591 \\
Total Bonus Cost & - & $\$ 17,883,964$ & $\$ 35,912,033$ \\
Cost per Additional Teaching Year & - & $\$ 448,289$ & $\$ 453,981$ \\
\hline \hline Male High Quality Teachers & & Retention Bonus at 2012-13 \\
& Baseline & Bonus 5K & Bonus $10 \mathrm{~K}$ \\
\hline Total Additional Years of Working & 2428 & 2433 & 2438 \\
Additional Teaching Years (Bonus minus Baseline) & - & 5 & 11 \\
Teachers Retired at 2012 & 55 & 53 & 51 \\
Teachers Non-Retired at 2013 & 451 & 453 & 455 \\
Total Bonus Cost & - & $\$ 2,263,666$ & $\$ 4,546,190$ \\
Cost per Additional Teaching Year & - & $\$ 428,642$ & $\$ 426,763$ \\
\hline \hline
\end{tabular}

Note: Simulation tracks high quality teachers in high poverty schools (4069 female teachers and 506 male teachers) for 30 years under three cases: without retention bonus and with two bonuses $-\$ 5,000$ and $\$ 10,000$ - paid at the 2012-2013 school year.

make use of the differential retirement probability by teachers at different age and experience levels. Because the bonus is one-time only and is unexpected, at the time the bonus is paid relatively few teachers are making retirement decisions that may be affected by the bonus. The one-time bonus does not generate much "pull" for teachers far from the pension peak who would have stayed anyway. For the vast majority of the high quality teachers the one-time bonus has little impact on their retirement decision, as a result the bonus is cost-inefficient. 


\section{Retention Bonuses for Targeted High Quality Teachers}

I now consider a retention bonus to high quality teachers who satisfy a given longevity condition. In this exercise I consider a bonus paid upon completing 31 years of teaching. I choose 31 years of experience because it is just beyond the retirement spike at 30 years experience that occurs under current rules. Thus, one goal of the bonus would be to nudge some of the teachers to stay on the job after passing the pension wealth peak. Obviously each teacher is eligible to receive the bonus at most once, but different teachers may receive the bonus in different years. In this sense the bonus is permanent instead of a one-time one.

The following analysis explains why a retention bonus targeted at certain longevity conditions can be more cost efficient than a one-time bonus given to all teachers. I consider the case of a bonus given to teachers with 31 years of experience. There are four mutually exclusive cases regarding how teachers respond to a retention bonus, each of which has different implications for incremental years of teaching and financial cost. In the first case, the teacher would have retired in year $s<31$ in absence of the bonus. Now she delays retirement and stays in the classroom for at least 31 years and collects the bonus. In the second case, the teacher would have retired in year $s<31$. She postpones retirement in anticipation of receiving the bonus, but ends up retiring prior to year 31 anyway due to a negative shock to utility (e.g., unanticipated poor health, family matters). Teachers in these first two cases would be considered "marginal". A third case is an "infra-marginal" teacher who planned to retire with 31 or more years of experience without a bonus. She now takes the bonus and retires as planned. Her years of teaching are unchanged but she receives the bonus anyway. A final case is a teacher who would have retired with less than 31 years experience prior 
to the bonus and does not change her retirement plans in response to the bonus.

An incentive that increases teaching years while minimizing the financial cost aims to create marginal teachers and avoid producing infra-marginal teachers. To do so, the bonus should be offered to teachers who are most likely to retire (so there is a bigger chance of producing a marginal teacher) and who are past the peak pension wealth year (so there is a saving in pension costs.) A bonus at 31 years of experience satisfies both criteria.

I examine two levels of bonus payments for teachers who reach 31 years experience: $\$ 10,000$ and $\$ 20,000$. I then simulate retirement for our cohort of senior teachers forward for the next 30 years under three scenarios: a baseline with no retention bonus and the two bonus payments.

Figure 2.15 plots the experience distribution of retired teachers in the baseline case and with different levels of retention bonuses. In all cases a bonus shifts the probability mass to the right. Not surprisingly, the larger the bonus, the larger the spike at 31 years of experience and the greater retention beyond. Table 2.11 provides more detailed information on retention and costs. A $\$ 10,000$ bonus would yield an expected 280 years of additional teaching for females and 58 years for males (the latter primarily reflecting the smaller employment share of males). The bonus cost (not including salary) per incremental year is roughly $\$ 40,000-\$ 47,000$. Interestingly, the average cost is largely independent of the size of the bonus since doubling the bonus roughly doubles the number of additional years. The net cost of the bonuses (that factors in the bonus-induced change in pension cost) is lower since most of the marginal teachers are induced to remain on the job past the peak of pension wealth in Figure 2.2. These savings to the pension plan range from $\$ 5000-\$ 6000$, which 
reduces the net cost per incremental teaching year somewhat. Figure 2.16 reports the share of high quality teachers among non-retired teachers in the baseline case and with different levels of retention bonuses for the next 15 years. The figure shows that a larger bonus produces a bigger increase in the share of high quality teachers.

Table 2.11: Effects of Retention Bonuses for High Quality Teachers at 31st Teaching Year

\begin{tabular}{lccc} 
Female High Quality Teachers & & \multicolumn{2}{c}{ Retention Bonus at Experience 31 } \\
& Baseline & Bonus $\$ 10 \mathrm{~K}$ & Bonus $\$ 20 \mathrm{~K}$ \\
\hline Total Additional Years of Working & 43268 & 43548 & 43856 \\
Additional Teaching Years (Total minus Baseline) & - & 280 & 588 \\
Bonus Costs per Additional Teaching Year & - & $\$ 53826$ & $\$ 51634$ \\
Pension Savings per Additional Teaching Year & - & $\$ 6738$ & $\$ 6395$ \\
Net Costs per Additional Teaching Year & - & $\$ 47088$ & $\$ 45240$ \\
\hline \hline Male High Quality Teachers & & Retention Bonus at Experience 31 \\
& Baseline & Bonus $\$ 10 \mathrm{~K}$ & Bonus $\$ 20 \mathrm{~K}$ \\
\hline Total Additional Years of Working & 8887 & 8945 & 9009 \\
Additional Teaching Years (Total minus Baseline) & - & 58 & 122 \\
Bonus Costs per Additional Teaching Year & - & $\$ 46787$ & $\$ 44970$ \\
Pension Savings per Additional Teaching Year & - & $\$ 5225$ & $\$ 4897$ \\
Net Costs per Additional Teaching Year & - & $\$ 41561$ & $\$ 40074$ \\
\hline \hline
\end{tabular}

Note: Simulation tracks high quality teachers (10307 female teachers and 1894 male teachers) for 30 years under three cases: without retention bonus and with two bonuses $-\$ 10,000$ and $\$ 20,000-$ paid in their 31st year of teaching.

Thus, I estimate a cost per additional teaching year of roughly $\$ 40,000$ for the range of retention bonuses considered. For comparison, Chetty et al. (2014) estimate that replacing a classroom teacher at the median level of effectiveness with a teacher at the 95th percentile raises the discounted present value of student earnings by $\$ 212,000$. This suggests that a retention bonus targeted to the best teachers in high 
Figure 2.15: Experience Distribution of Retired High Quality Teachers with Retention Bonuses at 31st Teaching Year
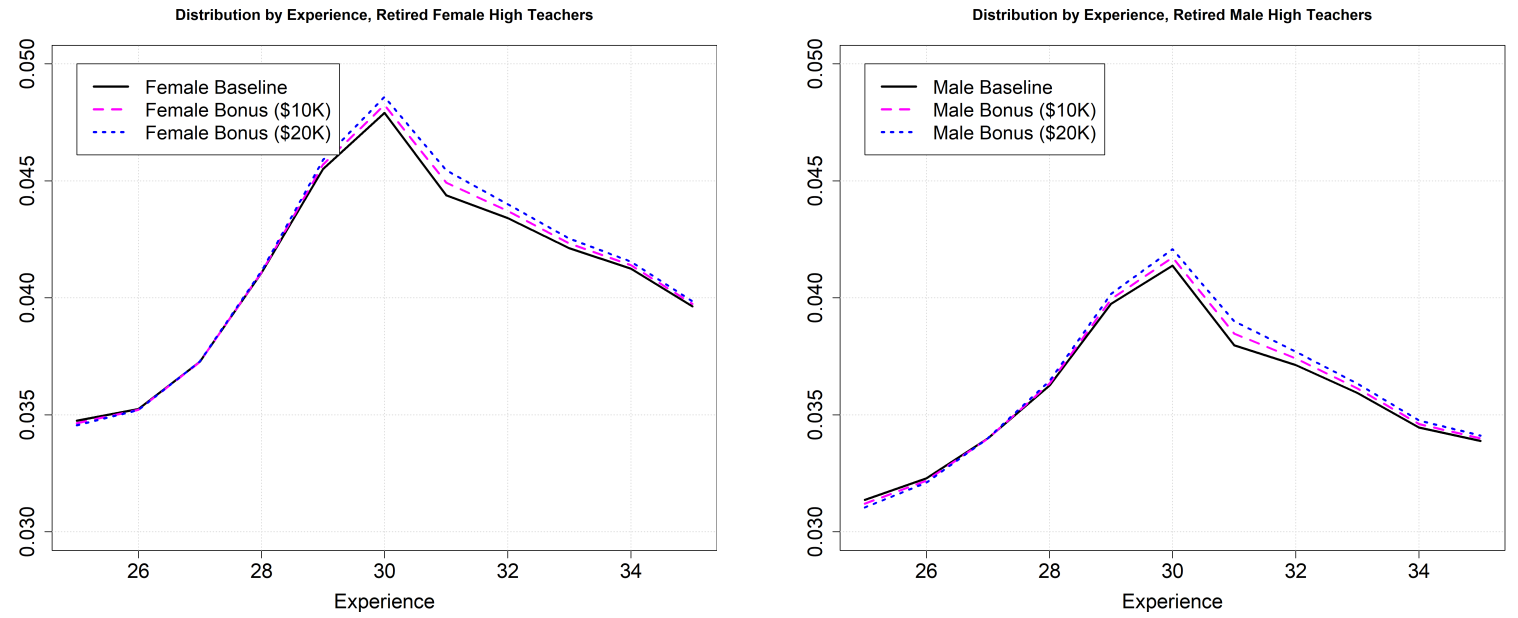

Note: The figure shows the experience distribution of retired high quality teachers for the next 15 years under three cases: a baseline with no retention bonus and the two bonus payments, $\$ 10 \mathrm{~K}$ and $\$ 20 \mathrm{~K}$.

Figure 2.16: Share of High Quality Teachers Among Non-Retired Teachers with Retention Bonuses
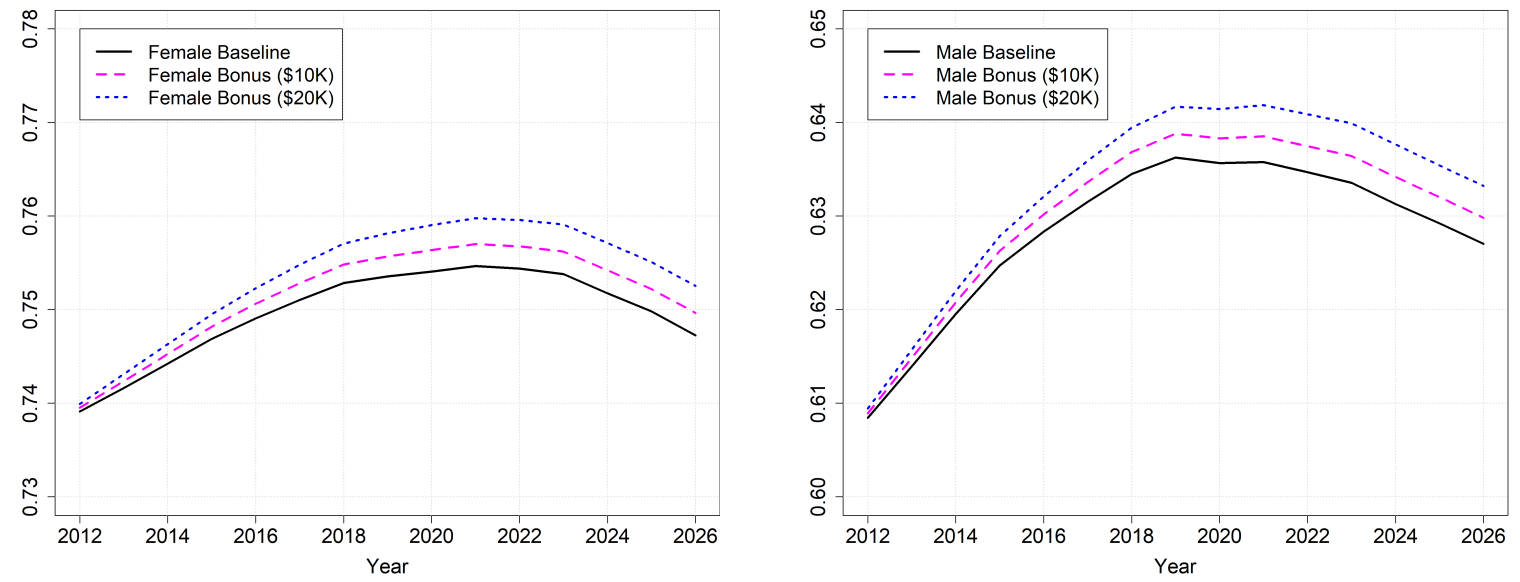

Note: The figure shows the share of high quality teachers in non-retired teachers for the next 15 years under three cases: a baseline with no retention bonus and the two bonus payments, $\$ 10 \mathrm{~K}$ and $\$ 20 \mathrm{~K}$.

need schools is likely to be justified by benefits to students.

${ }^{8}$ Of course, if these high quality teachers had retired they would have been replaced by novice teachers at lower pay, and of indeterminate, but likely lower quality. Assuming that all high quality 


\section{Retention Bonuses For Targeted High Quality Teachers in High Poverty Schools}

In this exercise I consider a bonus paid for high quality teachers on completing 31 years of experience only at high poverty schools. Table 2.3 shows that the share of high quality teachers among those who remain at the end of the sample period is higher or equal than that at the beginning of the sample, especially for male teachers. This suggests that a retention bonus targeting high quality male teachers in high poverty schools can be particularly effective.

As in the simulation above, I also examine two levels of bonus payments for teachers who reach 31 years experience: $\$ 10,000$ and $\$ 20,000$. I then simulate retirement for our cohort of senior teachers at high poverty schools forward for the next 30 years under three scenarios: a baseline with no retention bonus and the two bonus payments.

The longevity-based retention bonuses for high poverty schools have qualitatively similar effect to that for all schools. Figure 2.17 reports the experience distribution of retired teachers in the baseline case and with different levels of retention bonuses. In all cases a bonus shifts the probability mass to the right. Not surprisingly, the larger the bonus, the larger the spike at 31 years of experience and greater retention beyond.

Table 2.12 provides more detailed information on retention and costs. A $\$ 10,000$ bonus would yield an expected 107 years of additional teaching for females and 17 years for males (the latter primarily reflecting the smaller employment share of males).

The bonus cost (not including salary) per incremental year is roughly $\$ 30,000-\$ 46,000$.

teachers are replaced by novices, this would add roughly $\$ 25,000$ to the net costs per incremental year in Table 2.11. Presumably there would be a further reduction in teacher quality as well if an experienced high quality teacher is replaced by a random novice. 
Figure 2.17: Experience Distribution of Retired High Quality Teachers with Retention Bonuses at 31st Teaching Year in High Poverty Schools
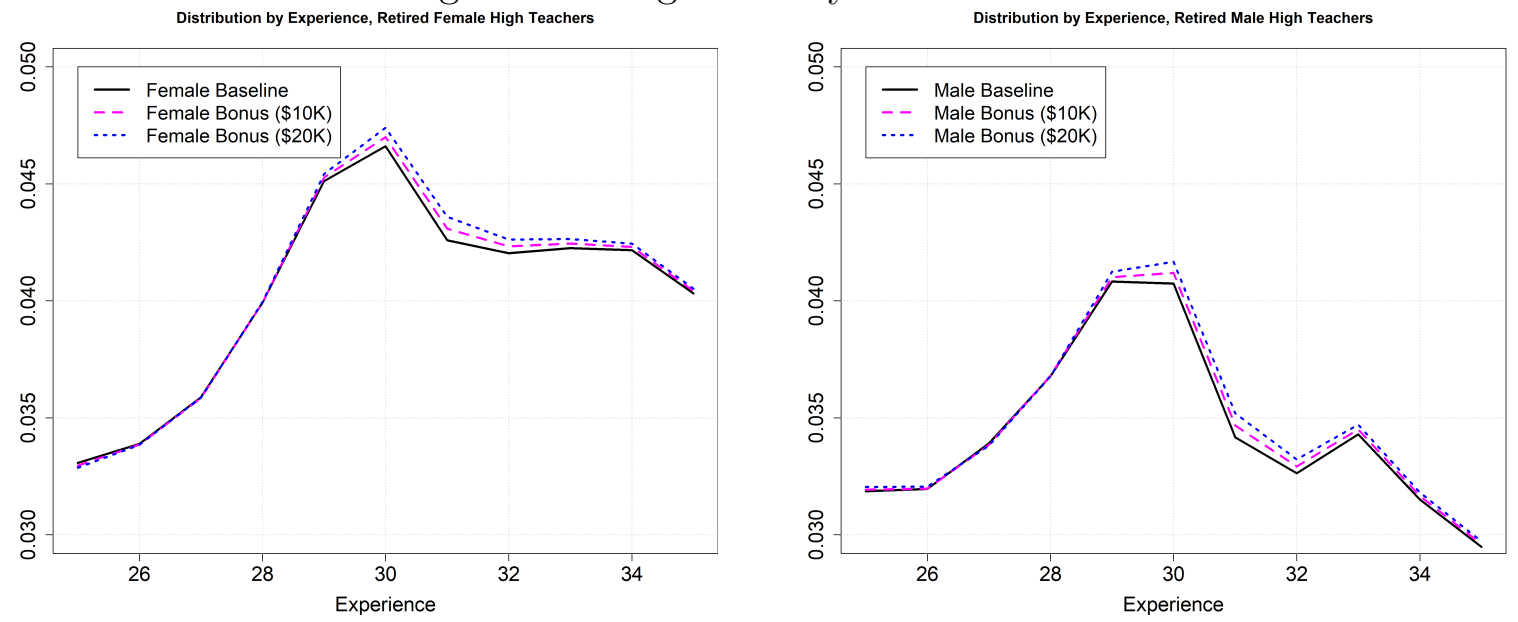

Note: The figure shows the experience distribution of retired high quality teachers for the next 15 years under three cases: a baseline with no retention bonus and the two bonus payments, $\$ 10 \mathrm{~K}$ and $\$ 20 \mathrm{~K}$.

Figure 2.18: Share of High Quality Teachers Among Non-Retired Teachers with Retention Bonuses in High Poverty Schools
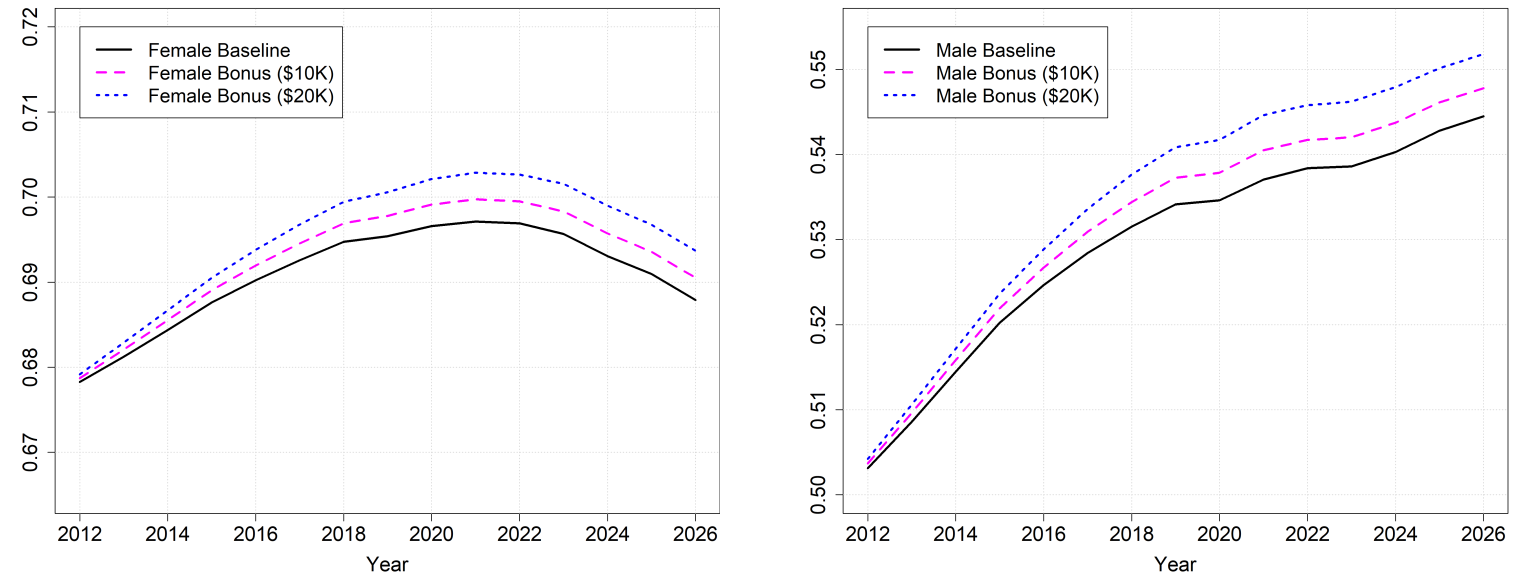

Note: The figure shows the share of high quality teachers in non-retired teachers for the next 15 years under three cases: a baseline with no retention bonus and the two bonus payments, $\$ 10 \mathrm{~K}$ and $\$ 20 \mathrm{~K}$.

The net cost of the bonuses is lower for male teachers in high poverty schools, as I expect. 
Table 2.12: Effects of Retention Bonuses for High Quality Teachers at 31st Teaching Year in High Poverty Schools

\begin{tabular}{lccc}
\hline \hline Female High Quality Teachers & & \multicolumn{2}{c}{ Retention Bonus at Experience 31} \\
& Baseline & Bonus $\$ 10 \mathrm{~K}$ & Bonus $\$ 20 \mathrm{~K}$ \\
\hline Total Additional Years of Working & 16976 & 17083 & 17201 \\
Additional Teaching Years (Total minus Baseline) & - & 107 & 225 \\
Bonus Costs per Additional Teaching Year & - & $\$ 53555$ & $\$ 51251$ \\
Pension Savings per Additional Teaching Year & - & $\$ 6933$ & $\$ 6557$ \\
Net Costs per Additional Teaching Year & - & $\$ 46622$ & $\$ 44694$ \\
\hline \hline & & Retention Bonus at Experience 31 \\
Male High Quality Teachers & Baseline & Bonus $\$ 10 \mathrm{~K}$ & Bonus $\$ 20 \mathrm{~K}$ \\
\hline Total Additional Years of Working & 2428 & 2445 & 2464 \\
Additional Teaching Years (Total minus Baseline) & - & 17 & 37 \\
Bonus Costs per Additional Teaching Year & - & $\$ 36370$ & $\$ 34943$ \\
Pension Savings per Additional Teaching Year & - & $\$ 4718$ & $\$ 4425$ \\
Net Costs per Additional Teaching Year & - & $\$ 31652$ & $\$ 30518$ \\
\hline \hline
\end{tabular}

Note: Simulation tracks high quality teachers in high poverty schools (4069 female teachers and 506 male teachers) for 30 years under three cases: without retention bonus and with two bonuses $-\$ 10,000$ and $\$ 20,000$ - paid in their 31 st year of teaching. 
Figure 2.18 plots the share of high quality teachers in non-retired teachers in the baseline case and with different levels of retention bonuses for the next 15 years. The share of remaining high quality male teachers in high poverty school increases over the next 15 years. Footnote 7 shows that this is because the hazard rate for retirement of high quality teachers in high poverty school is smaller every year over the 15 year period than that of low quality teachers.

\subsection{Conclusion}

In this paper, I make use of longitudinal administrative teacher data for Tennessee, where a statewide teacher evaluation system measures teacher performance, to study late-career workforce churn induced by teacher retirements.

The data show that teacher retirement is related to teacher quality. For both females and males, high quality teachers have a lower retirement rate given age and experience. This is especially true for male teachers in high poverty schools. I find a structural retirement model estimated using data from all schools provides good insample fit, including teachers in high poverty schools. The structural estimates imply that high quality teachers have lower disutility of teaching as compared to retirement. I used the structural estimates to simulate the effect of several policies intended to retain high quality teachers. Enhancing pension benefits for all teachers, regardless of quality, shortens teacher careers, especially those of high quality teachers, and as a result lowers average workforce quality. A one-time unexpected retention bonus to all high quality teachers in high poverty schools does postpose retirement, but at a very high cost per incremental teaching year. A more promising strategy targets 
high quality teachers who meet certain experience milestones. A retention bonus paid to high quality teachers who complete 31 years of service can delay retirement and improve the average quality of the workforce at a cost of roughly $\$ 40,000$ per incremental year, depending on teacher gender and the size of the bonus. Assuming the Tennessee system provides a reliable estimate of teacher quality, and given recent estimates of the lifetime value of a high quality teacher (Chetty et al., 2014), these estimates suggest that retention bonuses can be a cost efficient strategy to improve school quality.

Many states are facing challenges financing existing teacher retirement plans as well as staffing schools with qualified teachers. This study contributes to policy discussions relating to raising the quality of the teaching workforce and pension reform. The methodology in this paper is readily applicable to longitudinal employee data in other states and exploration of retirement plan alternatives. 


\section{Chapter 3}

\section{Teacher Attrition and Teacher Quality: Evidence from Early-Career Teachers}

\subsection{Introduction}

Recent research shows that teacher quality affects short-term and long-term student outcomes, such as high school graduation, college attendance, and labor market earnings (Chetty et al., 2014). Many states face the challenges of staffing public schools, especially disadvantaged schools, with high quality teachers. Previous research suggests that teacher quality is distributed unevenly across schools (Boyd et al., 2005) and is correlated with non-pecuniary factors, such as racial and socioeconomic characteristics of students (Clotfelter et al., 2011; Jackson, 2009; Scafidi et al., 2007; Steele et al., 2015; Hanushek et al., 2004). Teacher compensation has potentially important effect on teacher quality. Variables other than basic salary, including teacher pen- 
sion plans and health insurance plans, will influence the teacher turnover and thus redistribute the teachers in a system. Policy maker in public schools, not only aim to attract effective teachers, but also prefer to balance between junior and senior teachers to best use of the school resources (Dolton and Klaauw, 1999; Hendricks, 2015; Ballou and Podgursky, 2002).

The measurement of teacher quality has been discussed in previous studies. Valueadded model (VAMs) is a commonly used but controversial method to evaluate teacher efficiency (Parsons et al., 2018; Chetty et al., 2014; Koedel et al., 2015). This study takes advantage of a newly established Tennessee educator evaluation data set that includes both student-achievement-based and non-achievement-based components. Although Koedel et al. (2017) suggest a more differentiated teacher rating system, this new comprehensive system is likely more accurate than value-add models (Guarino et al., 2015).

Teacher quality changes in two ways. First, teacher quality changes over time as teachers become more experienced. Many studies focus on the pattern of teacher quality over career cycle. Most studies suggest that teacher quality develop more significantly in the first few years, (Rockoff, 2004; Henry et al., 2011), but some studies (e.g. Wiswall (2013); Harris and Sass (2011); Papay and Kraft (2015)) find continuous return to later-career experience. Second, teacher quality development depends on school environment. Jackson and Bruegmann (2009) find that there is persistent spillover effect of teaching quality in teaching workforce. Sass et al. (2012) find a stronger return productivity of experience in low-poverty schools. However, $\mathrm{Xu}$ et al. (2015) shows that relatively slow quality improvement with experience in high-poverty schools is not because of differential teacher learning between high- 
and low-poverty schools and the mobility and attrition behaviors may explain the disparities in teacher quality across different types of schools. Other than quality development with experience, the second case is that ratings for stayers change over time could because of idiosyncratic shocks, either due to rating system changes or a good or bad year for an individual teacher.

Previous literature finds that teacher attrition and teacher quality are correlated. Some studies suggest that the attrition rate is negatively correlated with teacher efficiency: Lower rated teachers leaving the teaching force, the ratings of the remaining teachers are higher than in absence of attrition. Krieg (2006) and Goldhaber et al. (2011) argue that the teachers with higher effectiveness are less likely to leave the teaching professions. However, Podgursky et al. (2004) find that high-ability teachers are more likely to exit. Feng and Sass (2017) suggest that the correlation of teacher quality and teacher attrition varies across the effectiveness distribution. The most effective and ineffective teachers are those who exit at a higher rate, compared with average-quality teachers.

Novice teachers usually have lowest salaries but experience the highest turnover rate. Retaining high quality novice teachers costs less and benefit more since they are gaining the teaching skills very fast during the first few teaching years.

Because teacher quality and teacher attrition both evolve with experience, it is reasonable to assume that teacher quality and teacher attrition are affected by some common factors. These factors may be captured by observable variables and unobservable variables. Because attrition affects the distribution of quality for the remaining teachers, it is necessary to examine the joint dynamics of teacher quality and teacher attrition in a panel data setting, instead of examining them separately. 
If there is a common unobserved component that drives attrition and quality then regressing one of them on the other results in endogeneity-induced bias.

This chapter asks the following research questions:

1. How do observable factors such as student poverty and teacher salary and unobservable factors affect attrition of novice teachers?

2. How does the evolution of the quality of novice teachers relate to the observable and unobservable factors that drive attrition?

3. Are there policy variables such as teacher salary that help retaining high-quality novice teachers?

To answer above questions, I need to model the rating and attrition of earlycareer teachers. I build a system of 2-vector probit model of binary attrition and binary rating in which the two error terms of the teacher quality and teacher attrition regressions contain a common serially correlated component. Estimates of this sequential indicate that teachers with lower salaries and without graduate degree are more likely to exit the teaching profession, especially those teachers in high poverty schools. Moreover, novice teachers usually experience a quality improvement because of increased experience, salary and even education level. The unobserved common component is correlated with both the probability of staying and being high quality.

This study contributes to the literature from the following aspects. First, this paper models the joint dynamics of attrition behaviors and ratings of novice teachers based on both observable and unobservable factors. Second, compared with previous study, the new rating system in Tennessee provides a more comprehensive evaluation of teacher quality and thus make this study of the quality dynamics more reliable. 


\subsection{Data and Empirical Patterns of All Teachers in Tennessee}

\subsubsection{Ratings, Administrative and School Profile Data}

I merge teacher evaluation data and administrative data during the 2011-2012 school year and the 2013-2014 school year from the Tennessee Department of Education. I also have school profiles of public schools in Tennessee.

As a winner in the US Department of Education "Race to the Top" grants competition, Tennessee received funding to implement a new statewide teacher evaluation system started at the 2011-2012 school year. Compared with evaluation using student achievement only, the new evaluation system is quite comprehensive. Half of a teacher's evaluation score is based on a qualitative non-achievement-based measure, classroom observations. The remaining half is based on student achievement measures, including student growth represented by a value-added score (35 percent) and student achievement (15 percent). Thus the teachers are rated by multi-dimensional

measures. Every teacher in the new evaluation system is evaluated regardless of teaching experience or tenure status. There are five effectiveness levels for evaluation scores, which can differentiate teachers into 5 levels. Level 1 is the lowest, which stands for a teachers performs "Significantly below Expectation". Level 5 is the highest, which stands for a teacher is "Significantly Above Expectation".

The administrative data from the Tennessee Department of Education provide the basic information of teachers each year, including age, teaching experience, salary, race, gender, and education level.

The data about public school profiles in Tennessee include the percentage of stu- 
dents eligible for free or reduced-price lunch (FRPL). This information measures the percentage of low-income students and provides a proxy for a school's poverty level. In the following analysis, I divide schools into 2 groups using FRPL: (1) high poverty schools (FRPL>60\%); (2) low poverty schools (FRPL $\leq 60 \%)$.

The above three datasets capture the characteristics of both teachers and their teaching environment each year. Table 3.1 summaries the basic statistics for all teachers from the 2011-2012 school year to the 2013-2014 school year. The table shows that the proportion of high quality teachers persistently declines through the three years, possibly due to system-wide shifts in ratings. Around $80 \%$ of teachers are female teachers and around half of teachers are in high poverty schools. Moreover, the teacher workforce are getting younger slightly with time.

Table 3.1: Summary Statistics for All Teachers

\begin{tabular}{lccc}
\hline & $2011-2012$ school year & 2012-2013 school year & 2013-2014 school year \\
\hline Age & 44.417 & 44.202 & 43.933 \\
Experience & $(11.169)$ & $(11.058)$ & $(10.917)$ \\
& 14.144 & 13.848 & 13.654 \\
Salary & $(9.882)$ & $(9.662)$ & $(9.510)$ \\
& 47534.658 & 48422.414 & 47522.216 \\
FRPL (\%) & $(8934.658)$ & $(9160.234)$ & $(8266.777)$ \\
& 58.717 & 58.794 & 57.627 \\
High Quality Share & $(22.676)$ & $(23.045)$ & $(21.144)$ \\
Female Share & 0.725 & 0.696 & 0.642 \\
Poverty Share & 0.806 & 0.804 & 0.802 \\
Number of Teachers & 0.504 & 0.515 & 0.494 \\
\hline
\end{tabular}

Note: Standard deviations are in parentheses. 


\subsubsection{Empirical Patterns}

I will illustrate the empirical patterns of experience $(e)$ and ratings $(r)$ using the following two figures. In this section, I group teachers into 4 categories by rating: (1) $\mathrm{r}=1$, "Extremely Low Score" teachers for teachers with level 1 and 2; (2) r=2, "Low Score" teachers for teachers with level 3, (3) r=3, "High Score" teachers for teachers with level 4; (4) r=4, "Extremely High Score" teachers for teachers with level 5.

Figure 3.1 plots $p(e \mid r)$ using all data over the sample period. The experience distribution $p(e)$ decreases with experience. Novice teachers have higher $p(e)$ than middle career teachers and middle career teachers have higher $p(e)$ than senior teachers. This is expected if attrition of all ages is replaced by novice teachers. Moreover, over the sample period, teachers with the lowest rating $(r=1)$ are more likely to be novice teachers, and teachers with the highest rating $(r=4)$ are less likely to be novice teachers. Specifically, $p(e \mid r=1)>p(e \mid r=4)$ for $e \leq 5$. However, for novice teachers, the gap between low quality and high quality novice teachers diminishes with experience increasing.

Figure 3.2 plots $p(r \mid e)$. In Figure 3.2 , novice teachers with experience $\leq 5$ or very senior teachers with experience $\geq 35$ are more likely to have lower ratings. Therefore, the overall teacher quality for novice teachers persistently increases for the first five years.

In this paper, I focus on the teacher attrition behaviors and the dynamics of teacher quality of novice teachers (teachers with experience $\leq 5$ years). From Figure 3.1 and Figure 3.2, I find out the following facts: (1) teacher attrition differs significantly for novice teachers with different teacher quality; (2) the proportion of high teacher quality increases greatly at the first few years. 
Figure 3.1: Distribution of Experience at Given Teacher Rating

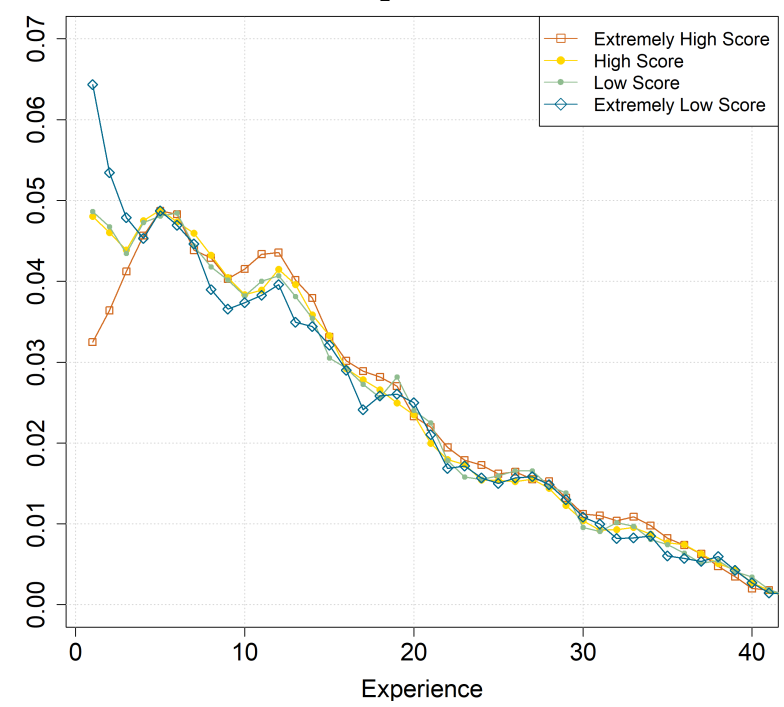

Note: The figure shows the experience distribution of teachers at four different ratings.

Figure 3.2: Distribution of Rating at Given Experience

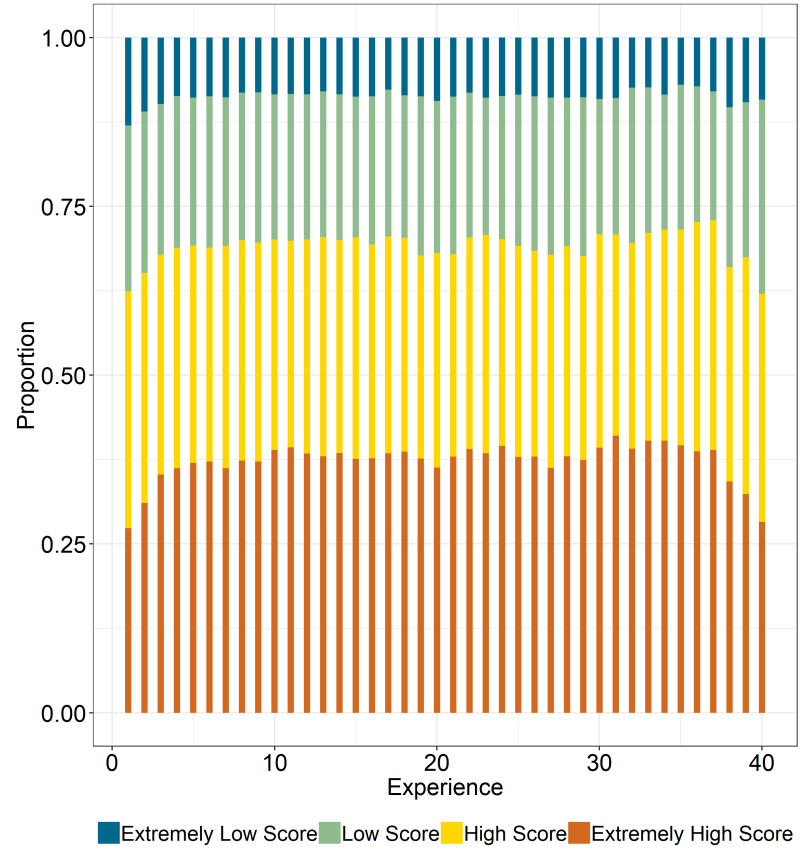

Note: The figure shows the rating distribution of teachers at different experience. 


\subsection{Model Teacher Attrition and Dynamics of Teacher Quality for Novice Teachers}

\subsubsection{Probit Model for Teacher Attrition and Teacher Qual- ity}

I consider a 2-vector panel data model of binary attrition and binary rating data. Teacher $i$, who has been teaching in period $t$ decides whether to stay in period $t+1$ based on the probit model with latent variable $y_{i t}^{*}: y_{i t}=1$ iff $y_{i t}^{*}>0$ and $y_{i t}=0$ iff $y_{i t}^{*} \leq 0$. The latent variable is determined by

$$
y_{i t}^{*}=x_{i t}^{\prime} \beta_{1}+v_{i t}
$$

for $t=1, . ., T, x_{i t}$ is a $k_{1} \times 1$ column vector; $v_{i t}$ is normal and is serially correlated:

$$
v_{i t}=\rho_{1} v_{i t-1}+u_{i t}
$$

If the teacher chooses to stay in period $t$, we observe the ratings $r_{i t}$. For simplicity, I only consider binary rating variable, $r_{i t}=1$ (high quality teachers with evaluation score of 4 and 5 ) and $r_{i t}=0$ (low quality teachers with evaluation score of 1,2 , and 3). In future research, the rating categories can be expanded to more than two types.

I model rating $r_{i t}$ by a probit model with latent variable $r_{i t}^{*}: r_{i t}=1$ iff $r_{i t}^{*}>\alpha$ and $r_{i t}=0$ iff $r_{i t}^{*} \leq \alpha$. Conditioning on $y_{i t-1}=1$, the latent variable

$$
r_{i t}^{*}=\gamma_{t}+z_{i t}^{\prime} \beta_{2}+\xi_{i t}
$$


for $t=1, . ., T, z_{i t}$ is a $k_{2} \times 1$ column vector, and $\xi_{i t}$ is correlated with $v_{i t-1}$,

$$
\xi_{i t}=\rho_{2} v_{i t-1}+\epsilon_{i t}
$$

The underline assumption here is that $v_{i t-1}$ measures the unobserved preference for staying. I expect the preference is positive correlated $0<\rho_{1}<1$ and is positively correlated with rating $\rho_{2}>0$. The shocks $u_{i t}$ and $\epsilon_{i t}$ are iid standard normal $N(0,1)$.

In the analysis of early-career teachers, $x_{i t}$ and $z_{i t}$ both includes variables of Experience $_{i t}$ (teaching experience of teacher i at time t), Experience ${ }_{i t}^{2}$, Salary Ext (teacher i's salary at time t (in thousand)), Poverty ${ }_{i t}$ (dummy variable to indicate whether teacher $\mathrm{i}$ at time $\mathrm{t}$ is in a high poverty school), Education ${ }_{i t}$ (dummy variable

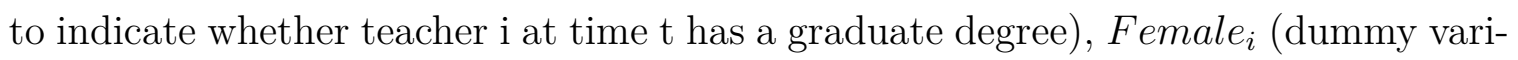
able to indicate whether teacher $\mathrm{i}$ is a female teacher), and $x_{i t}$ has more information on whether the teacher is eligible for normal pension at year t. I allow time-fixed effects that affects the rating $\gamma_{t}$ for all teachers. The parameter $\gamma_{t}$ captures aggregate shifts in the rating system (e.g., the degree of difficulty in tests or a change in the evaluation procedure.)

I drop the subscript for teacher $i$ whenever it does not cause confusion.

Suppose teacher $i$ leaves in period $T_{i}$ (hence $y_{t}=1$ for $t<T_{i}$ and $y_{T_{i}}=0$ ). The attrition history of teacher $i$ is denoted by $y_{i}=(1,1, \ldots, 1,0)$. Prior to her departure she receives rating $r_{i}=\left(r_{1}, \ldots, r_{T_{i}}\right)^{\prime}$. Observing the vector $y_{i}, r_{i}$, I denote the joint event of the history of attrition and rating for teacher $i$.

Denote $D_{t}=\left(y_{t}, r_{t}\right)^{\prime}, D=\left(D_{1}, . ., D_{T}\right)^{\prime}$. Denote $\gamma=\left(\gamma_{1}, . ., \gamma_{T}\right)$. Denote all model parameters as $\theta=\left(\beta_{1}, \beta_{2}, \gamma, \alpha, \rho_{1}, \rho_{2}\right)$. 
The likelihood of data for teacher $i$ leaving in period $T_{i}$ is

$$
L\left(D_{i} \mid x_{i}, z_{i}, \theta\right)=\operatorname{prob}\left(\left[\bigcap_{t=1}^{T_{i}-1}\left(y_{i t}^{*}>0 \bigcap I\left(r_{i t}^{*} \geq \alpha\right)\right] \bigcap\left[y_{i T_{i}}^{*} \leq 0\right] \mid x_{i}, z_{i}, \theta\right)\right.
$$

and the likelihood for teacher $i$ staying until the end of the sample period $T$ is

$$
L\left(D_{i} \mid x_{i}, z_{i}, \theta\right)=\operatorname{prob}\left(\left[\bigcap_{t=1}^{T-1}\left(y_{i t}^{*}>0 \bigcap I\left(r_{i t}^{*} \geq \alpha\right)\right] \bigcap\left[y_{i T}^{*}>0\right] \mid x_{i}, z_{i}, \theta\right)\right.
$$

where $I\left(r_{i t}^{*} \geq \alpha\right)$ stands for the fact that $r_{i t}^{*} \geq \alpha$ if $r_{i t}=1$ and $r_{i t}^{*}<\alpha$ if $r_{i t}=0$.

The $\operatorname{prob}(D \mid x, z, \theta)$ is computed via GHK. The AR structure of the errors permit an analytical expression of the Choleksy decomposition of the covariance matrix of $v_{i}=\left(\nu_{1}, . ., \nu_{T_{i}}\right)^{\prime}$ which allows us to avoid inverting the covariance matrix. The algorithm converts the problem of high dimensional integration into a sequence of one-dimensional integrations. More details for calculating the sample likelihood are

in the Appendix A. I estimate the model parameters by maximizing the sample likelihood.

\subsubsection{Data for Estimation}

Using the probit model, I began by estimating the related coefficients. The data I use for estimation consists of a cohort of Tennessee novice teachers (teachers with teaching experience $\leq 5$ ) at the beginning of the 2011-12 school year. I tracked this cohort of teachers forward to the 2013-14 school year. Descriptive statistics on this sample are shown in Table 3.2.

Figure 3.3 compares the average salaries of teachers in high-poverty and low- 
Table 3.2: Descriptive Statistics

\begin{tabular}{lccccc}
\hline & All at 2012 & Exit at 2012 & Exit at 2013 & Exit at 2014 & Teachers Stayed \\
\hline High Quality Share & 0.730 & 0.651 & 0.651 & 0.593 & 0.661 \\
High Poverty Share & 0.510 & 0.457 & 0.475 & 0.526 & 0.499 \\
Average Experience & 3.155 & 2.803 & 3.966 & 5.067 & 5.232 \\
Average Salary & 38470 & 39276 & 40958 & 41123 & 41293 \\
Average Age & 34.033 & 32.176 & 34.251 & 35.994 & 36.384 \\
Graduate Share & 0.404 & 0.413 & 0.515 & 0.550 & 0.525 \\
Female Share & 0.782 & 0.754 & 0.760 & 0.800 & 0.787 \\
Eligible For Pension & 0.004 & 0.006 & 0.021 & 0.024 & 0.010 \\
Number of Teachers & 8478 & 943 & 621 & 496 & 6418 \\
\hline
\end{tabular}

Note: This table tracks the novice teachers in the 2011-2012 school year to the 2013-14 school year. All numbers reported are the averages for teachers in that specific year.

poverty schools using the above data. This figure suggests that the salaries of teachers in high poverty schools are likely to be higher than those of teachers in low poverty schools. It appears some effort has been made to attract and retain more young teachers in high poverty schools by offering more salaries for those teachers.

\subsubsection{Estimated Parameters and Goodness of Fit}

MLE estimates of parameters in the probit model are reported in Table 3.3. Using the estimated parameters, I simulate the exit behaviors and the dynamics of ratings for novice teachers. Please note that the simulation results in the section are based on the following assumptions: (1) the teachers do not change their school poverty type if they stay; (2) the education levels of the novice teachers do not change in this three years. Figure 3.4 compares the observed and predicted survival rate from the 2011-12 school year to the 2013-14 school year. The figure illustrates that the probit 
Figure 3.3: Average Salaries in High-Poverty and Low-Poverty Schools

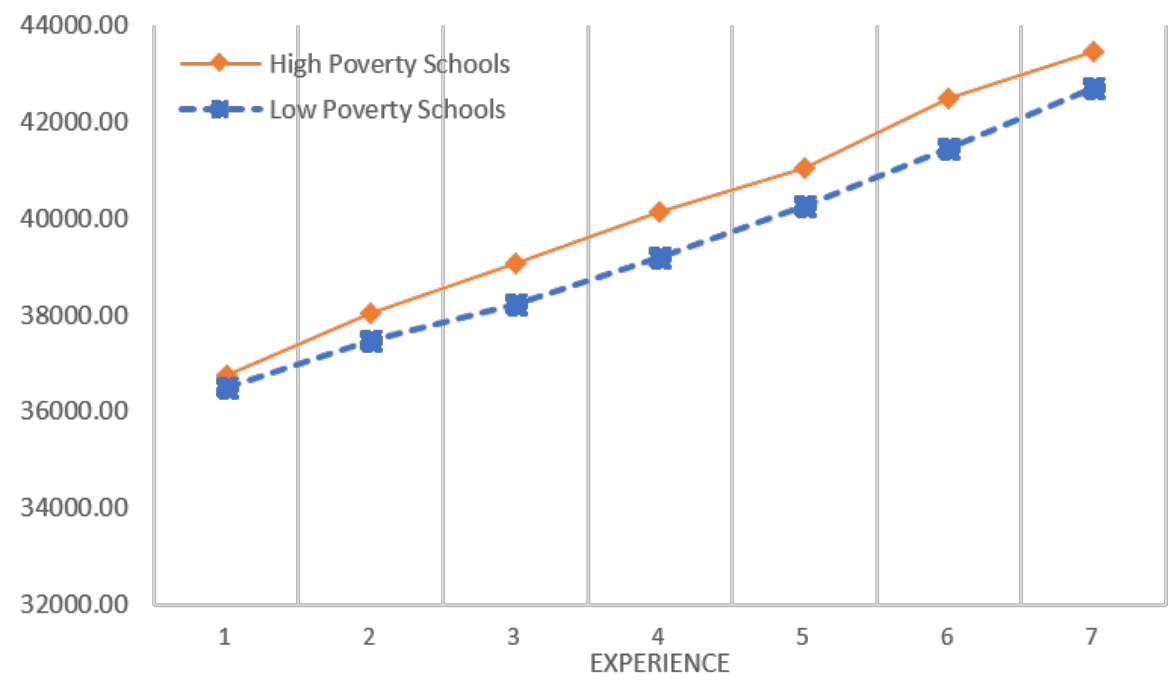

Note: The figure compares the average salaries of teachers in high-poverty and low-poverty schools using the data for estimation.

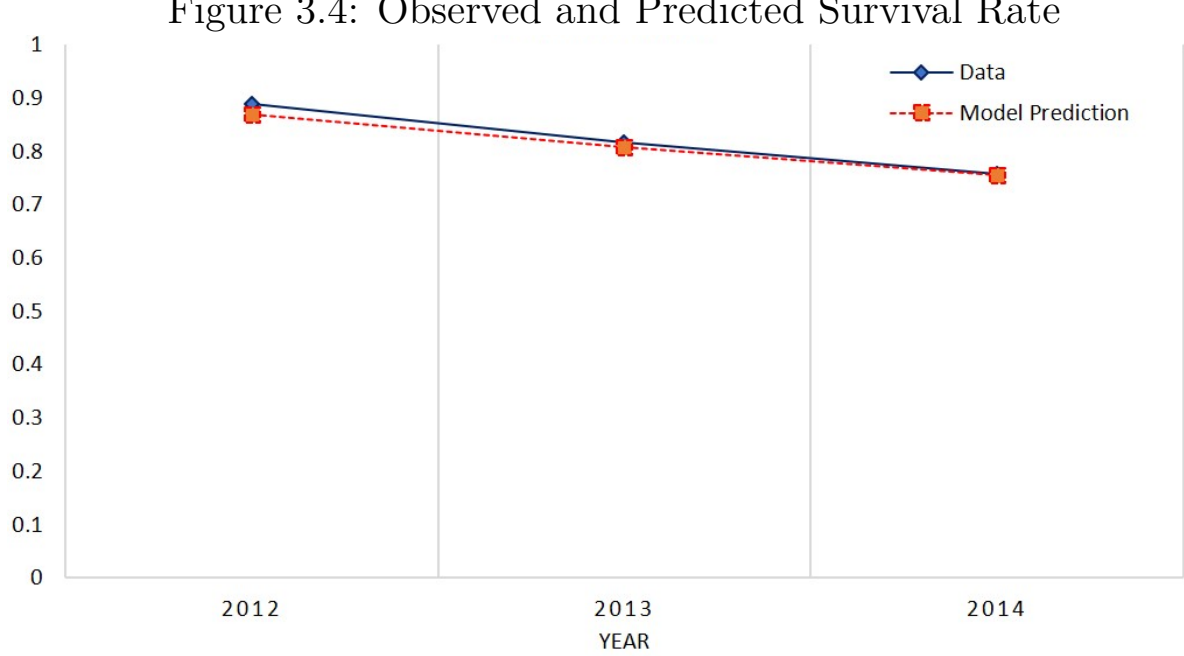

Note: The figure compares the observed and predicted survival rate from the 2011-12 school year to the 2013-14 school year.

model can predict the teacher exit decisions quite well.

Table 3.4 compare the observed and predicted number and proportion of high and low quality teachers for teachers staying at the end of 2013-14 school year. The 
Table 3.3: Estimated Parameters

\begin{tabular}{|c|c|c|c|}
\hline \multicolumn{2}{|c|}{ Attrition Probit Model } & \multicolumn{2}{|c|}{ Quality Probit Model } \\
\hline \multirow[t]{2}{*}{ Constant } & 0.127 & $\alpha$ & 0.329 \\
\hline & $(0.131)$ & & $(0.126)^{* * *}$ \\
\hline \multirow[t]{2}{*}{ Experience } & 0.379 & Experience & 0.254 \\
\hline & $(0.037)^{* * *}$ & & $(0.032)^{* * *}$ \\
\hline \multirow[t]{2}{*}{ Experience $^{2}$} & -0.054 & Experience $^{2}$ & -0.041 \\
\hline & $(0.005) * * *$ & & $(0.004)^{* * *}$ \\
\hline \multirow[t]{2}{*}{ Salary(000s) } & 0.022 & Salary $(000 s)$ & 0.010 \\
\hline & $(0.003)^{* * *}$ & & $(0.003)^{* * *}$ \\
\hline \multirow[t]{2}{*}{ Poverty } & -0.050 & Poverty & -0.324 \\
\hline & $(0.030)^{*}$ & & $(0.025)^{* * *}$ \\
\hline \multirow[t]{2}{*}{ Education } & 0.438 & Education & 0.303 \\
\hline & $(0.032)^{* * *}$ & & $(0.027)^{* * *}$ \\
\hline \multirow[t]{2}{*}{ Female } & -0.049 & Female & 0.417 \\
\hline & $(0.036)$ & & $(0.030)^{* * *}$ \\
\hline \multirow[t]{4}{*}{ Eligible } & -0.417 & Year2013 & -0.223 \\
\hline & $(0.628)$ & & $(0.056)^{* * *}$ \\
\hline & & Year2014 & -0.324 \\
\hline & & & $(0.061)^{* * *}$ \\
\hline \multirow[t]{2}{*}{$\rho_{1}$} & 0.716 & $\rho_{2}$ & 0.800 \\
\hline & $(0.014)^{* * *}$ & & $(0.032)^{* * *}$ \\
\hline Log-Likelihood & -21547.311 & & \\
\hline
\end{tabular}

Note: ${ }^{*} \mathrm{p}<0.1 ; \quad{ }^{* *} \mathrm{p}<0.05 ; \quad{ }^{* * *} \mathrm{p}<0.01 ; \quad$ The standard errors are in parentheses.

The parameters on the left are those in the first probit model;

The parameters on the right are those in the second probit model. 
Table 3.4: Observed and Predicted Teacher Quality Distribution at the End of Sample Period

\begin{tabular}{lcc}
\hline & Data & Model Prediction \\
\hline Number of High Quality Teachers & 4244 & 4012 \\
Number of Low Quality Teachers & 2174 & 2382 \\
Share of High Quality Teachers & $66.13 \%$ & $62.74 \%$ \\
Share of Low Quality Teachers & $33.87 \%$ & $37.26 \%$ \\
\hline
\end{tabular}

Note: This table shows the numbers and distribution of teachers with different quality at the end of 2013-14 school year.

model overpredicts the proportion of low quality teachers. The first reason could be the assumption of fixed education status. Table 3.2 shows that the proportion of teachers with graduate degree increases year by year. The second reason could be the assumption that teachers do not switch to a school with different poverty status. Both two facts will cause the over-prediction of the percentage of low quality teachers.

\subsubsection{Discussions}

Since the probit model produces good fits for both survival rate and quality distribution, I will discuss the estimated parameters, which reveal the patterns of exit behaviors and rating changes of novice teachers.

Table 3.3 shows the parameters of the 2-vector panel data model of binary attrition and binary rating data. The $y *$ and $r *$ increase greatly as the experience increases for the first three years. Increasing salary will increase both the probability of teachers' staying and teacher quality. Teachers with higher education level in low poverty schools tend to stay longer and receive higher evaluation scores. Moreover, female teachers are more likely to receive higher ratings. As is shown in the data, the 
evaluation scores have a declining trend in the system. The parameters of time fixed effects suggest the consistent finding since the year fixed effects are all negative and increasing in magnitude with time. The coefficients of "Female" and "Eligible" are both negative but not statistically significant. Most observable variables have the same sign in the attrition and quality equations and contribute to the positive correlation of the probability of staying and receiving a high rating.

The estimate of $\rho_{1}=0.716$ indicates that the unobserved preference for being teachers are positively correlated over time and persistent. The estimate of $\rho_{1}=0.800$ indicates that the preference of being teachers is positively correlated with rating. This indicates that like the observable variables of salary, student poverty level and teacher education level, the unobserved serially correlated component also contributes to the positive correlation of the probability of staying and a high rating.

I will conclude our discussion by answering the three questions in the first section.

1. Teachers with lower salaries and without graduate degree are more likely to exit the teaching profession. Moreover, teachers in high poverty schools are less likely to continue teaching and tend to get lower scores as well. Since part of the teacher evaluation includes the student achievement, teacher performance is correlated with student characteristics and thus correlated with poverty level of schools. Moreover, the under-rated teachers in high-poverty schools may be discouraged from this performance evaluation system.

2. The new teachers significantly improve their performance in the first three years of their career. Novice teachers who receive higher education and earn more salaries are more likely to have better teaching performance. Teacher quality differs significantly for teachers with different genders. The dynamics of teacher quality at 
the first few years depends on multiple factors. Generally, for the first few years, the teachers experience a performance enhancement because of increased experience, salary and even education level. The unobserved teacher heterogeneity contributes to the positive correlation of staying and high quality.

3. Increasing salaries will retain the novice teachers and motivate them to perform better. Therefore, increasing salaries of novice teachers will increase both the number and quality of novice teachers. Moreover, increasing the salaries for novice teachers could attract more teachers with higher education levels, which further improve the teaching workforce. However, increasing the salary for all novice teachers is costly. The retention policies tied to the teacher effectiveness could provide a tool for policymakers to retain high quality teachers and improve the quality of teaching workforce. The policies targeting at high quality novice teachers are even more important for high poverty schools since it is harder to keep high quality novice teachers in those schools.

\subsection{Conclusion}

This study captures the joint dynamics of attrition behaviors and teaching effectiveness of early-career teachers. Using a more comprehensive evaluation system, I analyze the research topics including the characteristics of teachers leaving teaching profession, the dynamics of teacher quality, and the retention policies for retaining high-quality teachers.

The data show that teacher attrition behaviors differs significantly for novice teachers with different ratings. Moreover, the teacher quality increases at the first 
few teaching years. This suggests that teacher attrition is correlated with teacher quality. Thus, to jointly model the teacher attrition and teacher quality for novice teachers, I use a 2-vector sequential probit model of binary attrition and binary rating. The probit model fits the data well, in terms of both survival rate and quality distribution.

I find that the teachers in high poverty schools are less likely to continue teaching and tend to get lower evaluation score as well. One important reason is that the teacher evaluation depends on student characteristics and the under-rating of teachers in high-poverty schools may further push teachers to exit. I also find that the novice teachers experience a performance enhancement because of increased experience, salary or even education level.

Retaining early-career teachers and improving teacher quality are always two important tasks in staffing at the public schools. To retain those novice teachers, increasing salaries could provide more job satisfaction, reduce turnover, and improve their performance. However, salary increase targeting only on high-quality teachers is even more cost effective. The pay raise based on performance awards high-quality teachers and inspire low-quality teacher to perform better. This study contributes to policy suggestions relating to linking the teacher quality to salaries at least for novice teachers. 


\section{Appendix A}

\section{Calculation of Social Security Benefits}

Public school teachers in St. Louis are covered by Social Security system. Social Security could provide teachers with inflation-protected income after retirement. Retirees should start collecting benefits between age 62 and age 70 .

\section{A.1 Social Security at Full Retirement Age}

First,calculate Average Indexed Monthly Earnings (AIME) using salary history. Get a list of earning history. All the wages are indexed to the average wages for the year you turn 60 using National Average Wage Index(NAWI). 1 For wages earned above 60 years old, the indexed wages are the actual wages. Get the highest 35 years' index wages(IW). Then get the AIME by dividing the sum of the top 35 indexed wages by 420 months.

\footnotetext{
${ }^{1}$ https://www.ssa.gov/oact/cola/AWI.html
} 


$$
\text { AIME }=\left(\sum_{i=0}^{35} I W_{i}\right) / 420
$$

Second, calculate Primary Insurance Amount (PIA) with AIME calculated above. ${ }^{2}$ Calculate the bend points $\left(b p_{1}\right.$ and $\left.b p_{2}\right)$ using $N A W I$ at the year when you attain age 62 , say $N A W I_{62}$.

$$
\begin{aligned}
& b p_{1}=N A W I_{62} \times \frac{180}{9779.44} \\
& b p_{2}=N A W I_{62} \times \frac{1085}{9779.44}
\end{aligned}
$$

The PIA is calculated as following:

$$
\mathrm{PIA}=\left\{\begin{array}{cc}
90 \% A I M E & \text { if } A I M E<b p_{1} \\
90 \% b p_{1}+32 \%\left(A I M E-b p_{1}\right) & \text { if } b p_{2}<A I M E<b p_{2} \\
90 \% b p_{1}+32 \%\left(b p_{2}-b p_{1}\right)+15 \%\left(A I M E-b p_{2}\right) & \text { if } A I M E>b p_{2}
\end{array}\right.
$$

PIA is the monthly benefit you will receive if you begin benefits at your Full Retirement Age (FRA).

\section{A.2 Social Security at Early Retirement Age}

Social Security benefits will be reduced if you retire earlier than your Full Retirement Age. The reduced benefit depends on FRA and the earliest age you can collect social security is 62. For the collection age within 3 years before FRA, then the PIA will be reduced by $0.2 / 3$ every year. For the collection age beyond 3 years before FRA, then PIA will be further reduced by $5 \%$ every year.

\footnotetext{
${ }^{2}$ https://www.ssa.gov/oact/cola/piaformula.html

${ }^{3}$ https://www.ssa.gov/planners/retire/retirechart.html

${ }^{4}$ https://www.ssa.gov/planners/retire/agereduction.html
} 


\section{A.3 Social Security at Delayed Retirement Age}

Social Security benefits will be increased if you delay your retirement after full retirement age.5 If you collection age is beyond 70, there will be no further increase afterwards.

Table A.1: Benefit Increase for Delayed Retirement

\begin{tabular}{ccc}
\hline Year of Birth & 12-Month Rate of Increase & Monthly Rate of Increase \\
\hline $1933-1934$ & $5.50 \%$ & $11 / 24$ of $1 \%$ \\
$1935-1936$ & $6.00 \%$ & $1 / 2$ of $1 \%$ \\
$1937-1938$ & $6.50 \%$ & $13 / 24$ of $1 \%$ \\
$1939-1940$ & $7.00 \%$ & $7 / 12$ of $1 \%$ \\
$1941-1942$ & $7.50 \%$ & $5 / 8$ of $1 \%$ \\
1943 or later & $8.00 \%$ & $2 / 3$ of $1 \%$ \\
\hline
\end{tabular}

${ }^{5}$ https://www.ssa.gov/planners/retire/delayret.html 


\section{Appendix B}

\section{Calculation of Sample Likelihood Function and Correcting for Sample Selection Bias in a Dynamic Structural Retirement Model}

\section{B.1 Sample Likelihood Function}

Denote $f_{t}^{\dagger}=g_{t}\left(r_{t}^{\dagger}\right) / K_{t}\left(r_{t}^{\dagger}\right)$. The condition for teachers staying at time $\mathrm{t}$ is $\nu_{t}>-f_{t}^{\dagger}$, while the condition for teachers retiring at time $\mathrm{t}$ is $\nu_{t} \leq-f_{t}^{\dagger}$. The probability that teacher retires in period $\mathrm{t}$ is $\operatorname{prob}\left[\nu_{t} \leq-f_{t}^{\dagger}\right]$.

Denote the parameters $\gamma, k, k_{1}, \beta, \sigma, \rho$ in Chapter 1 and $\gamma, k, k_{1}, k_{2}, \beta, \sigma, \rho$ in Chapter 2 as $\Theta$. 
For cross-section data at period t, the likelihood is

$$
L(\Theta \mid Y, B, P, D)=\prod_{i=1}^{I} \Phi\left(f_{t}^{\dagger} / \sigma_{\nu}\right)^{d_{i t}}\left(1-\Phi\left(f_{t}^{\dagger} / \sigma_{\nu}\right)\right)^{1-d_{i t}},
$$

where $d_{i t}$ is a dummy variable, which is 1 if teacher i chooses to retire and is 0 otherwise. $\Phi($.$) is the cumulative distribution function of standard normal distribution,$ and $\sigma_{\nu}$ is the standard deviation of $\nu_{t}$.

For panel data, suppose year 1 is the first year of our sample period, and year $\mathrm{N}$ is the last year of our sample period. Denote $V_{t_{1}, t_{2}}=\left(\nu_{t_{1}}, \ldots, \nu_{t_{2}}\right), F_{t_{1}, t_{2}}^{\dagger}=\left(f_{t_{1}}^{\dagger}, \ldots, f_{t_{2}}^{\dagger}\right)$. If teacher i chooses to retire at year $\mathrm{n}(n \leq N)$, the likelihood (unconditional probability) for this teacher is

$$
\operatorname{prob}\left(V_{1, N} \in A_{i}\right)=\operatorname{prob}\left[\left(V_{1, n-1}>-F_{1, n-1}^{\dagger}\right) \cap\left(\nu_{n}<-f_{n}^{\dagger}\right)\right]
$$

If teacher i chooses to stay until year $\mathrm{N}$, the likelihood (unconditional probability) for this teacher is

$$
\operatorname{prob}\left(V_{1, N} \in A_{i}\right)=\operatorname{prob}\left[\left(V_{1, N}>-F_{1, N}^{\dagger}\right]\right.
$$

Thus, the likelihood for the whole sample is

$$
L(\Theta \mid Y, B, P, D)=\prod_{i=1}^{I} \operatorname{prob}\left(V_{1, N} \in A_{i}\right)
$$

We will note in Section B.2 that this standard formula needs correction for sample selection bias. 


\section{B.2 Correcting for Selection Bias in Baseline Sam- ple}

Since the timing of retirement is the key variable of interest, the study focuses on a teacher population who are eligible to retire during the sample period. However, teachers who would have been in the sample but chose to retire before the baseline year are excluded in the baseline sample, while those who chose to stay remain in the sample. For the same age and experience, the "stayers" have preference errors that are in favor of staying. This produces sample selection bias and results in overprediction of retirement for teachers (Ni and Podgursky, 2016).

The probability of a teacher appearing in the sample differs by teacher. Suppose at the first year of our sample period, a teacher was eligible for retirement (or early retirement) $J$ years ago. We express the probability that the teacher appears in the sample as a function of the structural parameters based on the option-value model. To see why this is the case, assume the sample period start in year 1 and the teacher in year $-J$ became retirement eligible for the first time. In every year leading to year 0, the teachers in our sample should stay. Mathematically, during this period before our sample the condition (1.8) was not satisfied, i.e., $-g_{t}\left(r_{t}^{\dagger}\right) / K_{t}\left(r_{t}^{\dagger}\right)<\nu_{t}$ (which means the relative value of retirement is lower than the preference error). Suppose the preference error $\nu_{t}$ is positively correlated over time, then the sequence $\left(\nu_{-J}, . ., \nu_{0}\right)$ are truncated. Estimates based on the assumption that $\nu_{0}$ has a zero mean will be biased.

We correct this selection bias by using conditional probability to weight teacher observations in our baseline sample. The probability a teacher was retired in our sample period will be conditioned on the fact that the teacher was not retired at the 
beginning of sample period.

If a teacher chooses to retire at year $\mathrm{n}$, the conditional probability of retiring is:

$$
\begin{aligned}
& \operatorname{prob}\left(V_{1, N} \in A_{i} \mid \text { appearing in sample }\right) \\
& =\operatorname{Prob}(\text { retiring at } n \mid \text { appearing in sample }) \\
& =\frac{\operatorname{Prob}(\text { retiring at } n \text { \& appearingin sample })}{\operatorname{Prob}(\text { appearingin sample })} \\
& =\operatorname{Prob}\left[\left(\left(V_{1, n-1}>-F_{1, n-1}^{+}\right) \cap\left(\nu_{n}<-f_{n}^{+}\right)\right) \mid V_{-J, 0}>-F_{-J, 0}^{+}\right] \\
& =\frac{\operatorname{Prob}\left[\left(V_{-J, n-1}>-F_{-J, n-1}^{+}\right) \cap\left(\nu_{n}<-f_{n}^{+}\right)\right]}{\operatorname{Prob}\left(V_{-J, 0}>-F_{-J, 0}^{+}\right)}
\end{aligned}
$$

If the teacher chooses to stay until the end of sample period $\mathrm{N}$, the conditional probability is:

$$
\begin{aligned}
& \operatorname{prob}\left(V_{1, N} \in A_{i} \mid \text { appearing in sample }\right) \\
& =\operatorname{Prob}(\text { staying at } N \mid \text { appearing in sample }) \\
& =\frac{\operatorname{Prob}(\text { staying at } N \text { \& appearingin sample })}{\operatorname{Prob}(\text { appearing in sample })} \\
& =\operatorname{Prob}\left[\left(\left(V_{1, N}>-F_{1, N}^{+}\right)\right) \mid V_{-J, 0}>-F_{-J, 0}^{+}\right] \\
& =\frac{\left.\operatorname{Prob}\left[\left(V_{-J, N}>-F_{-J, N}^{+}\right)\right)\right]}{\operatorname{Prob}\left(V_{-J, 0}>-F_{-J, 0}^{+}\right)}
\end{aligned}
$$

Thus, the likelihood for the whole sample is

$$
L(\Theta \mid Y, B, P, D)=\prod_{i=1}^{I} \operatorname{prob}\left(V_{1, N} \in A_{i} \mid \text { appearing in sample }\right) .
$$

We use the likelihood in (B.5) to estimate our structural model. Computing probabilities in the numerator and denominator involves high-dimensional numerical integrations, for which we apply the Geweke-Hajivassiliou-Keane (GHK) simulator (see e.g., Börsch-Supan and Hajivassiliou (1993)), which is more efficient than bruteforce Monte Carlo simulations. 


\section{Appendix $\mathrm{C}$}

\section{Calculation of Sample Likelihood in a Probit Model}

\section{C.1 Individual Likelihood}

Denote the normal $N\left(m, \sigma^{2}\right)$ truncated at $(a, b)$ as $T N_{(a, b)}\left(m, \sigma^{2}\right)$, denote the pdf and cdf of standard normal as $\phi($.$) and \Phi($.$) .$

One can write $v_{t}=\rho^{t} v_{0}+\rho^{t-1} u_{1}+\rho^{t-2} u_{2}+\ldots+\rho u_{t-1}+u_{t}$. Note the generated $v_{t}$ in this the sequential drawings are biased. For example $v_{1}$ is drawn without taking into account the data in period $t>1$. But the joint probability computed are unbiased because the later draws of $v_{t}$ for $t>1$ are from truncated errors in $u_{t}$ (instead of $N(0,1))$, in accordance with observations after $t>1$. In the simplified study, $r_{i t}=1$ for high quality teachers and $r_{i t}=0$ for low quality teachers. Thus, in the following formula, $\alpha_{-1}=-\infty, \alpha_{0}=\alpha$, and $\alpha_{1}=+\infty$.

If $T_{i}<T$, teacher $i$ leave teaching in period $T_{i}$ and the likelihood can be computed 


$$
\begin{aligned}
& L\left(D_{i} \mid x_{i}, z_{i}, \theta\right)=\iint . . \int \phi\left(v_{i 0}\right) \Phi\left(x_{i 1}^{\prime} \beta_{1}+\rho_{1} v_{i 0}\right) \\
& \times\left[\Phi\left(\alpha_{r_{i 1}}-\gamma_{1}-\left(z_{i 1}^{\prime} \beta_{2}+\rho_{2} v_{i 0}\right)\right)-\Phi\left(\alpha_{r_{i 1}-1}-\gamma_{1}-\left(z_{i 1}^{\prime} \beta_{2}+\rho_{2} v_{i 0}\right)\right)\right] \\
& \times \Phi\left(x_{i 2}^{\prime} \beta_{1}+\rho_{1}^{2} v_{i 0}+\rho_{1} u_{i 1}\right) \\
& \times\left[\Phi\left(\alpha_{r_{i 2}}-\gamma_{2}-\left(z_{2}^{\prime} \beta_{2}+\rho_{2}^{2} v_{i 0}+\rho_{2} \epsilon_{1}\right)\right)-\Phi\left(\alpha_{r_{i 2}-1}-\gamma_{2}-\left(z_{2}^{\prime} \beta_{2}+\rho_{2}^{2} v_{i 0}+\rho_{2} \epsilon_{1}\right)\right)\right] \\
& . \times \Phi\left(x_{i T_{i}-1}^{\prime} \beta_{1}+\rho_{1}^{T_{i}-2} v_{i 0}+\rho_{1}^{T_{i}-3} u_{i 2}+. .+\rho_{1} u_{i T_{i}-2}\right) \\
& \times\left[\Phi\left(\alpha_{i T_{i}-1}-\gamma_{T_{i}-1}-\left(z_{i T_{i}-1}^{\prime} \beta_{2}+\rho_{2}^{T_{i}-2} v_{i 0}+\rho_{2}^{T_{i}-3} u_{i 2}+. .+\rho_{2} u_{i T_{i}-2}\right)\right)\right. \\
& -\Phi\left(\alpha_{\left(i T_{i}-1\right)-1}-\gamma_{T_{i}-1}-\left(z_{i T_{i}-1}^{\prime} \beta_{2}+\rho_{2}^{T_{i}-2} v_{i 0}+\rho_{2}^{T_{i}-3} u_{i 2}+. .+\rho_{2} u_{i T_{i}-2}\right)\right] \\
& \times\left(1-\Phi\left(x_{i T_{i}}^{\prime} \beta_{1}+\rho_{1}^{T_{i}-1} v_{i 0}+\rho_{1}^{T_{i}-2} u_{i 2}+. .+\rho_{1} u_{i T_{i}-1}\right)\right) \\
& \times\left[\Phi\left(\alpha_{i T_{i}}-\gamma_{T_{i}}-\left(z_{i T_{i}}^{\prime} \beta_{2}+\rho_{2}^{T_{i}-1} v_{i 0}+\rho_{2}^{T_{i}-2} u_{i 2}+. .+\rho_{2} u_{i T_{i}-1}\right)\right)\right. \\
& -\Phi\left(\alpha_{i T_{i}-1}-\gamma_{T_{i}}-\left(z_{i T_{i}}^{\prime} \beta_{2}+\rho_{2}^{T_{i}-1} v_{i 0}+\rho_{2}^{T_{i}-2} u_{i 2}+. .+\rho_{2} u_{i T_{i}-1}\right)\right] d v_{i 0} d u_{i 1} . . d u_{i T_{i}-1} .
\end{aligned}
$$

If $T_{i}=T$, teacher $i$ remains teaching at the end of the sample period and her likelihood can be simulated as above except that the last period is $T_{i}=T$ :

$$
\begin{aligned}
& L\left(D_{i} \mid x_{i}, z_{i}, \theta\right)=\iint . . \int \phi\left(v_{i 0}\right) \Phi\left(x_{i 1}^{\prime} \beta_{1}+\rho_{1} v_{i 0}\right) \\
& \times\left[\Phi\left(\alpha_{r_{i 1}}-\gamma_{1}-\left(z_{i 1}^{\prime} \beta_{2}+\rho_{2} v_{i 0}\right)\right)-\Phi\left(\alpha_{r_{i 1}-1}-\gamma_{1}-\left(z_{i 1}^{\prime} \beta_{2}+\rho_{2} v_{i 0}\right)\right)\right] \\
& \times \Phi\left(x_{i 2}^{\prime} \beta_{1}+\rho_{1}^{2} v_{i 0}+\rho_{1} u_{i 1}\right) \\
& \times\left[\Phi\left(\alpha_{r_{i 2}}-\gamma_{2}-\left(z_{2}^{\prime} \beta_{2}+\rho_{2}^{2} v_{i 0}+\rho_{2} \epsilon_{1}\right)\right)-\Phi\left(\alpha_{r_{i 2}-1}-\gamma_{2}-\left(z_{2}^{\prime} \beta_{2}+\rho_{2}^{2} v_{i 0}+\rho_{2} \epsilon_{1}\right)\right)\right] \\
& . . \times \Phi\left(x_{i T_{i}-1}^{\prime} \beta_{1}+\rho_{1}^{T_{i}-2} v_{i 0}+\rho_{1}^{T_{i}-3} u_{i 2}+. .+\rho_{1} u_{i T_{i}-2}\right) \\
& \times\left[\Phi\left(\alpha_{i T_{i}-1}-\gamma_{T_{i}-1}-\left(z_{i T_{i}-1}^{\prime} \beta_{2}+\rho_{2}^{T_{i}-2} v_{i 0}+\rho_{2}^{T_{i}-3} u_{i 2}+. .+\rho_{2} u_{i T_{i}-2}\right)\right)\right.
\end{aligned}
$$




$$
\begin{aligned}
& -\Phi\left(\alpha_{\left(i T_{i}-1\right)-1}-\gamma_{T_{i}-1}-\left(z_{i T_{i}-1}^{\prime} \beta_{2}+\rho_{2}^{T_{i}-2} v_{i 0}+\rho_{2}^{T_{i}-3} u_{i 2}+. .+\rho_{2} u_{i T_{i}-2}\right)\right] \\
& \times \Phi\left(x_{i T_{i}}^{\prime} \beta_{1}+\rho_{1}^{T_{i}-1} v_{i 0}+\rho_{1}^{T_{i}-2} u_{i 2}+. .+\rho_{1} u_{i T_{i}-1}\right) \\
& \times\left[\Phi\left(\alpha_{i T_{i}}-\gamma_{T_{i}}-\left(z_{i T_{i}}^{\prime} \beta_{2}+\rho_{2}^{T_{i}-1} v_{i 0}+\rho_{2}^{T_{i}-2} u_{i 2}+. .+\rho_{2} u_{i T_{i}-1}\right)\right)\right. \\
& -\Phi\left(\alpha_{i T_{i}-1}-\gamma_{T_{i}}-\left(z_{i T_{i}}^{\prime} \beta_{2}+\rho_{2}^{T_{i}-1} v_{i 0}+\rho_{2}^{T_{i}-2} u_{i 2}+. .+\rho_{2} u_{i T_{i}-1}\right)\right] d v_{i 0} d u_{i 1} . . d u_{i T_{i}-1} .
\end{aligned}
$$

\section{C.2 Algorithm of Calculating Likelihood}

The algorithm shows the steps to calculate the probability of separation in $T_{i}$ for a teacher $i$ : $\operatorname{prob}\left(\left[\bigcap_{t=1}^{T_{i}-1}\left(y_{i t}^{*}>0 \bigcap\left(I\left(r_{i t}^{*} \geq \alpha\right)\right] \bigcap\left[y_{i T_{i}}^{*} \leq 0\right] \mid x_{i}, z_{i}, \theta\right)\right.\right.$

Step 1: Starting in period 0, obtain K $v_{0}$ s from $N\left(0, \frac{1}{\sqrt{1-\rho_{1}^{2}}}\right)$.

Step 2: For $1<t<T_{i}$, conditional on $v_{t-1}^{(k)}$ (or $\left.v_{0}^{(k)}, u_{1}^{(k)}, \ldots, u_{t-1}^{(k)}\right)$ draw $u_{t}^{(k)}$ from $T N_{\left(-x_{i t}^{\prime} \beta_{1}-\rho \nu_{t-1}^{(k)}, \infty\right)}(0,1)$, which implies $v_{t}^{(k)}=\rho_{1} v_{t-1}^{(k)}+u_{t}^{(k)}>-x_{i t}^{\prime} \beta_{1}$.

Step 3: In period $T_{i}$ conditional on $v_{T_{i}-1}^{(k)}$ draw $u_{T_{i}}^{(k)}$ from $T N_{\left(-\infty,-x_{T_{i}}^{\prime} \beta_{1}-\rho_{1} v_{T_{i}-1}^{(k)}\right)}(0,1)$, which implies $x_{T_{i}}^{\prime} \beta_{1}+v_{T_{i}}^{(k)} \leq 0$.

The likelihood for teacher $i$ can be computed using the $K$ simulated sequences of v's as

$$
\begin{aligned}
& L\left(D_{i} \mid x_{i}, z_{i}, \theta\right) \approx \frac{1}{K} \sum_{k=1}^{K}\left(1-\Phi\left(x_{i T_{i}}^{\prime} \beta_{1}+\rho_{1} v_{T_{i}-1}^{(k)}\right)\left\{\prod_{t=1}^{T_{i}-1} \Phi\left(\frac{x_{i t}^{\prime} \beta_{1}+\rho_{1} v_{t-1}^{(k)}}{\sigma}\right)\right.\right. \\
& \left.\times\left[\Phi\left(\alpha_{r_{i t}}-\gamma_{t}-\left(z_{i t}^{\prime} \beta_{2}+\rho_{2} v_{i t-1}^{(k)}\right)\right)-\Phi\left(\alpha_{r_{i t}-1}-\gamma_{t}-\left(z_{i t}^{\prime} \beta_{2}+\rho_{2} v_{i t-1}^{(k)}\right)\right)\right]\right\} .
\end{aligned}
$$

If the teacher stays at the end of the sample period $T$, then keep steps 1 , replace step 2 and 3 by the following. For $1<t \leq T$, conditional on $v_{t-1}^{(k)}\left(\right.$ or $\left.v_{0}^{(k)}, u_{1}^{(k)}, . ., u_{t-1}^{(k)}\right)$ draw $u_{t}^{(k)}$ from $T N_{\left(-x_{i t}^{\prime} \beta_{1}-\rho \nu_{t-1}^{(k)}, \infty\right)}(0,1)$, which implies $v_{t}^{(k)}=\rho_{1} v_{t-1}^{(k)}+u_{t}^{(k)}>-x_{i t}^{\prime} \beta_{1}$. 
The probability can be computed using the $K$ simulated sequences of $v$ 's as

$$
\begin{array}{r}
L\left(D_{i} \mid x_{i}, z_{i}, \theta\right) \approx \frac{1}{K} \sum_{k=1}^{K}\left[\prod _ { t = 1 } ^ { T } \Phi ( x _ { i t } ^ { \prime } \beta _ { 1 } + \rho _ { 1 } v _ { i t - 1 } ^ { ( k ) } ) \left[\Phi\left(\alpha_{r_{i t}}-\gamma_{t}-\left(z_{i t}^{\prime} \beta_{2}+\rho_{2} v_{i t-1}^{(k)}\right)\right)\right.\right. \\
\left.-\Phi\left(\alpha_{r_{i t}-1}-\gamma_{t}-\left(z_{i t}^{\prime} \beta_{2}+\rho_{2} v_{i t-1}^{(k)}\right)\right)\right]
\end{array}
$$

The likelihood for the whole sample is $\prod_{i=1}^{I} L\left(D_{i} \mid x_{i}, z_{i}, \theta\right)$. 


\section{Bibliography}

Ballou, D. and M. Podgursky (2002). Returns to seniority among public school teachers. Journal of Human Resources, 892-912.

Börsch-Supan, A. and V. A. Hajivassiliou (1993). Smooth unbiased multivariate probability simulators for maximum likelihood estimation of limited dependent variable models. Journal of Econometrics 58(3), 347-368.

Boyd, D., H. Lankford, S. Loeb, and J. Wyckoff (2005). Explaining the short careers of high-achieving teachers in schools with low-performing students. American Economic Review 95(2), 166-171.

Brown, K. M. (2013). The link between pensions and retirement timing: Lessons from california teachers. Journal of Public Economics 98, 1-14.

Burnette, D. and M. Will (2018). Costly pension plans are fanning the flames of teacher unrest. Education Week 37(28), 1.

Chetty, R., J. N. Friedman, and J. E. Rockoff (2014). Measuring the impacts of teachers ii: Teacher value-added and student outcomes in adulthood. American Economic Review 104(9), 2633-79. 
Clotfelter, C. T., H. F. Ladd, and J. L. Vigdor (2011). Teacher mobility, school segregation, and pay-based policies to level the playing field. Education Finance and Policy 6(3), 399-438.

Costrell, R. M. and J. B. McGee (2010). Teacher pension incentives, retirement behavior, and potential for reform in arkansas. Education Finance and Policy 5(4), 492-518.

Costrell, R. M. and M. Podgursky (2009). Peaks, cliffs, and valleys: The peculiar incentives in teacher retirement systems and their consequences for school staffing. Education Finance and Policy 4(2), 175-211.

Dolton, P. and W. v. d. Klaauw (1999). The turnover of teachers: A competing risks explanation. Review of Economics and Statistics 81(3), 543-550.

Feng, L. and T. Sass (2017). Teacher quality and teacher mobility. Education Finance and Policy 12(3), 396-418.

Fitzpatrick, M. and M. Lovenheim (2014). Early retirement incentives and student achievement. American Economic Journal: Economic Policy 6, 120-154.

Friedberg, L. and S. Turner (2010). Labor market effects of pensions and implications for teachers. Education Finance and Policy 5(4), 463-491.

Furgeson, J., R. P. Strauss, and W. B. Vogt (2006). The effects of defined benefit pension incentives and working conditions on teacher retirement decisions. Education 1(3), 316-348.

Goldhaber, D., B. Gross, and D. Player (2010). Teacher career paths, teacher quality, 
and persistence in the classroom: Are public schools keeping their best? Journal of Policy Analysis and Management 30, 57-87.

Goldhaber, D., B. Gross, and D. Player (2011). Teacher career paths, teacher quality, and persistence in the classroom: Are public schools keeping their best? Journal of Policy Analysis and Management 30(1), 57-87.

Guarino, C. M., M. D. Reckase, and J. M. Wooldridge (2015). Can value-added measures of teacher performance be trusted? Education Finance and Policy 10(1), $117-156$.

Hanushek, E. A., J. F. Kain, and S. G. Rivkin (2004). Why public schools lose teachers. Journal of Human Resources 39(2), 326-354.

Harris, D. N. and S. J. Adams (2007). Understanding the level and causes of teacher turnover: A comparison with other professions. Economics of Education Review 26(3), 325-337.

Harris, D. N. and T. R. Sass (2011). Teacher training, teacher quality and student achievement. Journal of Public Economics 95(7-8), 798-812.

Hendricks, M. D. (2015). Towards an optimal teacher salary schedule: Designing base salary to attract and retain effective teachers. Economics of Education Review 47 , $143-167$.

Henry, G. T., K. C. Bastian, and C. K. Fortner (2011). Stayers and leavers: Earlycareer teacher effectiveness and attrition. Educational Researcher 40(6), 271-280.

Jackson, C. K. (2009). Student demographics, teacher sorting, and teacher quality: 
Evidence from the end of school desegregation. Journal of Labor Economics 27(2), 213-256.

Jackson, C. K. and E. Bruegmann (2009). Teaching students and teaching each other: The importance of peer learning for teachers. American Economic Journal: Applied Economics 1(4), 85-108.

Judge, T., C. Thoreson, J. Bono, and G. Patton (2001). The job satisfaction-job performance relationship : A qualitative and quantitative review. Pschological Bulletin 127, 376-407.

Knapp, D., K. M. Brown, J. Hosek, M. G. Mattock, and B. J. Asch (2016). Retirement Benefits and Teacher Retention. Rand Corporation.

Koedel, C., J. Li, M. G. Springer, and L. Tan (2017). The impact of performance ratings on job satisfaction for public school teachers. American Educational Research Journal 54(2), 241-278.

Koedel, C., K. Mihaly, and J. E. Rockoff (2015). Value-added modeling: A review. Economics of Education Review 47, 180-195.

Koedel, C., S. Ni, and M. Podgursky (2014). Who benefits from pension enhancements? Education Next 9(2), 165-192.

Koedel, C., S. Ni, M. Podgursky, and B. Xiang (2014). Missouri charter schools and teacher pension plans: How well do existing pension plans serve charter and urban teachers. 
Koedel, C., M. Podgursky, and S. Shi (2013). Teacher pension systems, the composition of the teaching workforce, and teacher quality. Journal of Policy Analysis and Management 32(3), 574-596.

Koedel, C. and P. B. Xiang (2017). Pension enhancements and the retention of public employees. Industrial and Labor Relations Review 70(2), 519-551.

Kong, W., S. Ni, M. Podgursky, and W. Wu (2018). Pension enhancements and teacher retirement. CALDER WP 195.

Krausen, K. and J. Willis (2018). Silent recession: Why california school districts are underwater despite increases in funding. Technical report, WestEd.

Kreig, J. (2006). Teacher quality and attrition. Economics of Education 25, 13-27.

Krieg, J. M. (2006). Teacher quality and attrition. Economics of Education Review 25(1), 13-27.

Munnell, A. H. (2012). State and Local Pensions: What Now? Brookings Institution Press.

Ni, S. and M. Podgursky (2016). How teachers respond to pension system incentives: New estimates and policy applications. Journal of Labor Economics 34(4), 10751104.

Papay, J. P. and M. A. Kraft (2015). Productivity returns to experience in the teacher labor market: Methodological challenges and new evidence on long-term career improvement. Journal of Public Economics 130, 105-119. 
Parsons, E., C. Koedel, and L. Tan (2018). Accounting for student disadvantage in value-added models. Journal of Educational and Behavioral Statistics, 1076998618803889.

Podgursky, M., R. Monroe, and D. Watson (2004). The academic quality of public school teachers: An analysis of entry and exit behavior. Economics of Education Review 23(5), 507-518.

Rauh, J. (2017). Hidden debt, hidden deficits. Technical report, Hoover Institution.

Rockoff, J. E. (2004). The impact of individual teachers on student achievement: Evidence from panel data. American Economic Review 94(2), 247-252.

Sass, T. R., J. Hannaway, Z. Xu, D. N. Figlio, and L. Feng (2012). Value added of teachers in high-poverty schools and lower poverty schools. Journal of Urban Economics 72(2-3), 104-122.

Scafidi, B., D. L. Sjoquist, and T. R. Stinebrickner (2007). Race, poverty, and teacher mobility. Economics of Education Review 26(2), 145-159.

Springer, M., W. Swain, and L. Rodriguez (2016). Effective teacher retention bonuses: Evidence from tennessee. Education Evaluation and Policy Analysis 38(2), 347-368.

Steele, J. L., M. J. Pepper, M. G. Springer, and J. Lockwood (2015). The distribution and mobility of effective teachers: Evidence from a large, urban school district. Economics of Education Review 48, 86-101.

Steinberg, M. P. and L. Sartain (2015). Does teacher evaluation improve school performance? experimental evidence from chicago's excellence in teaching project. Education Finance and Policy 10(4), 535-572. 
Stock, J. H. and D. A. Wise (1990). Pensions, the option value of work, and retirement. Econometrica 58(5), 1151-1180.

Wiswall, M. (2013). The dynamics of teacher quality. Journal of Public Economics $100,61-78$.

Xu, Z., U. Özek, and M. Hansen (2015). Teacher performance trajectories in high-and lower-poverty schools. Educational Evaluation and Policy Analysis 37(4), 458-477. 


\section{VITA}

Xiqian Wang was born in China. In 2009, she graduated from Sichuan University in economics. In 2012, she got a master's degree in economics from Peking University and a master's degree in finance from the University of Hong Kong. And she received a Ph.D. in economics from University of Missouri-Columbia in May 2019. 